\title{
Peer education and life skills for HIV prevention among Yemeni young people : a case study from a conservative moslem setting
}

Citation for published version (APA):

Al-Iryani, B. (2011). Peer education and life skills for HIV prevention among Yemeni young people : a case study from a conservative moslem setting. [Doctoral Thesis, Maastricht University]. Datawyse / Universitaire Pers Maastricht. https://doi.org/10.26481/dis.20110629ba

Document status and date:

Published: 01/01/2011

DOI:

10.26481/dis.20110629ba

Document Version:

Publisher's PDF, also known as Version of record

Please check the document version of this publication:

- A submitted manuscript is the version of the article upon submission and before peer-review. There can be important differences between the submitted version and the official published version of record.

People interested in the research are advised to contact the author for the final version of the publication, or visit the DOI to the publisher's website.

- The final author version and the galley proof are versions of the publication after peer review.

- The final published version features the final layout of the paper including the volume, issue and page numbers.

Link to publication

\footnotetext{
General rights rights.

- You may freely distribute the URL identifying the publication in the public portal. please follow below link for the End User Agreement:

www.umlib.nl/taverne-license

Take down policy

If you believe that this document breaches copyright please contact us at:

repository@maastrichtuniversity.nl

providing details and we will investigate your claim.
}

Copyright and moral rights for the publications made accessible in the public portal are retained by the authors and/or other copyright owners and it is a condition of accessing publications that users recognise and abide by the legal requirements associated with these

- Users may download and print one copy of any publication from the public portal for the purpose of private study or research.

- You may not further distribute the material or use it for any profit-making activity or commercial gain

If the publication is distributed under the terms of Article 25fa of the Dutch Copyright Act, indicated by the "Taverne" license above, 


\section{Peer Education and Life Skills for HIV Prevention among Yemeni Young People: \\ A Case Study from a Conservative Moslem Setting}


The research in this thesis was conducted under the auspices of the School for Public Health and Primary Care (Caphri), which participates in the Netherlands School of Primary Care Research (CARE), acknowledged in 1995 by the Royal Academy of Arts and Sciences (KNAW).

๑ Copyright Buthaina Al-Iryani, Maastricht 2011

ISBN 978-94-6159-063-3

Production: Datawyse / Universitaire Pers Maastricht 


\title{
Peer Education and Life Skills for HIV Prevention among Yemeni Young People: A Case Study from a Conservative Moslem Setting
}

\author{
DISSERTATION \\ To obtain the degree of Doctor at Maastricht University, \\ on the authority of the Rector Magnificus, Prof. Dr. G.P.M.F. Mols, \\ in accordance with the decision of the Board of Deans,
} to be defended in public on Wednesday 29 June 2011, at 10.00 hours by

Buthaina Al-Iryani

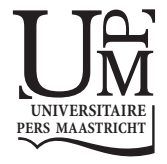




\section{Supervisors}

Prof. dr. H.W. van den Borne

Prof. dr. G.J. Kok

\section{Assessment Committee}

Prof. dr. N.K. de Vries (Chair)

Prof. dr. A.M. Al- Haddad (Sana'a University, Republic of Yemen)

Prof. dr. H.J. Hospers

Dr. A. Krumeich

Dr. R.A.C. Ruiter 
In memory of Professor Herman Schaalma

His intelligent guidance, kindness and great spirit have enabled me to pursue this research. 



\section{Contents}

$\begin{array}{ll}\text { Introduction } & 9\end{array}$

Chapter $1 \quad$ HIV knowledge and stigmatization among Yemeni adoles- 23 cents in schools

Chapter 2 Evaluation of a school-based HIV prevention intervention for 35 Yemeni adolescents

Chapter 3 A Quasi-experimental evaluation of a three-year communitybased peer education intervention for HIV prevention among Yemeni young people

Chapter 4 Process evaluation of school-based peer education for HIV prevention among Yemeni adolescents

Chapter 5 Process evaluation of a three-year community-based peer education intervention for HIV prevention among Yemeni young people

General Discussion

References

Summary

Samenvatting 163

Acknowledgements

Biography 



\section{Introduction}




\section{General Background on Yemeni Young People}

The republic of Yemen is located in the southern part of the Arabian Peninsula and is surrounded by Oman to the east, Saudi Arabia to the north, the Red Sea to the west and the Arabian Sea and the Gulf of Aden to the south. Yemen is the poorest country in the Middle East and one of the poorest countries in the world (Assaad, Barsoum, Cupito, \& Egel, 2009), where more than $45 \%$ of the population lives in poverty (UNDP, 2010). Yemen's population is around 22.5 million people, of which, $67.3 \%$ is younger than 25 years (Central Statistics Organization, Yemen Statistical Year Book., 2009). At $3.02 \%$, the country has one of the highest population growth rates globally, with the population expected to double in the next 23 years. This increases the demand for educational and health services, drinking water and employment opportunities. Yemen faces a severe water shortage, with available ground water depleting at an alarming rate (UNDP, 2010).

Yemen faces significant challenges in helping youth to reach their full potentials due to decreasing natural resources, low levels of human development, high levels of poverty, and policies and institutions that are not focusing on youth development (Assaad, Barsoum, Cupito, \& Egel, 2009). The Yemeni economy is caught in a slow growth cycle, with an unemployment rate of $35 \%$ in general and as high as $50 \%$ among youth, leading to stagnant per capita incomes and rising levels of unemployment, particularly amongst the youth (Library of Congress, 2008). Limited employment opportunities have forced many Yemenis to migrate for work to neighbouring countries leaving their families behind. Illiteracy rates are still high (47\%) with a huge gender gap, where $69.1 \%$ of the female population are illiterate compared to $27.3 \%$ of Yemeni males (Central Statistics Organization, Yemen Statistical Year Book., 2009). Yemen continues to occupy the last place in the gender gap index rankings of 134 countries and remains the only country in the world to have closed less than $50 \%$ of its gender gap (Hausmann, Tyson, \& Zahidi, 2009). A little more than one-fifth of youth surveyed in the Household Budget Survey (Central Statistical OrganizationHBS, 2005/2006)stated that they had never enrolled in school. Never-enrolment is almost exclusively a problem for girls: 5 percent of young men never had schooling while 35 percent of young women never went to school. According to the $2003 \mathrm{Arab}$ Family Health Survey, less than 40 percent of young women had ever used any type of contraception (AFHS Ministry of Health and Population, 2003). 
High rates of illiteracy, poverty, unemployment, mobility, and gender disparities place the predominantly young Yemeni nation vulnerable to HIV infection. In addition, Yemeni youth, are experiencing increased premarital sex, peer pressure to engage in risky behaviour, and changing lifestyle norms (Abu-Raddad, et al., 2010). Street children, an increasing phenomena in Yemen (Dyer, 2007), who are mainly young adolescents and children as young as 8 years of age, are a new emerging group to be especially at risk for HIV infection and are often subject to sexual abuse, rape, and in some cases, forced sex work (IRIN, 2010).

Despite the existing HIV risk factors facing young people, HIV and sex education is still very limited and usually lacking. The tribal and very conservative Moslem Yemeni cultural has not been a conducive environment for HIV education. In fact, Yemen is one of the most conservative Arab countries in the Middle East, also suffering from existing Islamic fundamentalist groups. These groups are known for their hostility to any ideas, trends, or programmes that, from their point of view, are coming from the western world. HIV education, since it relates to sex education, is considered by fundamentalist groups to promote promiscuity and pre-marital sex among young people. Sex education by itself is also considered by these fundamentalist groups as a "western plot" to crusade the Islamic world, and thus to dismantle Islamic teachings.

\section{HIV and AIDS in Yemen: Epidemiology, Programme, Policies and Research}

\subsection{Epidemiology}

UNAIDS estimates the HIV prevalence in Yemen at $0.2 \%$ (UNAIDS, UNGASS Yemen Progress Report on HIV and AIDS., 2010). However, the real HIV and AIDS epidemiological profile in Yemen is unknown, as no sero-prevalence, study has been conducted yet. The health surveillance system is still weak, and there are no ongoing behavioural surveillance surveys. The major mode of HIV transmission during the period of 1987-2008 had been mainly through heterosexual relations (47\%), with the next most frequent mode of transmission (8\%) being related to infection through contaminated blood or blood products, followed by homosexual relations $(6 \%)$, and mother to child transmission (1.3\%), while $35 \%$ of the reported cases were due to unknown reasons. In 2009, heterosexual relations continued to be the main mode of transmission (62\%) followed by homosexual transmission (7\%), mother to child 
transmission $(5 \%)$, and infection through contaminated blood or blood products (5\%); and $23 \%$ of the cases were of unknown sources. It should be noted that female cases were third of the accumulative HIV cases during the 1987-2009 period (UNAIDS, UNGASS Yemen Progress Report on HIV and AIDS., 2010).

\subsection{Programmes and Policies}

The National Strategic Framework (NSF) to Combat HIV and AIDS, endorsed by the government in 2003 and further updated in 2008, is a clear articulation of the Yemeni government's commitment to respond to problem of HIV and AIDS. The National AIDS Programme (NAP), which is under the authority of the Ministry of Health, is the leading technical government agency to follow-up on the implementation of the NSF and is supported by the National Population Council (NPC). The government and civil society response, although still limited, has increased dramatically over the past several years. Several HIV services for prevention, care, and support were established, mainly voluntary counselling and testing (VCT) centres, prevention of mother-to-child (PMTCT) services, and anti-retroviral treatment (ART) sites. In 2008, these services were only available in two major cities of two governorates, Sana'a and Aden, and were expanded in 2010 to include three more cities (Mukalla, Taiz, and Hodeida) located in three governorates (Hadhramout, Taiz, and Hodeida). Currently there are 838 people living with HIV (PLWH) (507 males, 274 females \& 57 children) enrolled in care, treatment, and support services. Within this, 380 PLWH (225 males, 135 females \& 20 children) are with CD4 (Cluster of Differentiation 4) counts below 350 and thus are receiving the triple therapy of anti-retro viral drugs - Zidovidine, lamivudine, and Efavirenz (National AIDS Programme, 2010).

Government funding for HIV services is still limited and the major part of the funding for services still relies on a grant from the Global Fund for Tuberculosis, AIDS, and Malaria (GFTAM), which was approved in 2005, as well as funding from United Nations (UN) agencies, especially UNICEF, UNAIDS, and WHO. Yemen. UN agencies also provide technical assistance in addition to financial assistance (National AIDS Programme, 2010).

It should be noted that in 2009, the parliament has endorsed the legislation on the rights of people living with HIV (PLWH). This legislation entails that PLWH have the right to live free of stigma and discrimination and have the right to access free of charge HIV prevention, care, and support services (UNAIDS, UNGASS Yemen Pro- 
gress Report on HIV and AIDS., 2010). All of the above progress in the national response to HIV and AIDS was the result of several years of advocacy, awareness raising, and capacity building at national and local levels. Despite all of this progress in programmes and legislations, the conservative and tribal traditional setting still pose a real challenge to address HIV education and prevention among adolescents and youth at national level, and is still limited to some urban governorates.

\subsection{Existing Literature on HIV in Yemen}

There are only two behavioural studies undertaken in the past few years to understand the vulnerability of Yemeni society to HIV and other sexually transmitted infections (STIs). The four governorate behavioural study, which was conducted among a sample of participants in their reproductive period (15-49 years) in the governorates of Hodeida, Taiz, Aden, and Hadhramout, generated data on (STIs) awareness and factors predicting vulnerability to HIV infection. The study identified risk factors for HIV infection, which included low awareness of the use of condoms, high level of sexually transmitted infections, and unprotected extra-marital sex. Poverty, a social cultural transition, variations in the sexual subcultures between sections of the Yemeni population, low HIV risk perception and population movements including migration for work, all have emerged as important underlying factors for HIV vulnerability. The vulnerable groups identified included marginalized groups (Al-akhdam), refugees, returnees, youth, truck drivers, Red Sea fishermen, prison inmates and the poorest in the society. The four-governorate behavioural study has shown that HIV-related risk behaviour was linked to heterosexual and homosexual behaviour. The data did not suggest a significant occurrence of injecting drug use (Busulwa R. , 2003; Busulwa, Takiyaddin, Azzubeidi, El Zein El Mousaad, Tawillah, \& Ziady, 2006).

In 2008, a bio-behavioural study (BBS) focusing on 244 females sex workers (FSWs) in Aden has found an HIV prevalence of $1.3 \%$ and syphilis prevalence of $4.9 \%$. The majority of FSWs (57.1\%) reported using condoms at last paid sex, as opposed to $28.8 \%$ at last non-paid sex. A substantial proportion of FSWs reported vaginal discharge (56.9\%) and genital ulcerations, itching and/or skin lesions in the last year (33.2\%). On the non-sexual behavioural side, $2.0 \%$ reported injecting drugs and $1.2 \%$ reported on sharing needles and other injecting equipment. Despite their high risk behaviour, only $14 \%$ of the interviewed FSWs thought that they were at risk of HIV infection (UNAIDS, UNGASS Yemen Progress Report on HIV and AIDS., 2010). 


\section{Justification for the selection of Aden as the site of HIV prevention interventions among young people}

Aden, located on the coastal line of the Arabian Sea, is inhabited by 589,419 people distributed in eight urban districts. As indicated by the four governorates study, Aden governorate, especially its young people, are vulnerable to HIV infection (Busulwa R. , 2003; Busulwa, Takiyaddin, Azzubeidi, El Zein El Mousaad, Tawillah, \& Ziady, 2006). There was an urgent need to further explore risks and vulnerabilities to HIV among in and out of school young people, and to respond accordingly with cultural sensitive interventions. For this reason, two baseline surveys among students (AlIryani, Raja'a, Kok, \& van den Borne, 2010) and out of school young people (AlSerouri, Anaam, Al-Iryani, Ramaroson, \& Al-Deram, 2010) were conducted in 2005. The results of the two surveys revealed that young people in and out of schools had low levels of HIV knowledge, and high levels of stigma towards people living with HIV. All the existing high schools in Aden (27 high schools) were included in the baseline; in addition to the four poor and most-at-risk neighbourhoods of Abdul Qaui, Al Memdarah, Al Basateen, and Al Sesaban. The reason for targeting these four areas, which are inhabited by a total population of 71,740 people distributed in 11,000 households, was based on previous research documenting that most-at-risk groups existed in these four areas. The results from these surveys have been the basis for designing a school and community-based intervention.

\section{Development of the Community and School based interventions}

The results from the school baseline survey (Al-Iryani, Raja'a, Kok, \& van den Borne, 2010), and from the community baseline survey (Al-Serouri, Anaam, Al-Iryani, Ramaroson, \& Al-Deram, 2010) convinced key stakeholders from governmental and non-governmental organizations to implement school and community based peer education programmes for HIV prevention in Aden governorate (UNICEF, 2006). The programmes focused on decreasing the level of stigma and discrimination towards people living with HIV and on increasing the knowledge about modes of HIV transmission and prevention. 


\subsection{Peer Education and Life Skills as Methodologies of Choice}

For several reasons, peer education and life skills methodologies were chosen by key stakeholders in Aden Governorate as suitable methodologies for HIV prevention among young people in and out of schools. The Yemeni school system is far more rigid than in many other countries due to the conservative cultural, and the weak educational system (Assaad, Barsoum, Cupito, \& Egel, 2009); thus adding an additional educational component on HIV to the existing curriculum would not have been feasible. Previous studies in Africa have shown that HIV programs delivered by teachers are not very effective. Teachers are frequently reluctant to discuss sensitive issues with students, and are usually bound to organizational school issues, as well as various cultural and social inhibitions (Oshi \& Nakalema, 2005; Visser M. , 2005). In communities, given the high rates of illiteracy and presence of difficult to reach populations, peer education was considered by key community stakeholders in the targeted four neighbourhoods of Aden governorate as the methodology of choice. Life skills, especially in the Yemeni context, had been a crucial component of the intervention, as existing research is indicating that Yemeni young people, both in and out of schools lack basic life skills (Al-Nabulsi, 2004).

Previous studies have documented that peer education interventions were significantly associated with increased HIV knowledge in schools (Agha \& van Rossem, 2004; Ozcebe, Akin, \& Aslan, 2004; Chhabra, Springer, Rapkin, \& Merchant, 2008; Barss, Grivna, Ganczak, Bernsen, \& Al-Maskari, 2009; Li, et al., 2010; Medley, Kennedy, O'Reilly, \& Sweat, 2009), as well as in communities (Williams, et al., 2003; Norr, Norr, McElmurry, \& Moeti, 2004). Peer education interventions were also associated with increased condom use and decreased risky behaviours (Li, et al., 2010; Rickert, Jay, \& Gottlieb, 1991; Smith \& DiClemente, 2000; Kelly, et al., 1991)

There is also exiting research on life skills based HIV education that documents the positive effect on knowledge of (Harvey, Stuart, \& Swan, 2000; James, Reddy, Ruiter, Mccauley, \& van den Borne, 2006; Klepp, Ndeki, Leshabari, Hannan, \& Lyimo, 1997; Kinsler, Sneed, Morisky, \& Ang, 2004; Yankah \& Aggleton, 2008); as well as positive behavioural outcomes (Paine, Hart, Jawo, Jallow, Morison, \& Walraven, 2002; Ross, Changalucha, Obasi, Todd, Plummer, \& Cleophas-Mazige, 2007; Harvey, Stuart, \& Swan, 2000) 


\subsection{Theoretical Framework}

The theoretical model used in developing, implementing, and evaluating the school and community interventions included the theory of Diffusion of Innovations (Rogers, 2003). Diffusion of Innovations considers that an innovation can be new information, an attitude, a belief or a practice or any other object that is perceived as new by the individual or the community and can be diffused to a specific group. An innovation is communicated through certain channels over time amongst members of a social system (here, the schools and communities). A central point in this theory is the use of opinion leaders as 'change agents'. These opinion leaders are in effect peer educators. Peer educators are assumed to have this role by influencing not only those for whom the activities are organized (their peers), but also others of relevance in the peer's environment (family, friends, etc.) through an informal diffusion. Behavioural change thus comes about through a process of formal or informal communication and modelling by trained peers (Oldenburg \& Glanz, Diffusion of Innovations, 2008). Peer education is a process by which trained peer educators inform, teach and encourage their peers to recognize the risk factors and protect themselves against HIV (Turner \& Shepherd, 1999).

Although the Bandura's Social Cognitive Theory (SCT) could also be used as the framework for developing peer education programmes (Turner \& Shepherd, 1999), Diffusion of Innovations (DOI) was used for several reasons. DOI is largely a sociological theory that uses social roles, norms, and networks to explain behaviour. Diffusion concepts and research emphasize the macro nature of social change, whereas social learning and SCT emphasizes intrapersonal and interpersonal factors, that is, the micro level (Kegler \& Glanz, 2008). In fact the peer education interventions for HIV in this dissertation address the context in which behaviour change must take place. This approach is highly consistent with Roger's basic definition of elements of DOI: an innovation, communicated via certain channels, over a period of time, to members of social system (Bertrand, 2004).

Diffusion of Innovations has been used extensively in the development, implementation, and wide diffusion of HIV/AIDS programmes in both developed and developing countries (Bertrand, 2004; Oldenburg \& Glanz, Diffusion of Innovations, 2008). DOI was first employed in the design of AIDS/HIV peer education interventions in the gay community of three small American cities (Kelly, et al., 1991). DOI was also central to one of the most effective HIV/AIDS prevention programs in USA during the 1980's: STOP AIDS in San Francisco (Bertrand, 2004).Smith et al, documents the 
use of DOI as the basis for developing of a successful peer educational training curriculum for HIV prevention among adolescents in the rural areas of the southern states of America (Smith \& DiClemente, 2000). DOI was also used in the design and evaluation of a peer education intervention among gay men in London (Elford, Sherr, Bolding, Serle, \& Maguire, 2002). As the field of HIV prevention gradually shifts from a predominant focus on individual behaviour to recognition of the importance of social norms in defining sexual behaviour, DOI emerge as a useful theory in fight against HIV/AIDS (Bertrand, 2004).

\subsection{Messages used in the school and community based interventions}

The findings of the school and community baseline surveys were the basis of development of the HIV messages. Ten messages were developed, while ensuring the participation of young people and key stakeholders. The first message was on the definition of HIV and causative agents, the second on whether we can recognize an infected HIV person by the way he/she looks or do we have to do a blood test, and what does the window period means; the third message was on why HIV is a dangerous infection; the fourth message was on the epidemiology of HIV in Yemen, the middle east and in the world, the fifth was on the mode of transmission, the sixth was on modes of prevention and adopting the ABCD (abstinence, be faithful, use condoms, and don't use drugs) approach, the seventh was on major misconceptions, the eighth was on risk perception and whether young people can be at risk, the ninth was on how we should deal with PLWH, which stresses the importance of the right of PLWH to live free of stigma and discrimination, and the tenth message was on the role of young people in educating the community. The life skills messages were on communication and negotiation skills, self-awareness and self-esteem, decision making, respecting differences in opinions, and assertive behaviour.

\section{Implementation of the Community and School based interventions}

The community based intervention programme mainly focused on creating an enabling environment by advocacy with local councils and religious leaders; training youth peer education and community outreach networks in vulnerable neighbourhoods; partnership with community based organizations and non-governmental agencies; and reaching out to vulnerable and most-at-risk youth with HIV messages. 
The School based interventions focused on creating an enabling environment for HIV prevention activities in schools by advocacy with decision makers; training of school supervisor, social workers, principals, and vice principals; and training school peer educators, who have reach out to their peers during school academic year and in youth summer camps.

\subsection{School based interventions}

Training of school coordinators and management teams - A team of school coordinators were selected by the education office in Aden, consisting of the director of school supervision, director of school health, director of school social services, a teacher representing the school curriculum supervisory committee, and an expert on training of trainers' methodologies. The team was trained in a 9-days workshop conducted by two international Arabic speaking experts in this field, based on life skills and peer education package (UNICEF, 2006). The training package included topics on peer education and training of trainers' methodologies, HIV, reproductive health, sexually transmitted infections, puberty and changes during adolescents, and life skills education. The trained school coordinators team had two functions: coordinating with the schools' managements and parents; and conducting training workshops. To ensure support for peer educators at school level, school management teams, which consisted of school principals and vice-principals, were trained during a 5-day training workshop on peer education methodologies, life skills, and HIV prevention. School coordinators planned with peer educators and management teams the peer activities at their schools.

Selection and training of school peer educators -Peer educators from all 27 high schools were recruited on a voluntarily basis. From the students volunteered, students were selected who met standard criteria of having good communication skills, being accepted by classmates, and showing good academic achievements. The selection was done by a committee consisting of the school coordinators and school social workers. The school coordinators visited parents of selected peer educators to explain the programme and to obtain a signed consent form allowing their daughters/sons to participate. Several visits were required, especially to parents of female peer educators, as families are usually reluctant to have their daughters get involved in extracurricular activities, and especially as these relate to HIV and AIDS prevention. The school coordinators team had a pivotal role in advocating with families. There were three refusals from parents in the whole programme. In case of refusal of parents, 
another peer educator was selected. The selected school peer educators were trained in a 10-day workshop. The training was based on the Jordanian life skills and peer education package, in addition to 10 messages on HIV transmission, prevention, and common misconceptions, and 5 life skills messages. The selected school peer educators were trained in a 10-day workshop. The training was based on the Jordanian life skills and peer education package, in addition to 10 messages on HIV transmission, prevention, and common misconceptions, and 5 life skills messages.

Conducting peer education sessions in schools- Before implementation, a pre-field two-days training was conducted, where peer educators rehearsed the actual messages to be conducted at school level. The $10 \mathrm{HIV}$ messages and 2 life skills messages (self-esteem and assertive behaviour) were the major topics covered by peer educators. Peer education sessions were planned that each student would be targeted with two (90-minutes) sessions in addition to brief sessions during morning school broadcast. After the end of the second session, participants received leaflets on the 10 messages, as well as hats and T-shirts with a message: "Protect yourself with Abstinence and Knowledge". The slogan was chosen by the peer educators; the knowledge part referred to the knowledge on condoms and knowledge on avoiding drugs.

\subsection{Community based interventions}

Advocacy and capacity building of stakeholders -Because of the conservative setting in the targeted communities, the first step was to create an enabling environment through conducting advocacy sessions with religious leaders, local councils, district directors, and traditional leaders, which focused on the importance of establishing community based intervention where adolescents and young people lead peer education and outreach activities. The second step was building partnerships with Community Based Organizations (CBOs) and Non-Governmental Organizations (NGOs) existing in these communities through training programmes focusing on HIV prevention as well as on the right of adolescent and youth to participation and to access gender sensitive information and services. This was followed by creating community committees consisting of representatives of local councils, NGOs, CBOs, and the National AIDS Programme (NAP), which had the role of selecting community focal points and community peer educators from targeted communities, while ensuring at least $50 \%$ were girls to ensure a gender sensitive intervention. 
Training of community peer educators and focal points -The community outreach focal points and youth peer educators were trained in a 10-day workshop. The training was based on the Jordanian life skills and peer education package, in addition to 10 messages on HIV transmission, prevention, and common misconceptions, and 5 life skills messages. This was followed by 2 -days pre-field training before initiating peer education sessions and outreach activities.

Conducting peer education activities at community level -Targeting young people at community level was done through in-door peer education session as well as outreach activities. In-door peer education was conducted as structured sessions with pre-and post-test, where peer educators conducted 5-hours sessions in the course of two days. The ten HIV messages and two life-skills messages (self-esteem and assertive behaviour) were the major topics covered by peer educators. The peer educators used posters, one for each message. After the end of the second session, participants received leaflets on the 10 messages, as well as hats and T-shirts with a message: "Protect yourself with Abstinence and Knowledge". The slogan was chosen by the peer educators; the knowledge part referred to the knowledge on condoms and knowledge on avoiding drugs. In-door peer education sessions were conducted in NGOs and health centres. In neighbourhoods where no NGOs or health centres existed, schools were the site for peer education sessions during after school hours. Workers in community outreach focal points, who were familiar with the neighbourhoods, mobilized young people and families through home visits to encourage families to allow young people, especially adolescent girls, to participate. The outreach peer education activities were conducted in homes, especially during Qat (or Khat) chewing sessions, in motels, hotels, beauty parlours, bus stops, and Qat markets (Qat is a plant that is a mild stimulant with amphetamine-like properties ). Outreach aimed to equip the hard to reach youth with necessary prevention information.

\section{Evaluation of the Community and School based interventions}

To ensure measuring the impact of the HIV prevention interventions in schools and communities, two quantitative impact assessments for community and school-based interventions were conducted between October 2008 and March 2009. The impact assessment of school-based interventions included 2,510 students selected from all 27 secondary schools in Aden (Al-Iryani, Basaleem, Al-Sakkaf, Crutzen, Kok, \& Borne, Evaluation of a School-Based HIV Prevention Intervention for Yemeni Adolescents, 
In Press). The impact assessment of the community-based interventions included 700 young people from 600 households of the four poor and vulnerable areas in Aden (Al-Iryani, Basaleem, Al-Sakkaf, Kok, \& van den Borne, A Quasi-Experimental Evaluation of A Three-Year Community-Based Peer Education Intervention For HIV Prevention Among Yemeni Young People, Submitted).

To have a deeper understanding on the implementation of the intervention, the quantitative impact evaluations were followed by qualitative process evaluations for school and community interventions. The school process evaluation included 12 focus groups discussions and 12 in-depth interviews with school peer educators, students, school social workers, school principals, and parents (Al-Iryani, Basaleem, Al-Sakkaf, Kok, \& Borne, Process Evaluation of School-Based Peer Education for HIV Prevention among Yemeni Adolescents). The community process evaluation included five focus group discussions and 15 in-depth interviews with community peer educators, community outreach focal points, targeted young people, local councils, NGO leaders, and most-at-risk young people (Al-Iryani, Al-Sakkaf, Basaleem, Kok, \& Borne, Process evaluation of a three-year community-based peer education intervention for HIV prevention among Yemeni young people, Submitted-a).

\section{Purpose and outline of the Dissertation}

This dissertation aims to study the effect of peer education and life skills based HIV youth prevention interventions, which were implemented in Aden Governorate during the period starting 2005 until 2008.

The interventions consist of two main integral parts: school-based and communitybased interventions. The school-based intervention targeted students in 27 high schools, while the community-based intervention targeted youth in four vulnerable and poor neighbourhoods. The interventions were initiated in 2005 by conducting two baseline surveys in schools and communities. The school baseline (Chapter 1: HIV knowledge and stigmatization among Yemeni adolescents in schools) included a sample of 2,274 students from 27 schools (Al-Iryani, Raja'a, Kok, \& van den Borne, 2010). The community baseline included a sample of 600 youth from 500 households of the four poor communities (Al-Serouri, Anaam, Al-Iryani, Ramaroson, \& AlDeram, 2010). The baseline studies were the basis of developing and implementing an intervention programme for both schools and communities. 
The evaluations of the school and community interventions were conducted between October 2008 and March 2009, after three years of implementation. Two quantitative impact assessments for community and school based interventions were first conducted. The impact assessment of school based interventions included 2,510 students selected from 27 secondary schools in Aden (Chapter 2: Evaluation of a schoolbased HIV prevention intervention for Yemeni adolescents) (Al-Iryani, Basaleem, Al-Sakkaf, Crutzen, Kok, \& Borne, Evaluation of a School-Based HIV Prevention Intervention for Yemeni Adolescents, In Press).The impact assessment of the community based interventions included 700 young people from the four poor and vulnerable areas in Aden (Chapter 3: A Quasi-experimental evaluation of a three-year community-based peer education intervention for HIV prevention among Yemeni young people) (Al-Iryani, Basaleem, Al-Sakkaf, Kok, \& van den Borne, A QuasiExperimental Evaluation of A Three-Year Community-Based Peer Education Intervention For HIV Prevention Among Yemeni Young People, Submitted).

The quantitative impact evaluations were followed by qualitative process evaluations for school and community interventions. The school process evaluation included 12 focus group discussions and 12 in-depth interviews with school peer educators, students, school social workers, school principals, and parents (Chapter 4: Process Evaluation of School-Based Peer Education for HIV Prevention among Yemeni Adolescents) (Al-Iryani, Basaleem, Al-Sakkaf, Kok, \& Borne, Process Evaluation of School-Based Peer Education for HIV Prevention among Yemeni Adolescents, Submitted-a). The community process evaluation included 5 focus group discussions and 15 in-depth interviews with community peer educators, community outreach focal points, targeted young people, local councils, NGO leaders, and most-at-risk young people (Chapter 5: Process evaluation of a three-year community-based peer education intervention for HIV prevention among Yemeni young people) (Al-Iryani, Al-Sakkaf, Basaleem, Kok, \& Borne, In Press).

The studies included in this dissertation included a sample of 6235 participants and were conducted over the period of March 2005 and February 2009. The school baseline was a cross-sectional and school-based, while the community baseline was a household survey. Both, the school and community impact evaluations were quantitative quasi-experimental, while the process evaluations were qualitative in nature. The main question raised by this research: Is life-skills and peer education in schools and communities a successful approach to reach out to adolescents and young people in conservative traditional Muslim settings? 


\section{Chapter 1}

\section{HIV knowledge and stigmatization among Yemeni adolescents in schools}

\section{Published as:}

Buthaina Al-Iryani, Yahia A. Raja'a, Gerjo Kok, and Bart van den Borne (2010).

HIV knowledge and stigmatization among Yemeni adolescents in schools. International Quarterly of Community Health Education, 30 (4), 311-320. 


\begin{abstract}
The number of assessments on HIV knowledge and stigmatization among adolescents in Yemen is still very limited. This cross-sectional study aimed to have a better understanding on the level of knowledge on HIV transmission and prevention. Also, this study explored the level of stigma and discrimination among students towards people living with HIV (PLWH). The study sample consisted of 2,274 male and female students (mean age 16.6 years) randomly selected from 27 high schools in Aden, Yemen. The results revealed low levels of knowledge on major prevention measures, such as condoms, where only $49.4 \%$ knew that condoms could protect from HIV infection; and high levels of misconceptions on the modes of transmission. In addition, the study revealed a high level of stigma and discrimination towards people living with HIV. The results would serve as a baseline for implementing a schoolbased educational programme on HIV/AIDS.
\end{abstract}




\section{Introduction}

The cumulative number of HIV positive cases in Yemen reported to the National AIDS Programme is around 1,530 as of December 2004 (National AIDS Programme, 2004). However, until now, an adequate epidemiological assessment of HIV/AIDS in Yemen has not been conducted, mainly due to the absence of a reliable surveillance system, and to the lack of formal designed HIV sero-prevalence studies.

Several empirical studies were undertaken to understand the vulnerability of Yemeni society to HIV/AIDS and other sexually transmitted infections (STIs). Two situation analysis studies were conducted between 2001 and 2002. The Sana'a City study (AlSerouri \& Takioldin, 2002) collected data on HIV awareness among the population and health facility risks of transmission of the infection. The four governorate behavioural study (Busulwa, Takiyaddin, Azzubeidi, El Zein El Mousaad, Tawillah, \& Ziady, 2006)among a sample of participants in their reproductive period (15-49 years) in the governorates of Hodeida, Taiz, Aden, and Hadhramout generated data on STI awareness and factors predicting vulnerability. This study also included qualitative data about persons engaged in high risk behaviour. The study identified risk factors to HIV infection, which included low awareness on the use of condoms, high level of sexually transmitted infections, and unprotected extra-marital sex. Poverty, a social cultural transition, variations in the sexual subcultures between sections of the Yemeni population, low HIV risk perception and population movements including a migrant worker tradition, all have emerged as the main underlying factors to HIV vulnerability. The vulnerable groups identified included marginalized groups (AlAkhdam), refugees, returnees, youth, truck drivers, Red Sea fishermen, prison inmates and the poorest in the society. This 2002 behavioural study has shown that HIV-related risk behaviour is linked to heterosexual and homosexual behaviour. The data did not suggest a significant occurrence of injecting drug use. Female commercial sex workers and men who have sex with men were confirmed to exist in the four governorates behavioural study (Busulwa, Takiyaddin, Azzubeidi, El Zein El Mousaad, Tawillah, \& Ziady, 2006)

All studies mentioned above indicate the existence of high risk factors, and according to the National AIDS Programme, most of the HIV and AIDS cases are reported from Aden. Several vulnerable groups exist in Aden, such as Commercial Sex Workers (CSWs), Men who have Sex with Men (MSM), refugees, returnees, "Marginalized Groups" (Al-Akhdam), and Sea Fisherman. 
The aim of this study was to measure the level of knowledge on HIV transmission and prevention among Yemeni adolescent students, including the use of condoms; and to explore the level of stigma and discrimination towards people living with HIV (PLWH). This study was conducted to serve as a baseline measurement for a schoolbased HIV prevention programme.

\section{Methods}

\section{Setting}

Aden is a governorate in the Republic of Yemen, located on the Arabian Sea, and inhabited by 589,419 people, distributed in eight urban districts with a total of twenty seven high schools. As in other Yemeni governorates, the schools are under the direct authority of the Education Office. Given the conservative school and cultural setting, previous advocacy work with the Education Office in Aden was pursued one year before the survey. Three key staff of the Education Office in Aden - director of school supervision, director of school health, and director of social work, were trained on life skills and peer education for HIV prevention among youth. This team has been the driving force to advocate with the Director General of the Education Office, as well as the school principals on the importance of conducting a survey on HIV among high school students. A letter of consent was obtained from the Director General of Education Office in Aden governorate, which also indicated when and why the study would be conducted. A copy of the consent was sent to all school principals prior to data collection. The study was conducted during the period of March-May 2005.

\section{Ethical Considerations}

The Ethics committee of the Faculty of Medicine and Health Science, Sana'a University, granted the ethical approval to conduct this study.

\section{Design, Participants, and Sampling}

This is a school-based cross-sectional study that included 2274 male and female students from all 27 high schools in Aden Governorate. From each school a class of grade 10 and another one of grade 11 were selected by simple random sampling. All the students of the selected classes present at the day of the study were invited to participate. 


\section{Instrument and Data Collection Procedure}

A self-administered questionnaire, consisting of mainly closed-ended and some open-ended questions, was used as the main study instrument. The questionnaire was initially adapted from the Multiple Indicator Cluster Survey Questionnaire (UNICEF, 2005-a), and from the Arabic version of the questionnaire developed by the WHO Global Programme on AIDS Social and Behavioural Research Unit.

Before the pre-testing process, the questionnaire was discussed with the Education Office of Aden Governorate. All sexual behavioural questions were deleted, since such questions are not allowed in schools as per the policy of the Ministry of Education. The questionnaire was further modified after pre-testing. The questionnaire was composed of four parts; the first part was about the personal characteristics of the student (e.g. grade, sex, age and type of school). The next part contained questions about sources of information about HIV/AIDS, understanding the meaning of AIDS, nature of the causative agent and infectivity. The third part assessed the knowledge about transmission and prevention. The fourth part was composed of three open questions to assess students' suggested actions to be taken by the government, community, and individuals towards people living with HIV as an indirect measure of stigmatizing attitudes. Students filled the questionnaires in their classrooms during school hours, and in the presence of data collectors. A brief introduction was given to the students, where they were requested not to put their names on the questionnaires to ensure anonymity.

\section{Measures}

Demographic characteristics that were measured included age and gender. The main study outcome variables included the following:

- Sources of information and general HIV/AIDS awareness- represent the assessment of three different variables:

- Sources of Information-was assessed through a closed-ended question with eleven choices; the student also had the option of mentioning a source not available in the list in the "other" option.

- HIV Infectivity-was assessed through a closed-ended question on whether HIV is contagious, with options of "yes", "no", and "don't know". 
- Existence of HIV/AIDS- was assessed with two closed-ended questions on whether students thought HIV/AIDS cases existed in Yemen and Aden, with options of "yes", "no", and "don't know"

- Knowledge about HIV/AIDS transmission and prevention-Students' knowledge regarding HIV transmission and prevention were assessed through 12 statements on modes of transmission, prevention and misconceptions; three options were available, "yes", "no", and "don't know".

- As an indirect measurement of attitudes towards people living with HIV/AIDS, suggested actions towards these people were assessed by three open-ended questions, stated as follows: What actions should be taken with persons infected with AIDS by government? What actions should be taken with persons infected with AIDS by society? What actions should be taken with persons infected with AIDS by individuals?

The top frequent seventeen suggestions for each question were coded. Then answers from all the three questions were grouped into three categories: "Care, Support, and Treatment"; "Community Education and Prevention"; and "Punishment". Suggestions not falling into these categories were categorized as "other suggestions".

\section{Data Analysis:}

Data were analysed using Statistical Package for Social Sciences software version 11.5 (SPSS Incorporation, Chicago, IL, USA). Descriptive statistics including means, frequencies and proportions were calculated. Pearson's Chi-square $\left(\chi^{2}\right)$ was performed for the comparison among proportions. The statistical significance level was set at $\mathrm{p}$ value $<.05$.

\section{Results}

\section{Characteristics of the participants}

Females were $58.8 \%$ and males were $41.2 \%$ of the sample. Students were equally distributed between the grades 10 (51\%) and 11 (49\%). Mean age of the students was $16.6 \pm 0.9$ years. The mean age of males was $16.7 \pm 1$ years and that of the females was $16.4 \pm 0.9$ years $(\mathrm{p}<.0001)$. All the students were enrolled in public schools except for 
one school (semi-public). Only four students $(0.18 \%)$ reported that they did not hear about AIDS prior to this survey.

\section{Sources of information and general HIV/AIDS awareness}

Most of the students (88.5\%) heard about AIDS from TV, school (71.5\%), newspapers $(60.7 \%)$ and from friends (53.2\%). Most of the students (77\%) thought that HIV/AIDS was a disease that existed in Yemen; however a lower proportion (54.9\%) perceived its existence in Aden. The majority of the students (87.4\%) believed that $\mathrm{HIV}$ is infectious, $7.2 \%$ thought it is not contagious while $5.2 \%$ didn't know.

\section{Knowledge about HIV/AIDS transmission and prevention}

The students were asked 12 questions on the modes of transmission and prevention and misconceptions. Female students had statistically higher knowledge regarding sharing piercing devices, and possibility of a healthy looking person to be infected with HIV. However, male students had statistically higher knowledge on use of condoms and on the risk related to male-to-male sex. Male students had also lower levels of misconceptions related to HIV transmission compared to female students (Table $1)$.

\section{Suggested actions to deal with People living With HIV/AIDS}

We looked at the suggestions of students for actions to be taken towards people living with HIV by the government, society, and individuals. Nearly $94 \%$ of the students suggested one or more actions. In total 6234 actions were suggested by students. The most frequent suggested actions to be taken by the government were isolation (616), establishing health facilities (436), and providing medical treatment (215). For society, most frequent actions included isolation (639), health education for the community (418), and care \& support (340). At individual level, most frequent suggestions were isolation (700), care \&support (339), and treatment (220).

When grouped into the three different categories "punishment"; "prevention and community education"; "care and support"- content analysis showed that around $40 \%$ of the suggestions concerned actions for punishment of People living with HIV/AIDS, prevention and community education (26.6\%), and $25.6 \%$ concerned provision of care, support, and treatment (Table 2). 
Table 1: Correct modes of transmission/prevention and misconceptions

\begin{tabular}{|c|c|c|c|c|}
\hline Correct modes of transmission/prevention & $\begin{array}{c}\text { Total } \\
(\%)\end{array}$ & $\begin{array}{c}\text { Male } \\
(\%)\end{array}$ & $\begin{array}{c}\text { Female } \\
(\%)\end{array}$ & $\begin{array}{l}\text { Significance } \\
\text { p- value }\end{array}$ \\
\hline $\begin{array}{l}\text { Having sex with HIV infected person can transmit } \\
\text { HIV infection }\end{array}$ & 96.2 & 95.3 & 96.9 & NS \\
\hline Blood transfusion is a risk factor of HIV infection & 93.8 & 92.8 & 94.2 & NS \\
\hline $\begin{array}{l}\text { Shared use of piercing devices with HIV infected } \\
\text { person can transmit HIV }\end{array}$ & 91.6 & 89.0 & 93.1 & $p<.01$ \\
\hline $\begin{array}{l}\text { Possibility of HIV transmission from infected mother } \\
\text { to her baby }\end{array}$ & 88.0 & 86.4 & 88.8 & NS \\
\hline $\begin{array}{l}\text { Possibility of HIV transmission from infected mother } \\
\text { through breastfeeding }\end{array}$ & 71.0 & 72.2 & 70.7 & NS \\
\hline Male-to-male Sex is a risk factor for HIV infection & 75.2 & 81.4 & 70.5 & $p<.0001$ \\
\hline $\begin{array}{l}\text { Proper use of male condom is protective against } \\
\text { HIV/AIDS }\end{array}$ & 49.4 & 54.6 & 45.6 & $p<.0001$ \\
\hline $\begin{array}{l}\text { Possibility of carrying HIV infection by a healthy } \\
\text { person }\end{array}$ & 43.0 & 37.5 & 46.8 & $p<.0001$ \\
\hline $\begin{array}{l}\text { Incorrect modes of transmission/prevention } \\
\text { (misconception) }\end{array}$ & $\begin{array}{c}\text { Total } \\
(\%)\end{array}$ & $\begin{array}{c}\text { Male } \\
(\%)\end{array}$ & $\begin{array}{c}\text { Female } \\
(\%)\end{array}$ & $\begin{array}{l}\text { Significance } \\
\text { p- value }\end{array}$ \\
\hline Handshaking and kissing can transmit HIV & 21.6 & 20.6 & 22.3 & NS \\
\hline $\begin{array}{l}\text { Eating and drinking with HIV infected person can } \\
\text { transmit HIV }\end{array}$ & 39.7 & 36.6 & 43.9 & $p<.01$ \\
\hline $\begin{array}{l}\text { Possibility of HIV transmission through swimming } \\
\text { pools }\end{array}$ & 31.5 & 28.4 & 33.7 & $p<.05$ \\
\hline Possibility of HIV transmission through mosquito bite & 49.3 & 45.7 & 51.6 & $p<.01$ \\
\hline
\end{tabular}

${ }^{*}$ p-value calculated with Pearson's Chi-Squares 
Table 2: Overall Suggested actions to deal with People living With HIV/AIDS $<{ }^{*} I^{*}$

\begin{tabular}{|c|c|c|}
\hline Suggested Actions By Students & $\mathrm{No}^{* *}$ & $\%$ \\
\hline Punishment & 2659 & $40.0^{*}$ \\
\hline Isolation & 1955 & 29.4 \\
\hline Reporting to Authorities & 340 & 5.1 \\
\hline Killing or Whipping & 158 & 2.4 \\
\hline Imprisonment & 127 & 1.9 \\
\hline Deterrence of marriage or sexual intercourse & 79 & 1.2 \\
\hline Prevention and Community Education & 1768 & $26.6^{*}$ \\
\hline Health Education for the Community & 802 & 12.1 \\
\hline Combating Illegal Sex & 306 & 4.6 \\
\hline Cleanliness and Sterilization of Medical Devices & 215 & 3.2 \\
\hline Identification of Risk Factors and Prevention of the Disease & 199 & 3.0 \\
\hline HIV Testing of arrivals at ports, pre-marriage, and donated blood & 176 & 2.7 \\
\hline Closure of night Clubs & 52 & 0.8 \\
\hline Early Marriage & 18 & 0.3 \\
\hline Care, Support, and Treatment & 1714 & $25.8^{*}$ \\
\hline Providing Care and Support & 765 & 11.5 \\
\hline Providing Medical Treatment & 496 & 7.5 \\
\hline Establishing Health Facilities & 453 & 6.8 \\
\hline Other Suggestions & 93 & $1.4^{*}$ \\
\hline No Suggestion & 421 & 6.3 \\
\hline Total of Suggestions & 6234 & $93.7^{*}$ \\
\hline Total of Responses & 6655 & 100 \\
\hline
\end{tabular}

${ }^{\star *}$ Number of Reponses

${ }^{\star}$ Percentages of total suggestions per category in relation to total responses

\section{Discussion}

Although many researchers might underestimate the added value of knowledge studies compared with behavioural studies, this particular study is an important step towards exploring views of young people in schools regarding HIV in a very conservative setting like Yemen. The study reveals a knowledge gap on the modes of transmission and prevention, which is a pre-requisite for adapting safe behaviour as well as to decreasing stigma and discrimination. 
Stigma and discrimination levels are high among adolescents in the schools of Aden, as the main suggested actions mentioned by students call for punishing PLWH, which included suggestions for killing PLWH. These findings are similar to the results of a community based baseline survey among young people out of schools in Aden (Al-Serouri, Anaam, Al-Iryani, Ramaroson, \& Al-Deram, 2010), which was conducted in the same year as this study.

The gender differences in the level of knowledge are a reflection of the conservative Yemeni setting. Male students had better knowledge on condoms and male-tomale sex, which are considered a very sensitive issue to be discussed, and thus girls have little chance to access such information. However, female students had better knowledge on non-sensitive issues related to modes of transmission, such as sharing piercing devices. Future interventions should ensure closing this gender gap, and ensure that female students are given full information on the protective role of condoms.

The results from our study suggest that HIV education programs should be developed for Yemeni schools. Previous research has indicated that school educational programs can decrease HIV risk behaviour among students (Milburn, 1995). The delivery of such programs should be based on life-skills training and peer educational methodologies, as previous studies have shown that school-based HIV programs delivered by teachers are not very effective. Teachers are frequently reluctant to discuss sensitive issues with students, and are usually bound to organizational school issues, as well as various cultural and social inhibitions (Oshi \& Nakalema, 2005; Visser M. , 2005)

Developing such a school based peer educational program will not be an easy task given the very conservative setting at both school and community level. Creating an enabling environment with all concerned stakeholders, i.e., school management, teachers, parent-teacher associations, religious leaders, and media will be a crucial pre-requisite. They have to be well informed about the relative advantage of initiating HIV prevention programs in schools and should be convinced that such a program will not be against religious and social norms. This is of tremendous importance, especially with parents of girls' students, as girls' high school enrolment is still as low as $27 \%$ (UNICEF, 2005-b). Yemen has one of the largest enrolment gender gaps in the world, and thus families should not feel to be "threatened" by any new health promotional program in schools.

The peer educational messages to be developed should bridge the gap in knowledge on modes of transmission and prevention, and to decrease the level of stigma and discrimination towards people living with HIV, and to build life-skills promoting 
preventive behaviour, mainly, abstinence and use of condoms. This will lead us to think on how to discuss the issue of condoms in such a very difficult setting, where use of condoms is linked with pre-marital and extra-marital sex, which is socially and religiously not acceptable in conservative traditional cultures. For this reason, the school education program should focus on the ABCD approach: Abstinence, Be Faithful, use Condoms, and Don't use drugs. The use of condoms should be addressed such that information is given on the protective role of condoms, without giving the notion that pre-marital sex is promoted among students. Adding religious quotations that promote tolerance can be useful when discussing stigma and discrimination against people living with HIV. We should not forget to ensure that such peer education and life-skills programs are based on concrete theory (Turner \& Shepherd, 1999; Leurs, Schaalma, Jansen, Mur-Veeman, Leger, \& De Vries, 2005) to increase the chances of developing effective educational programs.

It should be noted that there are several limitations related to this study. Cultural restrictions are inhibiting young people from speaking out about an issue such as HIV/AIDS, which is linked to sexuality. Discussing such issues in schools is even more difficult due to the strict educational system which aims to protect social and cultural norms. For this reason, questions related to actual sexual behaviour of students were not possible. Nevertheless, the results of this study are crucial in giving insight in how to develop educational messages on HIV transmission, prevention, and stigma elimination in the context of Yemen.

It is recommended that the findings of this study lead the design of culturally sensitive information, education, and communication (IEC) material to be used in HIV education in Schools of Aden as well as in schools of other Yemeni governorates. The fact that only $54.9 \%$ of students think that HIV and AIDS exist in Yemen, reflect low level of risk perception, and thus IEC material should also aim to increase risk perception among students. IEC material should not only contain messages on the correct modes of transmission and prevention. Addressing misconceptions on HIV transmission/prevention is crucial, as misconceptions were found to be predictors of HIV related stigma and discrimination (Bekele \& Ali, 2008). The messages should also focus on the right of People Living with HIV to live a normal life free of stigma and discrimination. 


\section{Conclusion}

The findings of this study calls for an urgent need to implement culturally and gender sensitive school-based educational programmes on HIV prevention. Such interventions should focus on decreasing the level of stigma and discrimination towards people living with HIV and on increasing risk perception and knowledge on modes of transmission and prevention. 


\section{Chapter 2}

\section{Evaluation of a school-based HIV prevention intervention among Yemeni adolescents}

Published as:

Buthaina Al-Iryani, Huda Basaleem, Khaled Al-Sakkaf, Rik Crutzen, Gerjo Kok, and Bart van den Borne. Evaluation of a School-Based HIV Prevention Intervention for Yemeni Adolescents. BMC Public Health 2011, 11:279 doi:10.1186/1471-2458-11279) 


\begin{abstract}
Background - This article describes an evaluation of a school-based peer education intervention for HIV prevention among students in twenty seven high schools in Aden, Yemen. The intervention was developed after a survey among the same population in 2005, which revealed a high level of stigma towards people living with HIV (PLWH) and a low level of HIV knowledge.
\end{abstract}

Methods - In a quasi-experimental design students who received the peer education intervention (78.6\%) were compared with students who did not receive the intervention (21.4\%). No systematic procedure was applied in selecting students for the intervention condition. Data were collected using a self-administered questionnaire from a sample of 2510 students from all 27 high-schools in Aden governorate. To increase internal validity, students were also compared with a cohort control sample surveyed in 2005, which was a random sample of 2274 students from the same schools.

Results - Sixty eight percent of students targeted by peer education had good knowledge scores, compared with $43.3 \%$ of students not targeted by peer education $\left(\chi^{2}=\right.$ $(\mathrm{df}=1)=111.15, \mathrm{p}<.01)$. Multi-level regression analysis revealed that, although there was a significant difference among schools, the intervention effect of peer education at the individual level was significant; students who received peer education had a statistically higher knowledge score ( 9.24 out of 12.0) compared with those not targeted (7.89 out of 12.0), OR $=2.11,95 \% \mathrm{CI}=1.04-4.27, \mathrm{p}<.05)$. Compared with the 2005 cohort control sample, students targeted by peer education had better knowledge on the modes of transmission and prevention and fewer misconceptions; and knowledge on the use of condoms increased from $49.4 \%$ to $67.8 \%$. In addition, students who received the peer education interventions suggested significantly more actions to provide care and support for PLWH. Also, the levels of stigma and discrimination were much higher among the 2005 cohort control group, compared with those who received the peer education intervention.

Conclusion - The school-based peer education intervention has succeeded in improving levels of knowledge on modes of transmission and prevention, and in decreasing levels of stigma and discrimination in a culturally conservative setting. 


\section{Background}

Yemen is one of the poorest countries in the Middle East and North Africa (MENA) region (Assaad, Barsoum, Cupito, \& Egel, 2009), and one of the poorest countries in the world, where more than $45 \%$ of the population lives in poverty (UNDP, 2010). Yemen's population is around 22.5 million people; and at $3.02 \%$, the country has one of the highest population growth rates globally, with the population expected to double in the next 23 years (Central Statistics Organization, 2009). The population in Yemen is one of the youngest in the MENA region, and unlike many countries in the region where the youth bulge has already peaked, the share of youth in Yemen's total population will not begin to diminish for many years to come (Assaad, et al., 2009). The Yemeni economy is caught in a slow growth cycle, leading to stagnant per capita incomes and rising levels of unemployment, particularly amongst the youth (Congress, 2008). Limited employment opportunities have forced many Yemenis to migrate for work to neighbouring countries leaving their families behind. Because of its proximity to conflict affected countries in the Horn of Africa, Yemen is hosting hundreds of thousands of refugees. Yemen also faces one of the largest gender gaps in human development in the world (Assaad, et al., 2009) and continues to occupy the last place in the gender gap index rankings of 134 countries and remains the only country in the world to have closed less than $50 \%$ of its gender gap (Hausmann, Tyson, \& Zahidi, 2009).

Epidemiologically, the HIV prevalence among the general population of Yemen, including youth is $0.2 \%$ (UNAIDS, 2010). However, high rates of poverty, unemployment, mobility, and gender disparities could place the predominantly young Yemeni population vulnerable to HIV infection. In addition, Yemeni youth, just like other youth in MENA, are experiencing increased premarital sex, peer pressure to engage in risky behaviour, and changing lifestyle norms (Abu-Raddad, Hilmi, et al., 2010)

Several studies were undertaken in the past few years to understand the vulnerability of Yemeni society to HIV and other sexually transmitted infections (STIs). The four governorate behavioural study (R Busulwa, 2003; R. Busulwa, et al., 2006), conducted in 2003 among a sample of participants in their reproductive period (1549 years) in the governorates of Hodeida, Taiz, Aden, and Hadhramout, generated data on (STIs) awareness and factors predicting vulnerability to HIV infection. The study identified vulnerabilities and risk factors for HIV infection, which included low awareness of the use of condoms, high level of sexually transmitted infections, and unprotected sex. Poverty, a social cultural transition, variations in the sexual subcul- 
tures between sections of the Yemeni population, low HIV risk perception and population movements including migration for work, all have emerged as important underlying factors for HIV vulnerability. The vulnerable groups identified included refugees, returnees, youth, truck drivers, Red Sea fishermen, prison inmates, the poorest in the society, and Al-akhdam (Al-akhdam literally means servants in Arabic language, and are a marginalized social group distinct from the majority by their more African features. As a low caste group, they are discriminated against and mostly confined to menial jobs). The study has shown that the main high risk groups are female sex workers and men who have sex with men. The data did not suggest a significant occurrence of injecting drug use (R Busulwa, 2003; R. Busulwa, et al., 2006). In 2008, a bio-behavioural study focusing on 244 female sex workers (FSWs) in Aden has found an HIV prevalence of $1.3 \%$ and syphilis prevalence of $4.9 \%$. The majority of FSW (57.1\%) reported condom use with their clients, $2.0 \%$ reported injecting drugs and $1.2 \%$ reported sharing needles and other injecting equipment (UNAIDS, 2010).

Numerous studies have been conducted to explore the knowledge and attitude of young people. A recent comprehensive study on HIV in MENA region has revealed that MENA countries have made considerable gains in increasing HIV/AIDS basic awareness and knowledge in recent years (Abu-Raddad, Akala, et al., 2010). Comprehensive knowledge, however, including on the use of condoms, is yet far from optimal, and in Yemen, the situation is not much different.

In March-May 2005 a survey among Yemeni high school students in Aden revealed that only $49.4 \%$ recognized the protective role of condoms (Al-Iryani, Raja'a, Kok, \& van den Borne, 2010). Stigma and discrimination levels were high among students. Around $40 \%$ of the suggested actions by students on how to deal with people living with HIV (PLWH) were punishment actions, which included suggestions for killing PLWH. The results from this study convinced the Education authorities in Aden, Yemen to implement a school-based peer education programme for HIV prevention, which focused on decreasing the level of stigma and discrimination towards people living with HIV and on increasing the knowledge about modes of HIV transmission and prevention. Peer education was selected as the methodology for implementation as it is considered a non-traditional health education method (Merakou, 2006), and because the results of the 2005 baseline revealed that schools and friends were the main source of HIV information for students. 
Peer Education has a long history; it began being applied in health education and especially for HIV prevention during the 1980s. In recent years, it has been relatively popular in health education, perhaps because of the positive component of the method, which is the interaction it brings between peers (Merakou, 2006). Peer education interventions for HIV/AIDS prevention are usually based on behavioural theories. The design of the intervention discussed here is based partly on the Theory of Diffusion of Innovations (Rogers, 2003), which considers that an innovation can be new information, an attitude, a belief or a practice or any other object that is perceived as new by the individual or the community and can be diffused to a specific group. An innovation is communicated through certain channels over time amongst members of a social system (here, the school). A central point in this theory is the use of opinion leaders as 'change agents'. Peer educators are assumed to have this role by influencing not only those for whom the activities are organized (their peers), but also others of relevance in the peer's environment (family, friends, etc.) through an informal diffusion (Oldenburg \& Glanz, 2008). Behavioural change thus comes about through a process of formal or informal communication and modelling by trained peers (Oldenburg \& Glanz, 2008). School-based HIV peer education is a process by which trained students (peer educators) inform, teach and encourage their schoolmates (peers) to recognize the risk factors and protect themselves against HIV. Efforts are made for prevention to become a peer norm.

There is existing research evaluating the efficacy of peer education for HIV prevention in schools, mainly, from countries with concentrated or generalized HIV epidemics, as well as low prevalence countries in Europe (Agha \& van Rossem, 2004; Chhabra, Springer, Rapkin, \& Merchant, 2008; Maas \& Otte, 2009; Medley, Kennedy, O’Reilly, \& Sweat, 2009; Merakou, 2006; Ozcebe, Akin, \& Aslan, 2004; Strange, Forrest, Oakley, \& the RIPPLE Study Team, 2002; Visser, 2007). However, there is limited research evaluating school-based peer education for HIV prevention in cultural and conservative settings such as Yemen, where discussing any issue related to sexuality is difficult, and especially in school settings.

The aim of this evaluation was to assess whether peer education is an effective method for HIV prevention in a high school setting in a culturally conservative Islamic setting. The initial hypothesis was whether the use of peer education methodology could improve knowledge on the modes of prevention and transmission, decrease the level of stigma and discrimination against PLWH, and improve life skills. 


\section{Methods}

\section{The School-Based Intervention}

\section{Overview}

All twenty seven high schools in Aden, Yemen (12 boys' schools, 14 girls' schools, and one mixed school), representing all existing high-schools were the site of the intervention. The intervention included training of school coordinators, selection and training of peer educators, training of school management teams, and implementation at school level.

\section{Training of School Coordinators}

A team of school coordinators were selected by the education office in Aden, consisting of the director of school supervision, director of school health, director of school social services, a teacher representing the school curriculum supervisory committee, and an expert on training of trainers methodologies. The team was trained in a 9days workshop ( 8 hours/day) conducted by 2 international Arabic speaking experts in this field of training of trainers on youth reproductive health, HIV prevention, life skills, and peer education, and the training package was based on a Jordanian life skills and peer education package supported by UNICEF Middle East and North Africa Regional Office (UNICEF, 2006). The training package included topics on peer education and training of trainers' methodologies, HIV, reproductive health, sexually transmitted infections, puberty and changes during adolescence, and life skills education. The trained school coordinators team had two functions: coordinating with the schools' managements and parents; and conducting training workshops.

\section{Selection and Training of Peer Educators}

Peer educators from all 27 high schools were recruited on a voluntarily basis. Among those students volunteered, students were selected who met standard criteria of having good communication skills, being accepted by classmates, and good academic achievement. The selection was done by a committee consisting of the school coordinators and school social workers. The school coordinators visited parents of selected peer educators to explain the programme and to obtain a signed consent form allowing their daughters/sons to participate. Several visits were required, especially to parents of female peer educators, as families are usually reluctant to have their daughters get involved in extra-curricular activities, and especially as these relate to HIV and AIDS prevention. The school coordinators team had a pivotal role in advocating 
with families. In case of refusal of parents, another peer educator was selected. Parents' refusals mainly occurred in 2005; among the 30 peer educators selected, three parents refused to allow their children to participate, and thus only 27 students were trained as peer educators. However, in the following years, there were no parental refusals, and therefore, during the three years of programme implementation (20052008), three refusals were faced among 140 selected peer educators, and thus only 137 peer educators participated in the programme.

The selected peer educators were trained in a 10-days ( 8 hours/day) workshop. The training was based on the Jordanian life skills and peer education package, in addition to 10 messages on HIV transmission, prevention, and common misconceptions, and 5 life skills messages. HIV messages involved the following: the first message was on the definition of HIV and causative agent; the second on whether we can recognize an infected HIV person by the way he/she looks or do we have to do a blood test, and what does the window period means; the third message was on why HIV is a dangerous infection; the fourth message was on the epidemiology of HIV in Yemen, the middle east and in the world; the fifth was on the mode of transmission; the sixth was on modes of prevention and adopting the ABCD (abstinence, be faithful, use condoms, and don't use drugs) approach; the seventh was on major misconceptions; the eighth was on risk perception and whether young people can be at risk; the ninth was on how we should deal with PLWH, which stresses the importance of the right of PLWH to live free of stigma and discrimination; and the tenth message was on what is the role of young people in educating the community. The life skills messages were on communication and negotiation skills, self awareness and self-esteem, decision making, respecting difference in opinions, and assertive behaviour.

\section{Training of School Management teams}

To ensure support for peer educators at school level, school management teams, which consisted of school principals and vice-principals, were trained during a 5-days (7 hours/day) training workshop on peer education methodologies, life skills, and HIV prevention. School coordinators planned with peer educators and management teams the peer activities at their schools.

\section{Implementation at School level}

Before implementation, a pre-field two-days training was conducted, where peer educators rehearsed the actual messages to be conducted at school level. The ten HIV messages and 2 life skills messages (self-esteem and assertive behaviour) were the 
major topics covered by peer educators. Peer educators conducted educational sessions as an extra-curricular activity once a week for 90 minutes in a class room setting. Peer education sessions were planned that each student would be targeted with two (90-minutes) sessions in addition to brief sessions during morning school broadcast.

The peer educators used $70 \times 50 \mathrm{~cm}$ posters, where each message was displayed on one poster. Also, peer education sessions were conducted during youth summer activities in the same class-room style. After the end of the second session, participants received leaflets on the 10 messages, as well as hats and T-shirts with a message: "Protect yourself with abstinence and knowledge". The slogan was chosen by the peer educators; the knowledge part referred to the knowledge on condoms and knowledge on avoiding drugs.

\section{Magnitude of Intervention}

The number of targeted schools was increased gradually, starting in 2005 with the training of 27 peer educators reaching 500 students in 5 schools. Then in 2006 a team of 50 peer educators were trained from 20 schools reached 3,800. In 2007, the existing team of peer educators reached 4,000 students in the same 20 schools, and in 2008, a team of 60 peer educators was established and 1000 students from 27 schools were targeted.

\section{The Evaluation}

\section{Design and Participants}

A quasi-experimental design for the evaluation of the school-based peer education interventions was applied. Assignment of students to the intervention condition was not based on random sampling, but was based on the time table for extra-curricular activities, where every two weeks around 25 "new" students per school participate in the sessions. The planning of students for extra-curricular activities was indiscriminate with no systematic selection. Randomization was not feasible as it was considered interfering too much with internal school affairs and was considered un-ethical by the implementing as well as funding organizations. The 2005 baseline survey, which was conducted on a randomly selected sample of 2274 students from the same schools, was used as cohort control group 


\section{Sampling}

The sample included in this study consisted of 2510 students selected from 52 randomly selected classes (out of a total of 250 classes) from the 27 high schools located in the 8 districts of Aden governorate. Proportional allocation technique was applied, i.e., class selection was weighted to ensure an appropriate number of classes from each district, dependant on the number of school classes in the district. In each school, the required number of classes was selected by simple random sampling. In the selected classes, all students who were present in the survey day were invited to complete the questionnaire "See additional file 1".

\section{Instrument and Data Collection Procedure}

A self administered structured questionnaire composed of mainly close-ended questions, and some open questions, was the main study instrument. The questionnaire used was based on the one previously used in the 2005 survey and was subjected to a thorough discussion between the office of education in Aden and active peer educators in high schools of the Aden governorate; the decision was to have the same questionnaire as the one in 2005, and add one more component to study the effects of peer education. Adding behavioural questions on condom use or sexual activity was refused as it was against the policy of the Ministry of Education, due to sensitivities in this conservative school setting. The questionnaire was then pre-tested among one hundred and fifty students from a school not included in the 2005 baseline and this school was excluded from the sample. Pre-testing helped in re-phrasing questions and estimating the approximate time required for completing the questionnaire.

Data collection was conducted during October 2008. The field team consisted of 12 persons subdivided into three smaller teams consisting of a supervisor and three enumerators, each sub-team responsible for almost equal numbers of surveyed classes.

\section{Measures}

Demographic characteristics that were measured included age and gender. The main study outcome variables included the following:

- General HIV/AIDS awareness- represent the assessment of two different variables:

- HIV Infectivity- was assessed through a closed-ended question on whether HIV is contagious, with options of "yes", "no", and "don't know". 
- Existence of HIV/AIDS- was assessed with two closed-ended questions on whether students thought HIV/AIDS cases existed in Yemen and Aden, with options of "yes", "no", and "don't know"

- Peer Education in Schools- whether a student was targeted by the intervention or not was assessed by a closed-ended question on whether the student have ever attended/heard of AIDS education by peers in his/her school; yes/no options were available. Those targeted by peer education were then asked through a closedended question on whether they found peer education beneficial; beneficial to some extent; or not beneficial.

- Knowledge about HIV/AIDS transmission and prevention- Students' knowledge regarding HIV/AIDS transmission and prevention were assessed through 12items. Three options were available: "Yes", "No", and "Don't Know". The answer to each question was scored 1 for correct and 0 for wrong or don't know answer. The total HIV/AIDS transmission and prevention knowledge score was calculated by summing student's responses for the 12 items. The total knowledge score ranged between 0 - 12 and was classified into: Good knowledge (ranging from 9 12) representing $75 \%$ and above of the maximum point in the score range; Average knowledge (ranging from $6-8$ ) representing $50 \%$ to less than $75 \%$ of the maximum point in the score range; and Poor knowledge (ranging from $0-5$ ) representing less than $50 \%$ of the maximum point in the score range.

\section{As an indirect measurement of HIV Stigma and Discrimination, suggested actions} towards People Living with HIV- was assessed by three open-ended questions, stated as follows: What actions should be taken with persons infected with AIDS by government? What actions should be taken with persons infected with AIDS by society? What actions should be taken with persons infected with AIDS by individuals?

- Life skills Changes- students who reported receiving peer education were asked in an open question on whether peer education changed their life skills and if yes, to explain such changes. Answers were coded and categorized into five categories: "No answer", "No change", "There is a change (non-specific)", "There is a specific life-skill change identified", and "Others". 


\section{Data Analysis}

Data were analysed using the Statistical Package for Social Sciences software version 15 (SPSS Incorporation, Chicago, IL, USA). Open ended questions were recorded and coded. Bivariate associations using Pearson Chi-square $\left(\chi^{2}\right)$ were performed for the comparison among proportions. The statistical significance level was set at $\mathrm{p}$ value $<.05$. The predictive ability of selected independent variables with potential determining relation to the study dependent variables was investigated using multivariate analysis. Knowledge score $(0=$ poor, $1=$ good $)$ and life skills change $(0=$ not reported, 1 = reported) were dichotomized for binary logistic regression analysis.

Multivariate analysis to explore the effect of the selected independent variables on the likelihood of students to be not receiving peer education, to have good HIV/AIDS knowledge score and to declare life skills changes after receiving HIV/AIDS peer education was performed by binary logistic regression. In this multivariate analysis, model fitness was checked by Hosmer- Lemeshow goodness-of -fit test.

Multi-level analysis was done to study the effect of peer education on the knowledge score, while taking into account the school effect, with knowledge, as an outcome linear variable, and peer education as a predictor variable.

\section{Ethical Considerations}

The Ethics committee of the Faculty of Medicine and Health Science, Sana'a University, granted the ethical approval to conduct this study. In addition, written consent from the Director General of Education Office in Aden was obtained.

\section{Results}

\section{Characteristics of the participants}

Forty-nine percent of the sample (2510 students) was females and fifty-one percent were males. Around 59\% were from grade 11 and $41 \%$ from grade 12 . The majority of students were in the age range 15-17 years (70.4\%) with a mean age of $17.06 \pm 0.89$ years. All students were enrolled in public schools except for one (semi-public). 


\section{General HIV/AIDS awareness}

Of all students $99.5 \%$ (2498 out of 2510) reported that they have heard about AIDS prior to this survey, and among them, $87.7 \%$ thought that HIV/AIDS was a disease that existed in Yemen; however a lower proportion (61.0\%) perceived its existence in Aden. The majority of the students (80.0\%) believed that HIV is infectious.

\section{Peer Education in Schools}

Being targeted by peer education was reported by (78.6\%) of students. Among those reported being targeted by peer education, (76.6\%) considered peer education beneficial, $(21.7 \%)$ considered it beneficial to some extent, and only $(1.7 \%)$ considered it not beneficial.

\section{Knowledge about HIV/AIDS transmission and prevention}

On average, $62.8 \%$ of the students had a good score on knowledge about HIV/AIDS transmission and prevention. By their sex, a statistically significant difference was detected $\left(\chi^{2}=(\mathrm{df}=2)=72.68, \mathrm{p}<.01\right)$ with $71.2 \%$ of the female students having a good knowledge score compared to $54.7 \%$ of male students.

Of students targeted by peer education $68 \%$ had good knowledge scores, compared with $43.3 \%$ of students not targeted by peer education $\left(\chi^{2}=(\mathrm{df}=1)=111.15, \mathrm{p}<.01\right)$. Students targeted by peer education had statistically less misconceptions and better knowledge on the modes of transmission and prevention. The only exception was the knowledge on having sex with an infected person, which was not statistically significant (Table 1).

To explore the effect of schools on the knowledge score, a multi-level regression analysis was performed. Although this analysis revealed that there was a significant difference between the twenty seven schools in the effect of peer education on knowledge (Wald $\mathrm{Z}=4.42, \mathrm{p}<.001$ ), the intervention effect of peer education at the individual level was significant. This means that those targeted by peer education had a higher knowledge score (9.24 out of 12.0) compared with those not targeted (7.89 out of 12.0$), \mathrm{OR}=2.11,95 \% \mathrm{CI}=1.04-4.27, \mathrm{p}=.05)$. Despite the difference between schools, being targeted by peer improved the knowledge of the students regardless of the school they belong to "See additional file 2". 
Compared with the cohort control group from the 2005 baseline survey, which included a random sample of 2274 students, those participating in the current study had better knowledge on the modes of transmission and prevention, and less misconceptions. The main difference had been in the knowledge on use of condoms, which increased from $49.4 \%$ in 2005 to $67.8 \%$ among targeted students in 2008 . Misconceptions had decreased, where $21.6 \%$ in 2005 reported that transmission through handshaking and kissing can transmit HIV compared with $10.9 \%$ in 2008 ; transmission through eating and drinking was $39.7 \%$ in 2005 compared with $13.1 \%$, transmission through swimming pools was $31.5 \%$ in 2005 compared with $15.6 \%$, and transmission through mosquitoes was $49.3 \%$ in 2005 compared with $21.1 \%$ of students targeted with peer education in 2008.

\section{Suggested actions to deal with People living with HIV/AIDS}

We looked at the suggestions of students for actions to be taken towards people living with HIV by the government, society, and individuals. Overall, the most frequent suggested actions were related to Care, Support, and No Discrimination. At government level, the most frequent suggested actions by students were providing medical treatment /specialized hospitals, care and support, and ensuring human rights. For society, most frequent actions included to be treated the same as everyone else by society and avoiding embarrassing/discriminating PLWH. At individual level, the most frequent suggested actions were sympathy/no discrimination and to be treated the same as everyone else by individuals.

We compared the most frequent suggested actions among those targeted and not targeted by peer education. Suggesting care, support and no discrimination actions were statistically associated with being targeted by peer education (Table 2).

Compared to the 2005 baseline survey, the most frequent actions suggested by the cohort control group were 2569 suggestions related to punishment and included 158 suggestions for killing PLWH. However, in this study, there were only 321 suggestions for punishment, and all related to isolation, but no suggestions for killing. 
Table 1: Knowledge of correct modes of transmission, prevention and misconceptions

\begin{tabular}{|c|c|c|c|c|c|}
\hline \multirow[b]{3}{*}{ Correct modes of transmission and prevention } & \multirow{2}{*}{$\begin{array}{c}2005 \\
\text { Total } \\
(\mathrm{N}=2270)\end{array}$} & \multicolumn{4}{|c|}{2008} \\
\hline & & $\begin{array}{c}\text { Total } \\
(\mathrm{N}=2498)\end{array}$ & $\begin{array}{c}\mathrm{PE}^{*} \\
(\mathrm{~N}=1964)\end{array}$ & $\begin{array}{l}\text { No } / \mathrm{PE}^{* *} \\
(\mathrm{~N}=534)\end{array}$ & $\begin{array}{l}\text { PE/No PE } \\
\text { Significance }\end{array}$ \\
\hline & $\%$ & $\%$ & $\%$ & $\%$ & p-value ${ }^{* * *}$ \\
\hline \multicolumn{6}{|l|}{ Having sex with infected person can transmit } \\
\hline HIV infection & 96.2 & 94.9 & 95.1 & 94.4 & NS \\
\hline $\begin{array}{l}\text { Blood transfusion is a risk factor of HIV infec- } \\
\text { tion }\end{array}$ & 93.8 & 94.7 & 95.5 & 91.8 & $p<.01$ \\
\hline $\begin{array}{l}\text { Shared use of piercing devices with HIV/AIDS } \\
\text { patient can transmit HIV }\end{array}$ & 91.6 & 90.9 & 92.3 & 85.8 & $p<.001$ \\
\hline $\begin{array}{l}\text { Possibility of HIV transmission from infected } \\
\text { pregnant mother to her baby }\end{array}$ & 88.0 & 87.4 & 88.7 & 82.4 & $p<.001$ \\
\hline $\begin{array}{l}\text { Possibility of HIV transmission through breast- } \\
\text { feeding from infected mother }\end{array}$ & 71.0 & 75.5 & 77.2 & 69.3 & $p<.001$ \\
\hline $\begin{array}{l}\text { Male-to-male sex is a risk factor for HIV infec- } \\
\text { tion }\end{array}$ & 75.2 & 70.5 & 71.8 & 65.5 & $p<.01$ \\
\hline \multicolumn{6}{|l|}{ Proper use of male condom is protective against } \\
\hline AIDS & 49.4 & 65.4 & 67.8 & 56.6 & $p<.001$ \\
\hline $\begin{array}{l}\text { Possibility of carrying HIV infection by a healthy } \\
\text { person }\end{array}$ & 43.0 & 44.2 & 47.8 & 31.1 & $p<.001$ \\
\hline \multicolumn{6}{|l|}{$\begin{array}{l}\text { Incorrect modes of transmission and preven- } \\
\text { tion (misconception) }\end{array}$} \\
\hline $\begin{array}{l}\text { Handshaking and kissing can transmit HIV } \\
\text { infection }\end{array}$ & 21.6 & 12.4 & 10.9 & 18.0 & $p<.001$ \\
\hline $\begin{array}{l}\text { Eating and drinking with HIV/AIDS patient can } \\
\text { transmit HIV infection }\end{array}$ & 39.7 & 14.7 & 13.1 & 20.8 & $p<.001$ \\
\hline $\begin{array}{l}\text { Possibility of HIV transmission through swim- } \\
\text { ming pools }\end{array}$ & 31.5 & 16.1 & 15.6 & 17.8 & $p<.001$ \\
\hline $\begin{array}{l}\text { Possibility of HIV transmission through mos- } \\
\text { quito bite }\end{array}$ & 49.3 & 23.8 & 21.2 & 33.1 & $p<.001$ \\
\hline
\end{tabular}

*Targeted by Peer Education

** Not targeted by Peer Education

${ }^{* * *} \mathrm{p}$-value calculated with Pearson's Chi-Squares. 
Table 2: Most frequent suggested actions by school students to deal with people living with HIV

\begin{tabular}{|c|c|c|c|c|c|}
\hline \multirow[b]{3}{*}{ Suggested Actions } & \multirow{3}{*}{$\begin{array}{c}2005 \\
\text { Total } \\
(\mathrm{N}=2270) \\
\%\end{array}$} & \multicolumn{4}{|c|}{2008} \\
\hline & & \multirow{2}{*}{$\begin{array}{c}\text { Total } \\
(\mathrm{N}=2498) \\
\%\end{array}$} & \multirow{2}{*}{$\begin{array}{c}\mathrm{PE}^{*} \\
(\mathrm{~N}=1964) \\
\%\end{array}$} & \multirow{2}{*}{$\begin{array}{c}\text { No } / \mathrm{PE}^{\star *} \\
(\mathrm{~N}=534) \\
\%\end{array}$} & \multirow{2}{*}{$\begin{array}{l}\text { PE/No PE } \\
\text { Significance } \\
\text { p-value }\end{array}$} \\
\hline & & & & & \\
\hline Empathy/no discrimination & 0 & 29.9 & 32.4 & 20.4 & $p<.001$ \\
\hline \multicolumn{6}{|c|}{ To be treated the same as everyone else by } \\
\hline the society & 0 & 29.9 & 32.1 & 21.5 & $p<.001$ \\
\hline Treatments/specialized hospitals & 7.5 & 25.1 & 26.2 & 21.2 & $p<.05$ \\
\hline Avoid embarrassing/discrimination & 0 & 20.1 & 22.0 & 13.1 & $p<.001$ \\
\hline \multicolumn{6}{|c|}{ To be treated the same as everyone else by } \\
\hline individuals & 0 & 18.3 & 20.1 & 12.0 & $p<.001$ \\
\hline Helping and supporting & 11.5 & 15.8 & 17.0 & 11.6 & $p<.01$ \\
\hline Ensuring human rights & 0 & 14.0 & 15.3 & 9.2 & $p<.001$ \\
\hline Killing or Whipping & 2.4 & 0 & 0 & 0 & - \\
\hline Imprisonment & 1.9 & 0 & 0 & 0 & - \\
\hline
\end{tabular}

*Targeted by Peer Education

** Not targeted by Peer Education

${ }^{* * *} \mathrm{p}$-value calculated with Pearson's Chi-Squares.

\section{Life Skills Changes and Student Knowledge}

Of students targeted by peer education 54\% reported life skills changes, with mainly communication skills reported as the main change. Female students reported a statistically higher percentage of life skills changes (65.5\%) compared to males $(44.5 \%)$, $\left(\chi^{2}(\mathrm{df}=1)=87.09, \mathrm{p}<.01\right)$.

We looked at the relation between reporting life skills changes and knowledge score, and we found a statistically higher percentage of students who had good knowledge score $(61.0 \%)$ reported life skills changes after peer education activities than those with poor knowledge score $(43.9 \%),\left(\chi^{2}=(\mathrm{df}=1)=50.18, \mathrm{p}<.01\right)$.

When a logistic regression analysis was done, it showed that males $(\mathrm{OR}=0.41 ; 95 \%$ CI: $0.34-0.50$ ), and those having poor knowledge score (OR=0.60; 95\% CI: 0.49 0.74 ), were at significantly reduced likelihood of changing their life skills after receiving HIV/AIDS peer education. 


\section{Discussion}

The school-based peer education interventions implemented in all twenty seven high schools of Aden had succeeded in improving the levels of knowledge of HIV transmission and prevention, and in decreasing the levels of misconceptions, and of stigma and discrimination towards people living with HIV.

The trend over the past several years shows that the level of knowledge on HIV prevention in the Middle East and North Africa (MENA) has increased, although such an improving trend varies among different groups and settings (Abu-Raddad, Hilmi, et al., 2010). The findings of this study further confirms this improving trend. One of the important findings of this study is related to the improved knowledge on the use of condoms, which is still considered a sensitive issue to discuss among school students in conservative Muslim and Arab settings (Bennett, 2007; Maulana, Krumeich, \& van den Borne, 2009). Compared with other levels of knowledge of condoms among youth in MENA countries, students in this survey had similar levels of condom knowledge to that in Gaza strip, but had better knowledge than youth in Morroco and Iran (Abu-Raddad, Akala, et al., 2010). Previous studies in Yemen among school students (Abu-Raddad, Akala, et al., 2010), and among out of school youth (Al-Serouri, Anaam, Al-Iryani, Ramaroson, \& Al-Deram, 2010) had aslo shown lower levels of knowledge on the use of condoms.

The levels of Misconceptions among the students targeted by peer education in this study are lower than other youth surveyed in several MENA countries (Abu-Raddad, Akala, et al., 2010). In the Islamic Republic of Iran, one-third of high school students believed that HIV can be transmitted by mosquitoes, and $67 \%$ out of school youth in Aden believed that HIV can be transmitted by mosquitoes. In addition to decreased levels of misconceptions, there were decreased levels of stigma and discrimination; although the decrease was more apparent among those targeted with peer education, also students not targeted by peer education have suggested far less punishment actions than the cohort control group in 2005. Existing research is also documenting that there is a trend of decreasing stigma and discrimination towards PLWH in MENA, although it is still far from optimal (Abu-Raddad, Akala, et al., 2010).

Although there is ample research exploring HIV knowledge and attitudes in MENA, there is far less on evaluating HIV school interventions among adolescents and young people. In fact, there is only one study, which documents a rapid school peer educa- 
tion intervention, implemented in the United Arab Emirates (UAE), a high income Arab country. In this study, peer education sessions were delivered to male and female students in UAE high schools by college medical students, who were previously trained by a training package developed by international experts (Barss, Grivna, Ganczak, Bernsen, \& Al-Maskari, 2009). The study revealed that the peer education intervention has improved knowledge and decreased stigma and discrimination among the students who received the intervention.

The relatively new aspect about this study, in addition to being implemented in the most traditional and disadvantaged country of the MENA region (Assaad, et al., 2009), it documents a three-year school-based peer education as well as a life skills intervention, where high school male and female adolescents were trained as peer educators and led the process in their own schools. Moreover, students were given messages on the protective role of condoms. This is noteworthy in such a conservative culture, where adolescents are not considered to have the right to information related to sexuality. The acceptance of the intervention, especially by families of peer educators is an important finding. The fact that there were only three refusals from parents, reflect the important advocacy work by the school programme coordinators. Although the conservative nature of Arab and Muslim societies had usually been blamed for not implementing school-based interventions on HIV and sexual health, this study indicates that such interventions in conservative settings are possible, and parents could be willing to accept the participation of their adolescent girls, given that they are well informed by schools.

The school-based peer education has increased not only the overall knowledge on condoms for HIV prevention compared with the school baseline survey, but has also decreased the knowledge gender gap on condoms, which was evident in the baseline survey conducted in 2005 (Al-Iryani, et al., 2010). The gender gap favouring males, regarding the knowledge on condoms, was also huge among young people in vulnerable communities of Aden, which was revealed by the study conducted by Al-Serouri et al in 2005 (Al-Serouri, et al., 2010). This gender difference is a reflection of the traditional Yemeni society, which gives young men more freedom than young women to discuss sexual related matters, such as condom use (Al-Serouri, et al., 2010). However, the result of this current study challenge this fact, where female students attained better knowledge on condoms after being targeted by peer education, compared to male students. They also reported more life skill changes than male students. This suggests that the design of the intervention was gender sensitive such 
that it was able to reach female students with the necessary information and skills. It also indicates that girls in Yemen make maximum benefit of all existing educational opportunities, and that girl's education is the most important determinant factor that can lead to gender equality, in a nation with huge gender disparities (Hausmann, et al., 2009). Previous research (Barss, et al., 2009) has also documented that female students had attained better knowledge than their male counterparts after participating in HIV peer education in schools, although female students had lower levels of knowledge at baseline.

Although some might argue that improving levels of knowledge and decreasing levels of stigma and discrimination do not necessarily lead to behavioural change, it should be noted that reporting life skills changes was associated with a good knowledge score, which indicates that the peer education intervention not only contributed to knowledge on HIV and decreasing stigma and discrimination, but also to improving life skills, which is an integral part of adopting safe sexual behaviour (Hagquist \& Starrin, 1997).

Several limitations are related to this study. The first limitation is due to the fact that this study evaluated an intervention which aimed to improve knowledge and decrease stigma and discrimination but did not measure the impact on sexual behaviour. Unfortunately, this was not possible due to the conservative school system and the cultural setting. Previous evaluations performed in developing countries have indicated that peer education contributed to knowledge and awareness, but had weak to moderate effects on adolescents' sexual risk behaviour (Aaro, et al., 2006; Gallant \& Maticka-Tyndale, 2004; Harrison, Smith, \& Myer, 2000; Mukoma, 2001). Other studies have shown that peer-led programs improved students' attitudes and behaviours compared with students who did not receive such prevention education (Li, et al., 2010; Medley, et al., 2009; Rickert, Jay, \& Gottlieb, 1991). However, in a setting like Yemen, where access to information by adolescents is still limited, increase in knowledge and awareness is a crucial step towards behaviour change, as one of the factors that influence HIV risk behaviour among young people is their HIV/AIDS knowledge (Fernandez, et al., 2004).

The second limitation is related to the quasi-experimental design of the study, where internal validity is a concern because of the lack of randomization among intervention and control groups. However, several measures were undertaken to improve the similarities between cases and controls. The fact that students from the same schools 
were cases and controls decreased the non-equivalency between them. Also, the 2005 baseline was used as a cohort control group, which helped to increase the internal validity of the study (Shadish, Cook, \& Campbell, 2002).

The third limitation is related to the external validity and generalizability of the study. The fact that this peer education intervention was conducted in Aden governorate does not necessarily mean that the findings can be generalized to all of Yemen. Aden governorate is an urban setting, while $75 \%$ of the Yemeni population is living in rural areas (Central Statistics Organization, 2009). The fourth limitation is related to the validity and reliability of studies that use structured quantitative tools, where young people might give the desirable answers regarding skills and attitudes. The fifth limitation is related to the fact that the significant change in knowledge and attitudes among students may in part reflect changes over time, rather due to the peer education intervention.

Although this study has all of the above detailed limitations, it has revealed that it is possible to address HIV, a sensitive issue related to sexuality, in schools of a conservative country like Yemen, and these findings could be a starting point for future school-based sexual and reproductive health programmes in Yemeni schools. Such programmes should be life skills based and culturally sensitive and should be integrated within the Yemeni school curriculum as a long term strategy. This integration requires policy development by the Ministry of Education and the gap in the short term should be filled through integration in extra-curricular activities. It is also recommended to conduct a youth risk assessment survey, which would be a valuable tool in the context of Yemen, where there is much more to learn about the risks and vulnerabilities associated with adolescents and young people in Yemen. Such a survey, although research tools are available from other countries, should be tailored to the Yemeni context. The survey should not only focus on youth vulnerabilities and risks to HIV, but also sexually transmitted infections, alcohol abuse, and Qat (Khat) consumption. Khat, a green shrub, which is a mild narcotic with amphetamine-like effects, is widely chewed by Yemeni youth. Previous research had conflicting conclusions on whether Khat could be a risk factor for HIV and other sexually transmitted infections (Beckerleg, 2010; Kebede, et al., 2005), and thus this issue has to be further explored within the context of a youth risk assessment survey. 


\section{Conclusion}

This evaluation demonstrated that HIV education among school adolescents is possible in very conservative settings, given the interventions are addressed in a culturally sensitive manner, and all key stakeholders are involved in the early stages of the interventions. The school-based peer education intervention has succeeded in improving levels of knowledge on modes of transmission and prevention, and in decreasing levels of stigma and discrimination. 


\section{Additional file 1: Sampling Details}

The sample included in this study consisted of 2510 students, which was around twenty percent of the total number of grade 11 and 12 high school students $(12,269)$ in Aden governorate were targeted in this study. According to the details provided by the office of education in Aden governorate the mean number of students in each class was 49 students with a total of 250 classes with grade 11 and 12 students. Thus the total number of classes for the sample was 51 (2510/49). The required number of classes in each district and schools was selected using the proportional allocation technique. In each school, the required number of classes was selected by simple random sampling. In the selected classes, all students who were present in the survey day were invited to complete the questionnaire. For instance, the total number of classes of grade 11 and 12 in the two secondary schools in Maalla district is 22 which is amounted to $8.8 \%$ of the total number of classes (22 out of 250). This means $8.8 \%$ of the total number of the required classes is needed from Maalla. Therefore, four classes were enrolled from Maalla (4 is $8.8 \%$ of 50 ). In each school, the required number of classes was selected by simple random sampling. In the example of Maalla, nine of the 22 classes are found in the girls' school whereas 13 in the boys' school. Therefore, two classes (one class from grade 11 and one from grade 12) were randomly selected from each school to attain the four required classes.

Distribution of grade 11 and 12 students in the different districts

\begin{tabular}{lcccccccc}
\hline District & $\begin{array}{c}\text { Grade 12 } \\
\text { Classes }\end{array}$ & $\begin{array}{c}\text { Grade 12 } \\
\text { Students }\end{array}$ & $\begin{array}{c}\text { Grade 11 } \\
\text { Classes }\end{array}$ & $\begin{array}{c}\text { Grade 11 } \\
\text { Students }\end{array}$ & $\begin{array}{c}\text { Total } \\
\text { students }\end{array}$ & $\begin{array}{c}\text { No. of } \\
\text { Classes }\end{array}$ & $\begin{array}{c}\text { \% of } \\
\text { classes }\end{array}$ & $\begin{array}{c}\text { Required } \\
\text { no. of } \\
\text { Classes }\end{array}$ \\
\hline Maalla & 11 & 550 & 11 & 532 & 1082 & 22 & 8.8 & 4 \\
Al-Tawahi & 13 & 526 & 12 & 553 & 1079 & 25 & 10.0 & 5 \\
Khor- Makser & 10 & 539 & 9 & 575 & 1114 & 19 & 7.6 & 4 \\
Sirah & 19 & 883 & 21 & 906 & 1789 & 40 & 15.9 & 8 \\
Al-Buraiqa & 14 & 641 & 14 & 694 & 1335 & 28 & 11.2 & 6 \\
Sheikh Othman & 21 & 1087 & 22 & 1097 & 2184 & 43 & 17.1 & 9 \\
Dar- Sa'ad & 16 & 792 & 19 & 966 & 1758 & 35 & 13.9 & 7 \\
Mansoura & 17 & 877 & 21 & 1051 & 1928 & 38 & 15.2 & 8 \\
Total & 121 & 5895 & 129 & 6374 & 12269 & 250 & 100 & 51 \\
\hline
\end{tabular}

Source: Aden Education Office. Secondary School Statistics in Aden (2007-2008) 
Distribution of sampled classes by schools in the eight districts of Aden Governorate

\begin{tabular}{ll}
\hline School & Classes \\
\hline Maalla District (4 classes) & 2 \\
Mareb & 2 \\
14th October & \\
\hline Al-Tawahi District (5 classes) & 1 \\
Muhrez & 2 \\
Garadah & 2 \\
\hline Tamna'a & 2 \\
\hline
\end{tabular}

Khor Makser District (4 classes)

Al-Dawliah Al-Shamilah 1

Mohammed Abdo Ghanem 1

Abdo Albary Kasem 2

Sirah District (8 classes)

Lutfi Gaafer Aman 3

Aban 2

$\begin{array}{ll}\text { Bakatheer } & 2\end{array}$

Al-Baihani 1

Al-Buraiqa District (6 classes)

Mohammed Al-Durah 1

Salah Addeen $\quad 1$

Al-Wahda 1

Nasser Rashed Luta $\quad 1$

Al-Sha'ab 1

Al-Quds 1

Sheikh Othman (9 classes)

Othman Abdo 3

Belqees $\quad 4$

$\begin{array}{ll}\text { Al-Nahda } & 2\end{array}$

Dar Sa'ad District (7 classes)

Zainab Ali Kasem 3

Aden 1

Al-Ahdel 3

Al-Mansoura District (8 classes)

$\begin{array}{ll}\text { Khadija } & 2\end{array}$

Al-Numan $\quad 4$

Ba-Dib 2

Grand Total 
Additional file 2:

Differences between schools in relation to knowledge among students targeted and not targeted by peer education.

\begin{tabular}{|c|c|c|c|c|c|}
\hline Schools & $\begin{array}{c}\text { Peer } \\
\text { Education }\end{array}$ & Count & $\begin{array}{c}\text { Knowledge } \\
\text { Mean }\end{array}$ & $\begin{array}{l}\text { Standard } \\
\text { Deviation }\end{array}$ & $\begin{array}{c}\text { Coefficient of } \\
\text { Variation }\end{array}$ \\
\hline \multirow[t]{3}{*}{ Garadeh } & yes & 37 & 8.11 & 1.853 & $22.8 \%$ \\
\hline & no & 39 & 6.59 & 2.302 & $34.9 \%$ \\
\hline & Total & 76 & 7.33 & 2.217 & $30.3 \%$ \\
\hline \multirow[t]{3}{*}{ Tamna'a } & yes & 48 & 7.79 & 2.103 & $27.0 \%$ \\
\hline & no & 15 & 7.53 & 1.767 & $23.5 \%$ \\
\hline & Total & 63 & 7.73 & 2.018 & $26.1 \%$ \\
\hline \multirow[t]{3}{*}{ Muhairez } & yes & 37 & 9.86 & 1.228 & $12.5 \%$ \\
\hline & no & 13 & 8.00 & 2.944 & $36.8 \%$ \\
\hline & Total & 50 & 9.38 & 1.978 & $21.1 \%$ \\
\hline \multirow[t]{3}{*}{ Moh'd Abdo Ghanem } & yes & 31 & 7.90 & 1.868 & $23.6 \%$ \\
\hline & no & 34 & 6.82 & 2.249 & $33.0 \%$ \\
\hline & Total & 65 & 7.34 & 2.131 & $29.0 \%$ \\
\hline \multirow[t]{3}{*}{ Abdulbari } & yes & 62 & 6.79 & 2.097 & $30.9 \%$ \\
\hline & no & 37 & 6.16 & 2.102 & $34.1 \%$ \\
\hline & Total & 99 & 6.56 & 2.110 & $32.2 \%$ \\
\hline \multirow[t]{3}{*}{ Al Dawliah } & yes & 39 & 7.95 & 2.339 & $29.4 \%$ \\
\hline & no & 4 & 7.50 & 1.291 & $17.2 \%$ \\
\hline & Total & 43 & 7.91 & 2.255 & $28.5 \%$ \\
\hline \multirow[t]{3}{*}{ Mareb } & yes & 72 & 8.10 & 1.855 & $22.9 \%$ \\
\hline & no & 28 & 7.86 & 1.693 & $21.6 \%$ \\
\hline & Total & 100 & 8.03 & 1.806 & $22.5 \%$ \\
\hline \multirow[t]{3}{*}{14 October } & yes & 99 & 10.62 & 1.383 & $13.0 \%$ \\
\hline & no & 9 & 8.33 & 1.936 & $23.2 \%$ \\
\hline & Total & 108 & 10.43 & 1.560 & $15.0 \%$ \\
\hline \multirow[t]{3}{*}{ Bakatheer } & yes & 61 & 7.98 & 2.053 & $25.7 \%$ \\
\hline & no & 7 & 6.71 & 2.360 & $35.2 \%$ \\
\hline & Total & 68 & 7.85 & 2.104 & $26.8 \%$ \\
\hline \multirow[t]{3}{*}{ Aban } & yes & 60 & 9.77 & 1.661 & $17.0 \%$ \\
\hline & no & 6 & 9.83 & 1.602 & $16.3 \%$ \\
\hline & Total & 66 & 9.77 & 1.644 & $16.8 \%$ \\
\hline \multirow[t]{4}{*}{$\overline{\text { Lutfi }}$} & yes & 106 & 8.89 & 2.108 & $23.7 \%$ \\
\hline & no & 30 & 7.63 & 2.157 & $28.3 \%$ \\
\hline & Total & 136 & 8.61 & 2.175 & $25.3 \%$ \\
\hline & yes & 43 & 10.79 & 1.081 & $10.0 \%$ \\
\hline \multirow[t]{2}{*}{ Al Baihani } & no & 2 & 11.00 & .000 & $.0 \%$ \\
\hline & Total & 45 & 10.80 & 1.057 & $9.8 \%$ \\
\hline
\end{tabular}




\begin{tabular}{|c|c|c|c|c|c|}
\hline Schools & $\begin{array}{c}\text { Peer } \\
\text { Education }\end{array}$ & Count & $\begin{array}{c}\text { Knowledge } \\
\text { Mean }\end{array}$ & $\begin{array}{l}\text { Standard } \\
\text { Deviation }\end{array}$ & $\begin{array}{c}\text { Coefficient of } \\
\text { Variation }\end{array}$ \\
\hline \multirow[t]{3}{*}{ Al Numan } & yes & 162 & 9.83 & 1.667 & $17.0 \%$ \\
\hline & no & 24 & 8.88 & 1.727 & $19.5 \%$ \\
\hline & Total & 186 & 9.70 & 1.700 & $17.5 \%$ \\
\hline \multirow[t]{3}{*}{ Batheeb } & yes & 75 & 10.60 & 1.952 & $18.4 \%$ \\
\hline & no & 9 & 11.44 & .726 & $6.3 \%$ \\
\hline & Total & 84 & 10.69 & 1.875 & $17.5 \%$ \\
\hline \multirow[t]{3}{*}{ Khadijah } & yes & 79 & 10.09 & 2.231 & $22.1 \%$ \\
\hline & no & 14 & 10.93 & .730 & $6.7 \%$ \\
\hline & Total & 93 & 10.22 & 2.095 & $20.5 \%$ \\
\hline \multirow[t]{3}{*}{ Othman } & yes & 124 & 9.31 & 2.108 & $22.6 \%$ \\
\hline & no & 47 & 8.02 & 2.715 & $33.8 \%$ \\
\hline & Total & 171 & 8.95 & 2.354 & $26.3 \%$ \\
\hline \multirow[t]{3}{*}{ Al-Nahdah } & yes & 73 & 8.86 & 1.805 & $20.4 \%$ \\
\hline & no & 45 & 7.78 & 2.163 & $27.8 \%$ \\
\hline & Total & 118 & 8.45 & 2.011 & $23.8 \%$ \\
\hline \multirow[t]{3}{*}{ Belqees } & yes & 127 & 9.39 & 2.020 & $21.5 \%$ \\
\hline & no & 34 & 9.44 & 1.829 & $19.4 \%$ \\
\hline & Total & 161 & 9.40 & 1.976 & $21.0 \%$ \\
\hline \multirow[t]{3}{*}{ Zainab } & yes & 155 & 10.13 & 1.467 & $14.5 \%$ \\
\hline & no & 10 & 10.10 & 1.370 & $13.6 \%$ \\
\hline & Total & 165 & 10.13 & 1.457 & $14.4 \%$ \\
\hline \multirow[t]{3}{*}{$\overline{\text { Aden }}$} & yes & 45 & 10.38 & 1.267 & $12.2 \%$ \\
\hline & no & 3 & 11.00 & 1.000 & $9.1 \%$ \\
\hline & Total & 48 & 10.42 & 1.252 & $12.0 \%$ \\
\hline \multirow[t]{3}{*}{ Al-Ahdel } & yes & 151 & 7.77 & 2.501 & $32.2 \%$ \\
\hline & no & 60 & 6.90 & 2.529 & $36.7 \%$ \\
\hline & Total & 211 & 7.53 & 2.534 & $33.7 \%$ \\
\hline \multirow[t]{3}{*}{ Mohamed Durrah } & yes & 70 & 10.00 & 1.523 & $15.2 \%$ \\
\hline & no & 4 & 8.75 & .957 & $10.9 \%$ \\
\hline & Total & 74 & 9.93 & 1.520 & $15.3 \%$ \\
\hline \multirow[t]{3}{*}{ Naser Rasheed Lutah } & yes & 40 & 8.28 & 2.353 & $28.4 \%$ \\
\hline & no & 15 & 7.53 & 1.407 & $18.7 \%$ \\
\hline & Total & 55 & 8.07 & 2.150 & $26.6 \%$ \\
\hline \multirow[t]{3}{*}{ Al Wehdah } & yes & 34 & 8.09 & 2.503 & $30.9 \%$ \\
\hline & no & 21 & 7.29 & 2.101 & $28.8 \%$ \\
\hline & Total & 55 & 7.78 & 2.370 & $30.5 \%$ \\
\hline \multirow[t]{3}{*}{ Salah Adeen } & yes & 43 & 9.35 & 2.126 & $22.7 \%$ \\
\hline & no & 5 & 9.40 & 1.949 & $20.7 \%$ \\
\hline & Total & 48 & 9.35 & 2.088 & $22.3 \%$ \\
\hline
\end{tabular}




\begin{tabular}{lccccc}
\hline Schools & $\begin{array}{c}\text { Peer } \\
\text { Education }\end{array}$ & Count & $\begin{array}{c}\text { Knowledge } \\
\text { Mean }\end{array}$ & $\begin{array}{c}\text { Standard } \\
\text { Deviation }\end{array}$ & $\begin{array}{c}\text { Coefficient of } \\
\text { Variation }\end{array}$ \\
\hline Al Shaab & yes & 41 & 10.32 & 1.540 & $14.9 \%$ \\
& no & 10 & 10.60 & .843 & $8.0 \%$ \\
& Total & 51 & 10.37 & 1.428 & $13.8 \%$ \\
\hline Alqudus & yes & 50 & 9.88 & 1.560 & $15.8 \%$ \\
& no & 9 & 8.56 & 1.944 & $22.7 \%$ \\
& Total & 59 & 9.68 & 1.676 & $17.3 \%$ \\
\hline Total & yes & 1964 & 9.24 & 2.165 & $23.4 \%$ \\
& no & 534 & 7.89 & 2.424 & $30.7 \%$ \\
& Total & 2498 & 8.95 & 2.290 & $25.6 \%$ \\
\hline
\end{tabular}

Estimates of Covariance Parameters (a)

\begin{tabular}{|c|c|c|c|c|c|c|}
\hline \multirow[t]{3}{*}{ Parameter } & \multirow{3}{*}{ Estimate } & \multirow[t]{3}{*}{ Std. Error } & \multirow[t]{3}{*}{ Wald Z } & \multirow[t]{3}{*}{ Sig. } & \multicolumn{2}{|c|}{ 95\% Confidence Interval } \\
\hline & & & & & Lower & Upper \\
\hline & & & & & Bound & Bound \\
\hline Residual & 3.823924 & .109424 & 34.946 & .000 & 3.615360 & 4.044519 \\
\hline $\mathrm{q} 16[$ subject $=\mathrm{q} 1]$ Variance & 1.459524 & .330034 & 4.422 & .000 & .936988 & 2.273467 \\
\hline
\end{tabular}

a Dependent Variable: Total knowledge of transmission \& prevention. 



\section{Chapter 3}

\section{A quasi-experimental evaluation of a three-year community-based peer education intervention for HIV prevention among Yemeni young people}

This chapter has been submitted for publication as:

Buthaina Al-Iryani, Huda Basaleem, Khaled Al-Sakkaf, Gerjo Kok and Bart van den Borne. A quasi-experimental evaluation of a three-year community-based peer education intervention for HIV prevention among yemeni young people. 


\begin{abstract}
A community-based peer education intervention for HIV prevention among young people, 15-24 years, living in four poor and high risk areas was implemented in Aden, Yemen over a three-year period (2005-2008). The intervention was developed after a baseline survey among the same population in 2005 , which included a random sample of 601young people. Young people were assigned to the intervention during the three years using a quasi-experimental design. The evaluation of the intervention was conducted at the end of 2008. Data were collected using an intervieweradministered questionnaire from a sample of 700 young people randomly selected from the households of the four targeted communities; among this sample, those targeted by the intervention were compared to those not targeted. To increase internal validity, students were also compared with the cohort control sample surveyed in 2005. Results revealed that young people targeted by peer education attained a higher percentage of good knowledge (47.5\%) compared to those who did not receive peer education (25.4\%). Levels of stigma and discrimination at individual level decreased among those targeted by peer education. Among those targeted by peer education, $90.4 \%$ reported behavioural change, mainly related to avoiding sharing needles $(53.3 \%)$, avoiding sex with female sex workers (37.6\%), avoiding male-to-male-sex (18.6\%), and avoiding sex with multiple partners (16.8\%), and use of condoms (3.3\%). In comparison with the 2005 baseline, knowledge on the protective role of condoms increased from $29 \%$ to $49.5 \%$. In $2008,82.0 \%$ perceived themselves at risk for HIV infection compared to $62.0 \%$ in 2005; and 65.6\% were willing to accept having a person living with HIV teaching their relatives in schools compared to $23 \%$ in 2005. The findings of this study demonstrate that community-based peer education for HIV prevention could improve knowledge and risk perception; and decrease stigma, and risky behaviour in culturally conservative setting.
\end{abstract}




\section{Introduction}

Yemen is a least developed country (UNCTAD, 2009), of a population around 22.5 million (Central Statistics Organization, Yemen Statistical Year Book., 2009). Epidemiologically, it is categorized as a low HIV prevalence country of $0.2 \%$. Young people are especially vulnerable to HIV infection, and recent Voluntary Counselling and Testing (VCT) reports have shown an increase of adolescents and young people infected with HIV (National AIDS Programme, 2009).

Several studies were undertaken in the past few years to understand the vulnerability of Yemeni society to HIV and other sexually transmitted infections (STIs). Two situation analysis studies were conducted between 2001 and 2002. The Sana'a City study collected data on HIV awareness among the general population (Al-Serouri \& Takioldin, 2002). The four governorate behavioural study among a sample of participants in their reproductive period (15-49 years) in the governorates of Hodeida, Taiz, Aden, and Hadhramout generated data on Sexually Transmitted Infections (STI) awareness and factors predicting vulnerability (Busulwa, Takiyaddin, Azzubeidi, El Zein El Mousaad, Tawillah, \& Ziady, 2006). The study identified risk factors for HIV infection, which included low awareness of the use of condoms, high level of sexually transmitted infections, and unprotected extra-marital sex. Poverty, a social cultural transition, variations in the sexual subcultures between sections of the Yemeni population, low HIV risk perception and population movements including migration for work, all have emerged as important underlying factors for HIV vulnerability. The vulnerable groups identified included marginalized groups (Alakhdam), refugees, returnees, youth, truck drivers, Red Sea fishermen, prison inmates and the poorest in the society. The 2002 behavioural study has shown that HIVrelated risk behaviour is linked to heterosexual and homosexual behaviour. The data did not suggest a significant occurrence of injecting drug use. Female sex workers (FSW) and men who have sex with men were confirmed to exist in the four governorates behavioural study, especially in poor and high risk neighbourhoods of Aden governorates.

To further explore risks and vulnerabilities in poor and high risk neighbourhoods of the Aden governorate, a community-based survey was conducted in 2005 among 601 young people living in such neighbourhoods. The study revealed low levels of HIV knowledge, low levels of HIV risk perception, and high levels of stigma and discrimination against People Living with HIV (PLWH) (Al-Serouri, Anaam, Al-Iryani, 
Ramaroson, \& Al-Deram, 2010). These results indicated the need, and served as a baseline, for designing and implementing HIV prevention and education intervention at community level.

The design of the intervention at community level here is based on the Theory of Diffusion of Innovations (Rogers, 2003), which considers that an innovation can be new information, an attitude, a belief or a practice or any other object that is perceived as new by the individual or the community and can be diffused to a specific group. An innovation is communicated through certain channels over time amongst members of a social system (here, the four targeted neighbourhoods in Aden). A central point in this theory is the use of opinion leaders as 'change agents'. Peer educators are assumed to have this role by influencing not only their peers for whom the activities are organized (active diffusion), but also others of relevance in the peer's environment (family, friends, etc.) through an informal (passive) diffusion (Oldenburg \& Glanz, Diffusion of Innovations, 2008). Behavioural change thus comes about through a process of formal or informal communication and modelling by trained peers.

This article describes the impact assessment of a three-year (2005-2008) HIV prevention intervention for young people living in poor communities of Aden, Yemen. The main question this study aims to answer is whether a community-based peer education intervention succeeded in improving HIV knowledge and risk perception, and in decreasing stigma and risky behaviours among those targeted by the intervention.

\section{Methods}

\section{Setting}

Abdul Qaui, Al Memdarah, Al Basateen, and Al Sesaban are four poor neighbourhoods in Aden city, with a total population of 71740, distributed in 11000 households. These four areas were the site of the 2005 baseline survey; the site of community based peer education during the three-year period of 2005-2008, and the site of this evaluation. These areas are inhabited by poor Yemeni citizens, marginalized groups (Al-akhdam), returnees, and refugees. Marginalized groups in Yemen, Alakhdam, which literally means servants, are a social group distinct from the majority by their more African features. As a low caste group, they are discriminated against 
and mostly confined to menial jobs. Their origins are unclear. In Yemen, they are popularly believed to be the descendants of Ethiopian soldiers of the Aksumite Empire that occupied Yemen more than 1500 years ago and who remained there as servants of the local population after the occupation ended. Al-akhdam are stereotyped as dishonourable, immoral, dependent and dirty (Al-Ahmadi \& Beatty, 1997). Returnees are low-paid Yemeni workers who were expelled from Saudi Arabia during the Gulf War in 1990. When they came back to Yemen, they became an Internally Displaced Population usually living in slum areas. Refugees in this study were mainly Somalis; some were with Yemeni descendants and the rest were Somalis who fled the war in their country. The common characteristic among the four poor neighbourhoods were the large number of commercial sex workers, because they represent transit hubs for migrant populations coming from the Horn of Africa, where the prevalence of HIV is higher than in Yemen, as well as a transit area for truck drivers and local travellers (Al-Serouri, Anaam, Al-Iryani, Ramaroson, \& Al-Deram, 2010).

\section{Community-based intervention}

\section{Overview}

A community based intervention in Aden governorate was initiated in 2005, which aimed to equip young people residing in the four poor targeted communities with HIV information and skills. This intervention included culturally sensitive community based peer education and outreach. The intervention was designed after conducting a baseline study in these communities (Al-Serouri, Anaam, Al-Iryani, Ramaroson, \& Al-Deram, 2010).

Creating an enabling environment: Advocacy and capacity building of stakeholders Because of the conservative setting in these communities, the first step was to create an enabling environment through conducting advocacy sessions with religious leaders, local councils, district directors, and traditional leaders, which focused on the importance of establishing a community based intervention where adolescents and young people lead peer education and outreach activities. The second step was building partnerships with Community Based Organizations (CBOs) and NonGovernmental Organizations (NGOs) existing in these communities through training programmes focusing on HIV prevention as well as on the right of adolescent and youth to participation and to access gender sensitive information and services. This was followed by creating community committees consisting of representatives of local councils, NGOs, CBOs, and the National AIDS Programme (NAP), which had 
the role of selecting community focal points and community peer educators from targeted communities, while ensuring at least $50 \%$ of community peer educators were girls to ensure a gender sensitive intervention.

\section{Training of community focal points and community peer educators}

The community outreach focal points and youth peer educators were trained in a 10days training workshops on life-skills and peer education, followed by 2-days prefield training before initiating peer education sessions and outreach activities. The training was based on the Jordanian Peer Education and Life-Skills Package, in addition to 10 messages on HIV transmission, prevention, common misconceptions, and 5 life-skills messages (UNICEF, Mapping of Children, Young People and HIV/AIDS Activities in the Middle East and North Africa Region, 2006). HIV messages involved the following: the first message was on the definition of HIV and causative agent; the second on whether we can recognize an infected HIV person by the way he/she looks or do we have to do a blood test, and what does the window period means; the third message was on why HIV is a dangerous infection; the fourth message was on the epidemiology of HIV in Yemen, the middle east and in the world; the fifth was on the mode of transmission; the sixth was on modes of prevention and adopting the ABCD (abstinence, be faithful, use condoms, and don't use drugs) approach; the seventh was on major misconceptions; the eighth was on risk perception and whether young people can be at risk; the ninth was on how we should deal with PLWH, which stresses the importance of the right of PLWH to live free of stigma and discrimination; and the tenth message was on what is the role of young people in educating the community. The life skills messages were on communication and negotiation skills, self-awareness and self-esteem, decision making, respecting difference in opinions, and assertive behaviour.

\section{Implementation at community level}

Targeting young people at community level was done through in-door peer education session as well as outreach activities. In-door peer education was conducted as structured sessions with pre-and post-test, where peer educators conducted 5-hours sessions in the course of two days (2.5 hours per day). The ten HIV messages and 2 life-skills messages (self-esteem and assertive behaviour) were the major topics covered by peer educators. The peer educators used posters, one for each message. After the end of the second session, participants received leaflets on the 10 messages, as well as hats and T-shirts with a message: "Protect yourself with Abstinence and 
Knowledge". The slogan was chosen by the peer educators; the knowledge part referred to the knowledge on condoms and knowledge on avoiding drugs

In-door peer education sessions were conducted in NGOs and health centres. In neighbourhoods where no NGOs or health centres existed, schools were the site for peer education sessions during after school hours. Workers in community outreach focal points, who were familiar with the neighbourhoods, mobilized young people and families through home visits to encourage families to allow young people, especially adolescent girls, to participate.

The outreach peer education activities were conducted in homes, especially during Qat (or Khat) chewing sessions, in motels, hotels, beauty parlours, bus stops, and Qat markets (Qat is a plant that is a mild stimulant with amphetamine-like properties ). Outreach aimed to equip the hard to reach youth with necessary prevention information.

In 2008, and after three years of establishing the community based intervention, Voluntary Counselling and Testing (VCT) services were established in the targeted vulnerable communities. Social mobilization for VCT services was integrated as part of peer education and outreach activities, which aimed to increase the utilization of the services among most-at-risk populations.

\section{The evaluation}

\section{Design and participants}

A quasi-experimental design for the evaluation of the community-based peer education intervention was applied. Assignment of young people at community level to the intervention condition was not based on random sampling, but was based on the outreach work done by the community focal points and the CBOs and NGOs in four targeted neighbourhoods. The criteria applied by CBOs and NGOs were age and place of residence; only those living in the targeted neighbourhoods, and of the age group 15-24 years were targeted with peer education, while ensuring to target equal numbers of male and female youth. The 2005 community baseline survey (Al-Serouri et al., 2010), which was conducted on a randomly selected sample of 601 young people from the same communities, was used as a cohort comparison (control) group. 


\section{Sampling}

The sample was planned to be comparable with the 2005 baseline survey (Al-Serouri et al., 2010). The required number of households in each area was selected using the proportional allocation technique. Each area was divided into blocks and each block was constituted of around 25-40 households. Inside each area, a list of all blocks was developed and the required number of blocks from each area to cover the needed sample size was selected randomly by simple random sampling technique. In each eligible block, all households were visited by the data collectors. In each household, a maximum of two eligible youth were included in the study trying to include one male and one female; having one in the age group 15-18 and one in the age group 19-24. Around 660 households were visited, and a total of 700 young people were included in the sample.

\section{Instrument and data collection procedure}

An interviewer assisted structured questionnaire composed of mainly close-ended questions, and some open questions, was the main study instrument. The questionnaire used in this study was adapted from the one used in the 2005 survey (Al-Serouri et al., 2010), in addition to some questions added on peer education and reported behaviour. Pre-testing was done in selected neighbourhoods that bear similarities to the targeted ones which were not included later in the sample. Pre-testing was useful in identifying difficult terms in the questionnaire and re-wording into local dialect. The house-to-house (household) survey was conducted in a ten days period (19-28 November, 2008) by two teams of data collectors each consisting of a supervisor and five data collectors. All data collectors had previous experience in household surveys, and in addition, were trained during a three-days training workshop on conducting the questionnaire. All data collectors (interviewers) were from Aden governorate to ensure that they spoke the dialect of the youth in the targeted areas. All households in the sampled blocks were visited. Participation of participants in the survey was on a voluntary basis. Measures were taken to ensure anonymity for study participants, as no names were asked by data collectors.

\section{Measures}

Demographic and socio-economic characteristics that were measured included age, gender, income, type of housing, educational level, and marital status.

Ever heard of AIDS- assessed with a closed-ended question, with options of "yes", "no", and "don't know". Those who say no are then excluded from further sample analysis. 
Peer education in communities - whether participants were targeted by the intervention or not was assessed by a closed-ended question on whether participants have ever attended/ heard of AIDS education by peers in their community; "yes"/ "no" options were available.

The main study outcome variables fall into four categories: knowledge, stigma and discrimination, risk perception, and behavioural outcomes:

\section{Knowledge outcome variables}

Knowledge on HIV - Participant's knowledge regarding HIV/AIDS transmission, prevention, and misconceptions were assessed through 18-item question. For each question, options for answers were "yes", "no", and "don't know".

Knowledge score - answer to each question was scored 1 for correct and 0 for wrong or don't know answer. The total HIV transmission and prevention knowledge score was calculated by summing participant's responses for the 18 items. The total knowledge score ranged between $0-18$ and was classified into: Good knowledge (ranging from $14-18$ ) representing $75 \%$ and above of the maximum point in the score range, and Poor knowledge (ranging from 0 - 13) representing less than $75 \%$ of the maximum point in the score range.

\section{Stigma and discrimination outcome variables}

Dealing with PLWH at individual level- was assessed by three closed-ended questions: willingness to care for a relative infected with HIV, willingness to buy greenery from a person infected with HIV, and acceptance of having a teacher infected with HIV to teach a relative. Options for answers were "yes", "no", and "don't know".

Dealing with PLWH at community (society) level- was assessed by a closed-ended question on how the community should deal with PLWH. Participants were given the following options (participants could choose more than one response): Isolation, rejection, burning, divorce from spouse, kindness and compassion, treatment, care \& support, others (specify).

Dealing with PLWH at government level- was assessed by a closed-ended question on how the government should deal with PLWH. Participants were given the following options (participants could choose more than one response): Killing, isolation in hospitals, imprisoning, treatment, and others (to be specified by participant). 
Risk perception outcome variables:

Existence of HIV in Aden- was assessed by a closed question stated as follows: Do you think AIDS cases exist in Aden? Options for answers were "yes", "no", and "don't know".

Personal risk perception-was assessed by a closed question stated as follows: Do you think you are at risk for HIV infection? Options for answers were Yes, High Possibility; "Yes", "Weak Possibility", and "No Possibility".

Perception of risk factors in communities- was assessed by closed-ended questions on whether they thought specific risk factors (multiple sex partners, female sex work, male-to-male sex, and intravenous drug use) caused HIV infection and if these risk factors existed in their communities. Options for answers were "yes", "no", and "don't know".

Willingness to seek HIV Voluntary and Confidential Testing (VCT) services- was assessed by asking whether the participant was willing to be tested voluntarily if confidentiality would be assured. Options for answers were "yes", "no", and "don't know". If yes, a consecutive open-ended question was asked on where he/she could get such test. If the participant answered no, they were asked with an open-ended question on why they were not willing to be tested.

\section{Behavioural outcome variables:}

\section{Reduction in risk-behaviours}

Participants who reported receiving peer education were asked in closed question on whether peer education changed their life-style, practices, and/or behaviour; options for answers were "yes" or "no"; if yes, they were asked a closed-ended question on what were the changes, with 7 possible answers, which included the following: avoiding sharing needles, avoiding cupping (blood-letting), avoiding sharing sharp blades, avoiding sex with FSW, avoiding male-to male sex, avoiding sex with multiple partners, using condoms, and an "others" option for additional modifications to be specified by the participants.

\section{Data analysis}

Data were analysed using the Statistical Package for Social Sciences software version 15 (SPSS Incorporation, Chicago, IL, USA). Open ended questions were recorded first in a separate sheet to identify the most frequently mentioned responses, and then entered into the dataset. Pearson Chi-square $\left(\chi^{2}\right)$ was used to investigate bivariate comparisons for proportions. A p-value of $<.05$ indicated statistical significance. 
Multivariate analysis was done by binary logistic regression analysis to identify significant variables associated with the dependent outcomes of the study. For this purpose, each dependent variable was dichotomized into two categories as follow: Peer education (Received peer education $=0$; Not received peer education $=1$ ); Knowledge score (poor $=0$; Good Knowledge $=1$ ); Reduction in risk-behaviours $(\mathrm{No}=0$; Yes=1).

\section{Results}

\section{Characteristics of the participants and households:}

Females were $54.6 \%$ and males were $45.4 \%$ of the study sample with a mean age of $19.15 \pm 2.88$ years. The majority was single $(80.7 \%)$, while $17.3 \%$ were married, and $2 \%$ were divorced. Illiterate participants constituted $16.1 \%$ of the sample; and those out of school/college settings represented $63.7 \%$ of the sample. Non-marginalized Yemeni citizens were 54.9\%; marginalized young people were $21.3 \%$; Somali Refugees represented $16.1 \%$ and returnees $7.7 \%$. The mean monthly family income was $30,490 \pm 16,149$ Yemeni Rials (equivalent to $153 \pm 81$ US Dollars), with $11.2 \%$ living in straw/tin huts or tents, and the majority had a father or husband as head of the household (91.6\%).

Ninety four percent (658 out of 700 participants) had heard about AIDS prior to the study. Forty six percent of the participants (303/658) stated that they received the HIV peer education intervention, compared with 54\% (355/658) who did not receive the intervention. Among those who received peer education, $51 \%$ ( 155/303) were females and $48.8 \%$ ( 148/303) were males.

\section{Knowledge outcomes}

Having a good knowledge score was significantly associated with being targeted by HIV peer education. Those targeted had higher good knowledge score $(47.5 \%)$ compared to those not targeted $(25.4 \%),\left(\chi^{2}=34.78, \mathrm{df}=1, \mathrm{p}<.005\right)$. The knowledge on the different modes of transmission and prevention and misconception has improved among those 
targeted compared with those not targeted and was significantly different in all the items except for the knowledge on blood transfusion, having sex with an infected person, and possibility of carrying HIV by a healthy person. By their sex, males targeted by peer education (57.4\%) had better knowledge score than females targeted by peer education $(38.1 \%)$ and this difference was statistically different $\left(\chi^{2}=11.39, \mathrm{df}=1\right.$, $\mathrm{p}<.005)$. It is worth mentioning the difference in knowledge on condoms between males and females who received peer education, where $66.9 \%$ of males knew about the protective role of condoms compared to $36.1 \%$ of females, and this difference was statistically significant $\left(\chi^{2}=56.95, \mathrm{df}=2, \mathrm{p}<.001\right)$.

Compared with the 2005 comparison cohort group, those targeted by peer education had higher levels of knowledge and lower levels of misconceptions; noteworthy is the knowledge on condoms, which increased from $29 \%$ (2005) to $45.5 \%$ (2008) (Table 1).

Knowledge score and association with educational level, occupation, income, and peer education

Logistic regression analysis was conducted to identify independent variables associated with having a good knowledge score. The chance of having a good knowledge score decreased for illiterate young people ( $\mathrm{OR}=0.42$; 95\% CI: 0.20 - 0.87); those who could only read and write $(\mathrm{OR}=0.39 ; 95 \% \mathrm{CI}$ : $0.22-0.68)$; and those having basic education $(\mathrm{OR}=0.52$; 95\% CI: 0.32 - 0.86) compared with young people who have completed high

school education. Homemakers (young people who are staying at home and doing household work) had a decreased chance of having a good knowledge score compared with students $(\mathrm{OR}=0.46$; 95\% CI: $0.24-0.89)$; and those with family income less than 25,000 Yemeni Riyals (equivalent to 125 US Dollars) had a decreased chance of having a good knowledge score compared with participants with family income above 25,000 Yemeni Riyals (OR=0.59; 95\% CI: 0.40 - 0.89). Similarly, a lower chance of having a good knowledge score was observed among those who did not receive HIV/AIDS peer education compared to those who received peer education $(\mathrm{OR}=0.46 ; 95 \% \mathrm{CI}: 0.32-0.68)$

\section{Stigma and discrimination outcomes}

Compared with those not targeted, those targeted by peer education were more willing to buy greenery and vegetables from a person living with HIV, to accept having PLWH teaching in schools, and to suggest that the community deal with PLWH with care and compassion, and this difference was statistically different. 
In comparison with the 2005 cohort comparison group, those targeted by peer education were more likely to suggest care and support and less likely to suggest punishment of PLWH (Table 2).

Table 1: Knowledge about HIV modes of transmission, prevention, diagnosis, and misconceptions

\begin{tabular}{|c|c|c|c|c|c|}
\hline & 2005 & & & 2008 & \\
\hline & $\begin{array}{c}\text { Total } \\
\mathrm{N}=601 \\
\%\end{array}$ & $\begin{array}{c}\text { Total }^{\infty} \\
\mathrm{N}=658 \\
\%\end{array}$ & $\begin{array}{c}\mathrm{PE}^{\star} \\
\mathrm{N}=303 \\
\%\end{array}$ & $\begin{array}{c}\mathrm{No} / \mathrm{PE}^{\star *} \\
\mathrm{~N}=355 \\
\%\end{array}$ & $\begin{array}{c}\text { PE/No PE } \\
\text { Significance } \\
\text { p-value }\end{array}$ \\
\hline \multicolumn{6}{|l|}{ Correct modes of transmission/prevention/ diagnosis } \\
\hline Blood transfusion is a risk factor of HIV infection & 92.0 & 95.3 & 96.4 & 94.4 & NS \\
\hline Having sex with infected person can transmit HIV infection & 94.0 & 94.4 & 96.4 & 92.7 & NS \\
\hline Using shaving blades may transmit HIV & 89.0 & 93.9 & 96.7 & 91.5 & $\mathrm{p}<.01$ \\
\hline Shared use of piercing devices with PLWH transmit HIV & 94.0 & 93.9 & 97.4 & 91.0 & $\mathrm{p}<.01$ \\
\hline $\begin{array}{l}\text { It is possible to know whether the person has AIDS or not by } \\
\text { laboratory investigations }\end{array}$ & 81.9 & 93.6 & 97.4 & 90.4 & $\mathrm{p}<.001$ \\
\hline Possibility of HIV transmission during pregnancy & 76.0 & 81.5 & 83.5 & 79.7 & $\mathrm{p}<.05$ \\
\hline Possibility of HIV transmission through breastfeeding & 64.0 & 70.4 & 71.6 & 69.3 & $\mathrm{p}<.001$ \\
\hline Possibility of HIV transmission during labour & 62.0 & 66.4 & 69.6 & 63.7 & $\mathrm{p}<.01$ \\
\hline Possibility of carrying HIV infection by a healthy person & 35.0 & 53.0 & 55.8 & 50.7 & NS \\
\hline Proper use of male condom is protective against AIDS & 29.0 & 42.2 & 49.5 & 36.1 & $\mathrm{p}<.001$ \\
\hline AIDS Patients can be treated & 17.0 & 26.6 & 31.5 & 20.8 & $\mathrm{p}<.01$ \\
\hline \multicolumn{6}{|l|}{ Misconceptions on HIV Prevention/Transmission } \\
\hline Handshaking and touching can transmit HIV infection & 28.0 & 16.3 & 14.9 & 17.5 & $\mathrm{p}<.01$ \\
\hline $\begin{array}{l}\text { Eating and drinking with HIV/AIDS patient can transmit } \\
\text { HIV infection }\end{array}$ & 46.0 & 29.8 & 23.8 & 34.9 & $\mathrm{p}<.001$ \\
\hline Possibility of HIV transmission through swimming pools & 41.0 & 30.5 & 28.1 & 32.7 & $\mathrm{p}<.001$ \\
\hline Possibility of HIV transmission through shared toilet & 40.0 & 29.2 & 26.7 & 32.7 & $\mathrm{p}<.001$ \\
\hline Wearing the cloths of someone who is infected with AIDS & 50.0 & 32.1 & 27.1 & 36.3 & $\mathrm{p}<.001$ \\
\hline Possibility of HIV transmission through mosquito bite & 67.0 & 56.2 & 47.2 & 63.9 & $\mathrm{p}<.001$ \\
\hline Kissing can transmit HIV infection & 56.0 & 57.8 & 56.1 & 59.2 & $\mathrm{p}<.001$ \\
\hline
\end{tabular}


Table 2: Participant's opinion on personal, governmental and societal actions towards PLWH

\begin{tabular}{|c|c|c|c|c|c|}
\hline & \multirow{2}{*}{$\begin{array}{c}2005 \\
\text { Total } \\
\mathrm{N}=601\end{array}$} & \multicolumn{4}{|c|}{2008} \\
\hline & & $\begin{array}{l}\text { Total }^{\infty} \\
\mathrm{N}=658\end{array}$ & $\begin{array}{c}\mathrm{PE}^{*} \\
\mathrm{~N}=303\end{array}$ & $\begin{array}{l}\text { No } P^{* *} \\
N=355\end{array}$ & $\begin{array}{l}\text { PE/No PE } \\
\text { Significance } \\
\text { p-value }^{\star * *}\end{array}$ \\
\hline Individual willingness to deal with PLWH & $\begin{array}{l}\text { Yes } \\
(\%)\end{array}$ & $\begin{array}{l}\text { Yes } \\
(\%)\end{array}$ & $\begin{array}{l}\text { Yes } \\
(\%)\end{array}$ & $\begin{array}{l}\text { Yes } \\
(\%)\end{array}$ & \\
\hline $\begin{array}{l}\text { Are you willing to take care of a family member infected } \\
\text { with AIDS? }\end{array}$ & 78.0 & 84.0 & 86.8 & 81.6 & NS \\
\hline $\begin{array}{l}\text { Are you willing to have a teacher infected with AIDS } \\
\text { teaching your relative in school? }\end{array}$ & 23.0 & 55.1 & 65.6 & 46.1 & $\mathrm{p}<.001$ \\
\hline $\begin{array}{l}\text { Are you willing to buy greenery from a person infected } \\
\text { with AIDS? }\end{array}$ & 21.0 & 38.4 & 49.7 & 28.6 & $\mathrm{p}<.001$ \\
\hline \multicolumn{6}{|l|}{ How should the community deal with PLWH? } \\
\hline Care and Support & 28.0 & 35.9 & 38.0 & 34.1 & NS \\
\hline Kindness and compassion & 24.0 & 31.9 & 37.3 & 27.3 & $\mathrm{p}<.05$ \\
\hline Isolation in hospitals & 39.0 & 18.8 & 16.9 & 21.1 & NS \\
\hline Treatment & 2.0 & 18.4 & 18.5 & 18.3 & NS \\
\hline \multicolumn{6}{|l|}{ How should the government deal with PLWH? } \\
\hline Treatment & 50.9 & 55.5 & 54.8 & 56.1 & NS \\
\hline Isolation in hospitals & 78.0 & 48.5 & 45.8 & 52.8 & $\mathrm{p}<.05$ \\
\hline Imprisoning & 18.0 & 7.3 & 7.6 & 7.0 & NS \\
\hline Killing & 13.0 & 6.5 & 6.3 & 6.8 & NS \\
\hline
\end{tabular}

$\infty$ Total of 2008 Sample

*Targeted by Peer Education

** Not targeted by Peer Education

${ }^{* * *}$ p-value calculated with Pearson's Chi-Squares.

\section{Risk perception outcomes}

Personal risk perception and perception of high-risk Behaviour:

When participants were asked about whether they think PLWH exist in Aden, 65.7\% answered yes; with no significant difference between the targeted (69.6\%) and not targeted (62.3\%) groups. Young people targeted by peer education had higher personal risk perception than those not targeted, but this difference was not statistically different.

Personal risk perception increased from $62 \%$ in 2005 to $82 \%$ among young people targeted by peer education (Table 3 ). 
Willingness to seek HIV Voluntary and Confidential Testing (VCT) services

Participants targeted by peer education were more willing to seek VCT services (79.7\%) compared with those not targeted (74.5\%), but this different was not statistically significant. When this group was asked whether they know the place of a VCT centre, over half of the participants $(57.5 \%)$ stated that they did not know such a place whereas $19.3 \%$ stated that it could be in any public clinic or hospital and only 9.9\% was able to name a specified place. Among those who were unwilling to go to a VCT centre, the most frequently mentioned reasons were: self confidence of not having committed a sexual risk-behaviour (48.3\%), feeling that they were not at-risk for HIV (21.5\%) and that they didn't trust such places (14.8\%). 
Table 3: Risk Perception and Risk Factors

\begin{tabular}{|c|c|c|c|c|c|}
\hline & \multirow{2}{*}{$\begin{array}{c}2005 \\
\text { Total } \\
\text { N=601 } \\
\text { Yes } \\
(\%)\end{array}$} & \multicolumn{4}{|c|}{2008} \\
\hline & & $\begin{array}{c}\text { Total }^{\infty} \\
\mathrm{N}=658 \\
\text { Yes } \\
(\%)\end{array}$ & $\begin{array}{c}\mathrm{PE}^{*} \\
\mathrm{~N}=303 \\
\mathrm{Yes} \\
(\%)\end{array}$ & $\begin{array}{l}\text { No } \mathrm{PE}^{\star *} \\
\mathrm{~N}=355 \\
\text { Yes } \\
(\%)\end{array}$ & $\begin{array}{l}\text { PE/No PE } \\
\text { Significance } \\
\text { p-value }\end{array}$ \\
\hline $\begin{array}{l}\text { Do you think HIV cases exist in Aden? } \\
\text { (Personal risk perception): } \\
\text { Are you at risk for HIV infection? }\end{array}$ & 59 & 65.7 & 69.6 & 62.3 & NS \\
\hline Yes, High Possibility & 45.0 & 55.6 & 56.5 & 54.7 & \\
\hline Yes, Weak Possibility & 17.0 & 26.2 & 28.6 & 24.2 & NS \\
\hline No Possibility & 28.0 & 18.2 & 15.0 & 21.1 & \\
\hline Risk factors for HIV infection & & & & & \\
\hline Multiple Sex Partners & --- & 93.0 & 96.0 & 90.4 & $\mathrm{p}<.01$ \\
\hline Female Sex Work (FSW) & --- & 94.2 & 95.4 & 93.2 & NS \\
\hline Male-to-male sex & 84.0 & 83.1 & 86.8 & 80.0 & NS \\
\hline Does Male-to-male sex exist in your neighbourhood? & 47.0 & 46.8 & 50.2 & 43.9 & $\mathrm{p}<.05$ \\
\hline Does FSW exist in your neighbourhood? & 52.0 & 48.5 & 51.8 & 45.6 & $\mathrm{p}<.05$ \\
\hline $\begin{array}{l}\text { Does Intra-venous Drug Use (IDU) exist in your } \\
\text { neighbourhood? }\end{array}$ & --- & 20.4 & 25.7 & 15.8 & $\mathrm{p}<.05$ \\
\hline
\end{tabular}

- -- questions were not included in the 2005 questionnaire.

$\infty$ Total of 2008 Sample

*Targeted by Peer Education

** Not targeted by Peer Education

${ }^{* * *} \mathrm{p}$-value calculated with Pearson's Chi-Squares

\section{Behavioural outcomes}

\section{Reduction in risk-behaviours}

Among those targeted by peer education, 90.4\% (274/303) reported behavioural change, mainly related to avoiding sharing shaving blades (54.7\%), avoiding sharing needles $(53.3 \%)$, avoiding sex with female sex workers (37.6\%), avoiding male-tomale-sex (18.6\%), avoiding sex with multiple partners (16.8\%), avoiding cupping (9.1\%), and use of condoms (3.3\%) 
Determinants of behaviour modification among those targeted by peer education

A significantly higher percentage of males (95.9\%) reported behavioural changes compared to females $(85.2 \%)\left(\chi^{2}=10.77, \mathrm{df}=4, \mathrm{p}<.01\right)$. Binary logistic regression analysis revealed that males were four times more likely to change their behaviour after receiving peer education compared to females (OR=4.29; 95\% CI: 2.75 - 6.86).

\section{Discussion}

The community based peer education intervention implemented among young people in four poor and high risk areas of Aden succeeded in improving the levels of HIV knowledge, in decreasing the levels of stigma and discrimination towards people living with HIV, and in promoting less risky practices and behaviours related to HIV infection. There are numerous studies reporting the positive role of communitybased peer education in HIV prevention among young people (Harper, Bangi, Sanchez, Doll, \& Pedraza, 2009; Williams, et al., 2003; Norr, Norr, McElmurry, \& Moeti, 2004). This study was unique due to the fact that it was implemented in a very conservative as well as disadvantaged setting with high levels of poverty and illiteracy rates. Despite all of that, there was an increase in HIV knowledge and a more positive attitude towards PLWH suggesting a sustained effect of the peer education intervention. The fact that significantly more young people in the targeted communities were more willing to accept having an HIV infected teacher in their schools and more willing to buy greenery from an HIV infected person, indicates that the peer intervention had an impact on attitudes towards PLWH.

The gender gap favouring males, regarding the knowledge on condoms, was huge among young people in communities, and this gap was also evident in the community baseline study conducted in 2005 (Al-Serouri, Anaam, Al-Iryani, Ramaroson, \& Al-Deram, 2010). The main reason might be the presence of a major confounding factor in the targeted communities, which is the high rates of illiteracy among females at community level compared to males. This study has shown that improvement in HIV knowledge was directly related to level of education, and being illiterate was significantly associated with being female and attaining lower levels of knowledge.

The effect of the peer education was also apparent in reported changes in high risk behaviour. The majority of young people reported reductions in sexual riskbehaviour. 
Although the use of condoms was reported, the increase in percentages of condom use by young people was much less than the reductions in other risk behaviours. This might indicate that the community peer education intervention focused on abstinence and mutual faithfulness as HIV preventive strategies far more than on promotion of condom use. The fact that males reported more reduction in riskbehaviours than females does not necessarily mean that females were more reluctant to change. It might be due to the fact that males were more engaged in high risk behaviour, or that females were less reluctant to disclose being engaged in high risk behaviour. The Yemeni culture, like other traditional culture, condemns females far more than males if they were engaged in sexual activity outside wedlock (Bennett, 2007; Chakraborty, 2010).

There are several limitations to this study. The first limitation of the study is due to the nature of the household setting, which did not always give privacy to young people, especially girls, to report on behavioural changes. This might be the reason why males reported more behavioural modifications than females. The second limitation is related to the closed-ended questions of the stigma related questions, where participants were asked on how the community and the government should deal with PLWH. The choices given to participants may have been leading answers, and might have resulted in over estimation of stigma, which included imprisonment and killing. The third limitation is related to the fact that the significant change in knowledge and attitudes among students may in part reflect changes over time, rather due to the peer education intervention. The fourth limitation is related to the quasi-experimental design of the study, where internal validity is a concern because of the lack of randomization of participants to intervention and control group. However, several measures were undertaken to improve the similarities between cases and controls. The fact that students from the same communities were cases and controls decreased the non-equivalency between them. Also, the 2005 community baseline was used as a cohort control group, which helped to increase the internal validity of the study (Shadish, Cook, \& Campbell, 2002).

\section{Recommendations}

This study indicated that community-based intervention could be a successful entry point to reach young people in very conservative settings, and the results could be used for scaling up similar intervention among other poor and high risk communities 
in Yemen. However, these interventions should also be synergized with other services. There is evidence from other studies that HIV services, such as increasing condom use (Ghys, 2002)improved Sexually Transmitted Infections (STI) management (Orroth, Gavyole, Todd, Mosha, Ross, \& Mwijarubi, 2000)and voluntary counselling and testing programmes can have a significant impact on HIV transmission (Sweat, et al., 2000).

The fact that there are still young people who suggest that the government should punish PLWH, calls for more emphasis on decreasing stigma and discrimination at community level. It is also recommended that future behavioural surveys should be conducted among young people, not just on sexual behaviour, but also on Intravenous Drug Use (IDU). Although Yemen is known to have no reported cases due to IDU, this study indicated that IDU exists in the neighbourhoods investigated in this study. Therefore future qualitative and quantitative research on this issue is needed.

Education is still the most determining factor to achieve a sustained and long-term strategy to combat HIV among young people (Bastien, 2008). Community-based HIV prevention programmes in Yemen, where only $62.2 \%$ of children of 6-15 years are enrolled in schools (Central Statistics Organization, Yemen Statistical Year Book., 2009), should also focus on re-integration of drop outs in schools and enrolling older adolescents in adult literacy classes. Leaving school early, at a life stage characterized by change and experimentation with potential risk behaviours, may be associated with a host of ill social, health and economic consequences. These might include alcohol and substance abuse, early marriage and sexual debut, unwanted or unintended pregnancy, unsafe abortion, sexually transmitted infections (STIs) including HIV, exploitation, violence and limited employment prospects (Bastien, 2008).

This study has showed that there still a gender gap in knowledge between males and females; which is a reflection of the huge gender disparities in Yemen (Hausmann, Tyson, \& Zahidi, 2009) and thus future interventions at community level should also focus on provision of gender-sensitive HIV information and services, which are culturally sensitive. Voluntary Counselling and Testing services can be an excellent entry point, especially if packaged within regular health care systems and within NGO settings. 


\section{Conclusion}

Community-based peer education for HIV prevention among young people in the four poor and vulnerable communities of Aden had succeeded in improving knowledge, decreasing stigma, increasing risk perception, and decreasing HIV risk behaviour in a culturally conservative Islamic setting. 


\section{Chapter 4}

\section{Process Evaluation of School-Based Peer Education for HIV Prevention among Yemeni Adolescents}

This chapter was submitted for publication as: Buthaina Al-Iryani, Huda Basaleem, Khaled Al-Sakkaf, Gerjo Kok and Bart van den Borne. Process evaluation of schoolbased peer education for HIV prevention among Yemeni adolescents. 


\begin{abstract}
This process evaluation aims to give a deeper understanding of the quasiexperimental evaluation, which was conducted in Aden, Yemen, among 2,460 students, and revealed that a school-based peer education intervention for HIV prevention has succeeded in improving HIV knowledge and skills; and in decreasing stigmatization of people living with HIV. Qualitative methodologies were pursued, where 12 focus group discussions and 12 in-depth interviews were conducted with peer educators, targeted students, school principals, social workers, and parents of peer educators. Results revealed that school-peer education was well received. There was an apparent positive effect on the life skills of peer educators, but the intervention had a lesser effect on targeted students. Key enabling factors have been the high quality of training for peer educators, supportive school principals, and acceptance by parents of the intervention. These findings are important for improving the life skills and peer education intervention at school level, and in better planning and implementation of life skills and peer programmes at a national scale.
\end{abstract}




\section{Introduction}

The estimated HIV prevalence in Yemen is 0.2\% (National AIDS Programme, 2009). Recent Voluntary Counselling and Testing (VCT) reports have shown an increase of adolescents infected with HIV (National AIDS Programme, 2009). Although out-ofschool young people are more at risk to HIV infection, Yemeni adolescents in schools are also vulnerable to HIV, due to economic hardship coupled with low access to reproductive services in general and HIV in particular. Aden, a governorate in the Republic of Yemen, located on the Arabian Sea, with close proximity to the Horn of Africa, is especially at risk to HIV infection. Previous studies have revealed that several risk factors exist in Aden, which include the presence of commercial sex work, male-to-male sex, and population movements to and from countries with high HIV infection (Busulwa, Takiyaddin, Azzubeidi, El Zein El Mousaad, Tawillah, \& Ziady, 2006; Al-Serouri, Anaam, Al-Iryani, Ramaroson, \& Al-Deram, 2010).

In 2005 a survey among 2274 high school students randomly selected from 27 high schools in Aden, Yemen was conducted (Al-Iryani, Basaleem, Al-Sakkaf, Crutzen, Kok, \& Borne, Evaluation of a School-Based HIV Prevention Intervention for Yemeni Adolescents, In Press).The results revealed low levels of knowledge on modes of HIV transmission and prevention and a high level of stigma and discrimination towards people living with HIV (PLWH). The results from this study served as a baseline to implement a school-based peer education intervention for HIV prevention.

In 2008, the evaluation of the school-based peer education intervention was conducted. Data were collected using a self-administered questionnaire from a sample of 2510 students randomly selected from the 27 high-schools; among this sample, and in a quasi-experimental design, students who received the peer education intervention (78.6\%) were compared with students who did not receive the intervention $(21.4 \%)$. No systematic procedure was applied in selecting students for the intervention condition. To increase internal validity, students were also compared with a cohort control sample surveyed in 2005 . The results revealed that $68 \%$ of students targeted by peer education had good knowledge scores, compared with $43.3 \%$ of students not targeted by peer education $\left(\chi^{2}=(\mathrm{df}=1)=111.15, \mathrm{p}<.01\right)$. Multi-level regression analysis revealed that, although there was a significant difference among schools, the intervention effect of peer education at the individual level was significant; students who received peer education had a statistically higher knowledge score ( 9.24 out of 12.0) compared with those not targeted (7.89 out of 12.0 ), $\mathrm{OR}=2.11,95 \% \mathrm{CI}=1.04-4.27$, 
$\mathrm{p}$ <.05). Female students attained statistically better knowledge on the modes of transmission and prevention, with the exception of knowledge on condoms and male-to-male sex as a risk factor for HIV infection, where male students had better knowledge. Compared with the 2005 cohort control, knowledge on the use of condoms increased from $49.4 \%$ to $67.8 \%$. In addition, students who received the peer education interventions suggested significantly more actions to provide care and support for PLWH. Also, the levels of stigma and discrimination were much higher among the 2005 cohort control group, compared with those who received the peer education intervention. Of students targeted by peer education $55.5 \%$ reported life skills changes, with mainly communication skills reported as the main change; a statistically higher percentage of students who had good knowledge score $(61.0 \%)$ reported more life skills changes after peer education activities than those with a poor knowledge score $(43.9 \%),\left(\chi^{2}=(\mathrm{df}=1)=50.18, \mathrm{p}<.01\right)$. Female students reported a statistically higher percentage of life skills changes $(65.5 \%)$ compared to males $(44.5 \%),(\chi 2(\mathrm{df}=1)=87.09, \mathrm{p}<.01)$. The process evaluation of the school-based intervention was conducted after the completion of this quasi-experimental study.

Given the very conservative school and cultural setting of Yemen, it was important to know why the school-peer education intervention succeeded in such a difficult setting. There is limited research on process evaluation of school-based life skills and peer education programmes for HIV prevention in culturally conservative settings. Frequently, the focus has been on studying the impact of interventions on outcomes such as self-reported knowledge, attitudes and behaviour. Much less research was conducted to document, assess, and explain how programs were implemented. A process evaluation identifies the procedures undertaken and the decisions made in developing the programme, describes how the program operates, the services it delivers, and the functions it carries out. By documenting the program's development and operation, it allows an assessment of the reasons for successful and unsuccessful performance, and provides information on potential replication (Steckler \& Linnan, 2002).

The process evaluation conducted on the present intervention program aimed to highlight the factors that facilitated or inhibited school peer education; and provides a deeper understanding of the quasi-experimental study outcomes. The evaluation was mainly based on qualitative data; however, some quantitative data were used, which were previously collected during the quasi-experimental outcome study. 


\section{The School-Based Intervention}

\section{Overview}

All 27 high schools in Aden, Yemen (12 boys' schools, 14 girls' schools, and 1 mixed school), representing all existing high-schools were the site of the intervention. The intervention included training of school coordinators, selection and training of peer educators, training of school management teams, and implementation at school level.

\section{Training of School Coordinators}

A team of school coordinators were selected by the education office in Aden, consisting of the director of school supervision, director of school health, director of school social services, a teacher representing the school curriculum supervisory committee, and an expert on training of trainers methodologies. The team was trained in a 9days workshop conducted by two international Arabic speaking experts in this field, and the training package was based on a Jordanian life skills and peer education package supported by UNICEF Middle East and North Africa Regional Office (UNICEF, 2006). The training package included topics on peer education and training of trainers' methodologies, HIV, reproductive health, sexually transmitted infections, puberty and changes during adolescents, and life skills education. The trained school coordinators team had two functions: coordinating with the schools' managements and parents; and conducting training workshops.

\section{Selection and Training of Peer Educators}

Peer educators from all 27 high schools were recruited on a voluntarily basis. From the students volunteered, students were selected who met standard criteria of having good communication skills, being accepted by classmates, and showing good academic achievements. The selection was done by a committee consisting of the school coordinators and school social workers. The school coordinators visited parents of selected peer educators to explain the programme and to obtain a signed consent form allowing their daughters/sons to participate. Several visits were required, especially to parents of female peer educators, as families are usually reluctant to have their daughters get involved in extra-curricular activities, and especially as these relate to HIV and AIDS prevention. The school coordinators team had a pivotal role in 
advocating with families. There were three refusals from parents in the whole programme. In case of refusal of parents, another peer educator was selected.

The selected peer educators were trained in a 10-day workshop. The training was based on the Jordanian life skills and peer education package, in addition to 10 messages on HIV transmission, prevention, and common misconceptions, and 5 life skills messages. HIV messages involved the following: the first message was on the definition of HIV and causative agents, the second on whether we can recognize an infected HIV person by the way he/she looks or do we have to do a blood test, and what does the window period means; the third message was on why HIV is a dangerous infection; the fourth message was on the epidemiology of HIV in Yemen, the middle east and in the world, the fifth was on the mode of transmission, the sixth was on modes of prevention and adopting the ABCD (abstinence, be faithful, use condoms, and don't use drugs) approach, the seventh was on major misconceptions, the eighth was on risk perception and whether young people can be at risk, the ninth was on how we should deal with PLWH, which stresses the importance of the right of PLWH to live free of stigma and discrimination, and the tenth message was on the role of young people in educating the community. The life skills messages were on communication and negotiation skills, self awareness and self-esteem, decision making, respecting differences in opinions, and assertive behaviour.

\section{Training of School Management teams}

To ensure support for peer educators at school level, school management teams, which consisted of school principals and vice-principals, were trained during a 5-day training workshop on peer education methodologies, life skills, and HIV prevention. School coordinators planned with peer educators and management teams the peer activities at their schools.

\section{Implementation at School level}

Before implementation, a pre-field two-days training was conducted, where peer educators rehearsed the actual messages to be conducted at school level. The $10 \mathrm{HIV}$ messages and 2 life skills messages (self-esteem and assertive behaviour) were the major topics covered by peer educators. Peer educators conducted educational sessions as an extra-curricular activity once a week for 90 minutes in a class room setting. Peer education sessions were planned that each student would be targeted with 
two (90-minutes) sessions in addition to brief sessions during morning school broadcast.

The peer educators used $70 \times 50 \mathrm{~cm}$ posters, where each message was displayed on one poster. Also, peer education sessions were conducted during youth summer activities in the same class-room style. After the end of the second session, participants received leaflets on the 10 messages, as well as hats and T-shirts with a message: "Protect yourself with Abstinence and Knowledge". The slogan was chosen by the peer educators; the knowledge part referred to the knowledge on condoms and knowledge on avoiding drugs.

\section{Extent of Intervention}

The number of targeted schools was increased gradually, starting in 2005 with the training of 27 peer educators reaching 500 students in 5 schools; then in 2006 a team of 50 peer educators were trained from 20 schools reached 3,800; in 2007, the existing team of peer educators reached 4,000 students in the same 20 schools, and in 2008, a team of 60 peer educators was established and 1000 students from 27 schools were targeted.

\section{On-going monitoring of school-based intervention}

The implementation at school level was monitored at different levels. The main researcher conducted bi-monthly visits to schools, to undergo classroom observations, check peer education sessions' log books which included pre and post-tests results, and meet with peer educators and school coordinators. Monitoring on a daily basis was done by school coordinators, who also provided support for peer educators and acted as resource persons during peer education sessions. The on-going monitoring aimed to ensure programme fidelity and accurate implementation at school level, as well as to provide support to peer educators.

\section{Methods}

Theoretical Model- The theoretical model used in designing, implementing, and analysing the process evaluation included the theory of Diffusion of Innovations (Rogers, 2003). Diffusion of Innovations considers that an innovation can be new information, an attitude, a belief or a practice or any other object that is perceived as new by the individual or the community and can be diffused to a specific group. An 
innovation is communicated through certain channels over time amongst members of a social system (here, the school). A central point in this theory is the use of opinion leaders as 'change agents' (Oldenburg \& Glanz, 2008).

Reaching a Consensus on Process Evaluation Questions: The main objectives of the evaluation are to provide a deeper understanding of the quasi-experimental study outcomes; assess acceptability and reaction among the students, school principals, social workers, and parents; and understand the enabling and constraining factors for implementation. The choice of the process evaluation instruments and the questions to be asked in each instrument was done in a participatory manner at several stages. The first stage was during brainstorming sessions between the principal researcher and the school coordinators in Aden. The second stage was during a four-day training of data collectors. During this training, the data collectors had the chance to conduct focus group discussions and in-depth interviews with young people, who were not part of this study. The training workshop for qualitative data collectors had prepared for the research skill itself, and also resulted in refining the questions to be asked.

Sample and Instruments-Multiple instruments were used to collect process data, while ensuring that all 27 schools were represented by the participants. Participants included 54 peer educators, 32 targeted students, 4 school principals, 4 school social workers, and 4 parents. Instruments included 12 focus group discussions (FGD) and 12 in-depth interviews (IDI) (Table 1). 
Table 1: Process Evaluation Instruments of School-Based Intervention

\begin{tabular}{|c|c|c|}
\hline $\begin{array}{l}\text { Target } \\
\text { Group }\end{array}$ & Objective / Questions & Tools \\
\hline $\begin{array}{l}\text { Targeted } \\
\text { students }\end{array}$ & $\begin{array}{l}\text { Objectives } \\
\text { 1. To evaluate the methodology of peer education in relation to: Frequency, } \\
\text { timing/ length/place of sessions, participatory/ interactive approach, and } \\
\text { space of classroom; if enabling environment existed: space, number of stu- } \\
\text { dents per sessions, place (in schools, in summer camps). } \\
\text { 2. To come up with recommendations to improve upcoming programmes. } \\
\text { Questions } \\
\text { 1. What do you think of HIV education programme in general? } \\
\text { 2. How do you view the positive and negative aspects of the programme? } \\
\text { 3. To what extent the sessions were participatory enough? Did you have a } \\
\text { chance to raise sensitive questions? } \\
\text { 4. To what extent the sessions were interactive? How could they be improved? } \\
\text { 5. Was the environment enabling (place, number per classroom, light, etc)? } \\
\text { 6. Do you think some of your friends are in need of the programme and why? } \\
\text { 7. If outside school, who do you prefer to give you HIV and life skills mes- } \\
\text { sages? } \\
\text { 8. What are your recommendations to improve the programme? }\end{array}$ & $\begin{array}{c}4 \text { FGDs }^{*} \\
\text { (2 males } \\
\text { FGDs; } \\
2 \text { females } \\
\text { FGDs) }\end{array}$ \\
\hline $\begin{array}{l}\text { Peer } \\
\text { Educators }\end{array}$ & $\begin{array}{l}\text { Objectives } \\
\text { 1. To evaluate the programme from their side } \\
\text { 2. To study the effect of life skills on their life and the life of their peers } \\
\text { 3. To come up with recommendations to improve the intervention. } \\
\text { Questions } \\
\text { 1. How do you evaluate your experience with the programme? } \\
\text { 2. To what extent do you think the programme has impact on you? } \\
\text { 3. How the programme affected your life skills and practices with the family as } \\
\text { well as friends inside and outside schools with examples? How has it af- } \\
\text { fected your life beyond peer education? } \\
\text { 4. To what extent did the programme affected your targeted colleagues with } \\
\text { regards to life skills and practices? } \\
\text { 5. To what extent did you have the chance to educate friends outside schools? } \\
\text { 6. Do you have friends who are engaged in high risk behaviour? If yes, where } \\
\text { you able to approach them with what you know on life skills and HIV pre- } \\
\text { vention? } \\
\text { 7. To what extent did the subject of homosexuality was raised during your } \\
\text { sessions? } \\
\text { 8. To what extent did the subject of condom as a protective method raise } \\
\text { during your session? What was the feedback from students on this subject? }\end{array}$ & $\begin{array}{c}8 \text { FGDs }^{*} \\
\text { (2 males } \\
\text { FGDs; } \\
2 \text { females } \\
\text { FGDs) }\end{array}$ \\
\hline
\end{tabular}




\begin{tabular}{ll}
\hline $\begin{array}{l}\text { Target } \\
\text { Group }\end{array}$ & Objective / Questions \\
\hline Key & Objectives \\
Informants: & $1 \quad$ To explore their overall opinion on the programme. \\
School & 2. To know their role in the programme implementation \\
Principals & 3. To come up with suggestions for improvements, scaling up and sustain- \\
& ability of the programme. \\
& Questions \\
& 1. What do you think about the programme? \\
2. What have been the strengths and weaknesses of the programme? \\
3. What was your role in the programme? \\
4. How do you see the role of youth in HIV prevention and life skills educa- \\
tion? \\
5. How could you view the role of social workers in the development of life \\
skills and youth practices? \\
6. What are you suggestions to improve the programme?
\end{tabular}

\begin{tabular}{lll}
\hline School Objectives & 4 IDIs $^{* *}$
\end{tabular}

Social workers 1. To explore their overall opinion on the programme.

2. To know their role in the programme implementation

3. To come up with suggestions for improvements, scaling up and sustainability of the programme.

\section{Questions}

1. What do you think about the programme?

2. What is your vision to improve the programme in future?

3. What is your recommendation in the sustainability of the programme?

4. How do you see your future role as social worker?

\begin{tabular}{|c|c|c|}
\hline \multirow{9}{*}{$\begin{array}{l}\text { Parents of } \\
\text { peer } \\
\text { educators }\end{array}$} & Objectives & \multirow[t]{9}{*}{4 IDIs $^{* *}$} \\
\hline & 1. To assess their acceptance for the peer education intervention. & \\
\hline & 2. To know the effect of peer education on their children with regards to: & \\
\hline & - relationship between the peers and their families; & \\
\hline & - relationship between peers and surroundings. & \\
\hline & Questions & \\
\hline & 1. Were you consulted on the involvement of your son/daughter? & \\
\hline & $\begin{array}{l}\text { 2. In your opinion, what is the impact of peer education on your } \\
\text { son/daughter? }\end{array}$ & \\
\hline & $\begin{array}{l}\text { 3. To what extent do you think peer education has impacted your son/ daugh- } \\
\text { ter's relation inside and outside the family? }\end{array}$ & \\
\hline
\end{tabular}

\footnotetext{
${ }^{\star} \mathrm{FGD}=$ Focus Group Discussion

${ }^{*}$ IDI $=$ In-depth Interview
} 


\section{Data Collection and Analysis}

Qualitative Data- In-depth interviews (12 IDI) and focus group discussion (12 FGDs, which included 86 students and peer educators) were facilitated by nine data collectors (6 females and 3 males), who were trained in a four-day workshop. All focus group discussions and in-depth interviews were conducted during February 2009. Focus group discussions and in-depth interviews were conducted over two consecutive sessions, with 10 minutes break in-between, where refreshments were served, and casual discussions were stimulated by data collectors to further build trust with participants. All interviews and focus group discussions were tape-recorded and then were fully transcribed. The transcripts were translated into English, and analysed line-by-line and coded thematically.

Quantitative data - Some quantitative results were used from the quasi-experimental evaluation, which included a random sample of 2510 students from the 27 highschools. These are mainly related to the following measure:

- Receiving Peer Education and whether students think it's beneficial- whether a student was targeted by the intervention or not was assessed by a closed question on whether the student have ever attended/heard AIDS education by peers in his/her school; yes/no options were available. For those answering yes they move to the next closed question on whether they considered peer education in schools beneficial with the following options: beneficial; beneficial to some extent; not beneficial.

\section{Ethical Considerations}

Written consent for the study was obtained from the Director General of the Education Office in Aden. Verbal consent was obtained from all study participants.

\section{Results}

The themes emerging from the analysis of the focus group discussions and in-depth interviews were grouped into the following categories:

- Students' experiences of the intervention

- Acceptance of the programme by parents

- The intervention as viewed by school principals and school social workers

- Effect of life skills on peer educators and students

- Addressing high-risk behaviour and condoms in classroom setting 
- Addressing high-risk behaviour and condoms out of classroom setting

- Difficulties faced during implementation

\section{Students' experiences of the intervention}

The results from the quantitative study (quasi-experimental evaluation) revealed that among $78.6 \%(1964 / 2498)$ of the students who stated that they had received peer education in schools, 76.6\% (1505/1964) considered it as beneficial and $21.7 \%$ $(426 / 1964)$ of students considered it as beneficial to some extent. Only $1.7 \%$ $(33 / 1964)$ of the students considered peer education as not beneficial.

In focus group discussions, there was a consensus among targeted students on the importance of the school-based peer education:

"It is a very important programme because it addresses educating the society in general and youth in particular who are the future of any country " - a female student

Role of peer educators as viewed by targeted students- Targeted students repeatedly mentioned the important role that peer educators played in the intervention. Most of the discussion was on how well the peer educators were trained, which affected positively the comprehension of messages:

"The peer educators are well trained and have good communication methods to communicate information to us"- a female student

Peer educators were also well received by targeted students because of their positive and pleasant attitude, and their patience in answering questions:

"The peer educators are friendly, hard workers, energetic, patient, knowledgeable about AIDS, and never get tired of our questions"- a male student

Peer educators had also a key role in stimulating participation of targeted students at classroom level:

"The proof that the sessions are interactive is that those students who are usually sleepy in the routine classes become active in the education session. Even, hesitated and very quiet students become active and participate in a good way"-a male student 


\section{Acceptance of the Programme by Parents}

All parents mentioned that their written consent for their children to participate in the peer education activities was asked by the programme coordinator from the Aden education office. They explained that their major concern was the effect of the programme on learning achievements. The school coordinators team has played a key role in advocating with parents to agree on their children's participation in the programme. As one mother reported:

"I agreed after extensive discussion with school administration and their strict confirmation that this activity will not interfere with my son's study"

School principals had also indicated that effective communication with parents resulted in acceptance of the programme:

"We gained the trust of parents and families" a school principal

All parents highly appreciated the positive effect of the peer education intervention on their children. However, they indicated that they would prefer future interventions to be conducted during summer vacation, so academic achievement would not be affected.

\section{The intervention as viewed by School principals and Social workers}

Role of School Principals and Social Workers and their general reaction on the interventions - School principals and social workers indicated that the peer education interventions had a positive impact on peer educators, students, social workers, and teachers.

"This is the best programme I had ever known although I had participated in many training courses. The programme is good in everything, starting from the idea to the trainers and the selected peer educators"- a school social worker

Both, school principals and school social workers were trained as part of the intervention on HIV prevention, youth participation, peer education and life skills education. They did not take part in the actual delivery at classroom level, but they facilitated the implementation. School principals were the contact focal point between the school and the project coordinator, who was also part of the school coordinators committee and was a senior advisor to the director general of the education office in Aden. 
School social workers described their role to select peer educators to be trained, and select students to receive the peer education sessions:

"Everything in the programme is good: the idea itself, its good consequences in raising the awareness not only for students but the community as well and its possession of all elements of success"- a school principal

The concept of adolescent-led extra-curricular activities - The peer education methodology was also accepted by school principals and social workers:

"The idea of having educators from the same age and educational level of student is great because they are more likely to be open with each other"- a school principal

Life skills as a success factor - Life skills education was a unanimously mentioned factor leading to the success of the interventions. They suggested that peer education and the life skills interventions should be started as early as $7^{\text {th }}$ grade. They believed that life skills education is a successful methodology to decrease risky behaviours among adolescents.

\section{Effect of Life skills on peer educators and students}

The school based-intervention had a clear effect on the life skills of peer educators, mainly, communication skills, assertive behaviour skills, decision making, self esteem, and self efficacy. This effect was repeatedly reported by peer educators, and parents of peer educators.

Effect of Life skills education on peer educators- Peer educators discussed passionately what impact life skills training had on them. They reported that life skills had positively influenced their attitude towards others and their role in life:

"Learned to be more responsible, faithful, patient, flexible, good listener, respect other's opinion, able to negotiate with older and younger people"- a male peer educator

Parents of peer educators' major comments on the intervention were on how their children's life skills had changed dramatically. They mainly mentioned life skills related to communication, negotiation, accepting other opinions, and self confidence: 
"They became, self-confident, and decisions makers for themselves"- a peer educator's parent

School principals also acknowledge the important effect the intervention had on building life-skills of peer educators:

"Trained peer educators are self confident, broad minded, good communicators not only for AIDS education but also in many life aspects"- a school principal

Effect of Life-skills education as reported by targeted students - There was a consensus among students about the importance of the programme with regard to improving their knowledge on HIV prevention and transmission and attitudes towards PLWH; however, changes in life-skills were less frequently mentioned:

"The education helped me a lot to be assertive in my behaviour, to be proud with who I am, and to express myself very well"- a female student

\section{Addressing high-risk behaviour and condoms in Classroom setting}

Male-to-male sex - Discussing male-to-male sex as high risk behaviour was a sensitive topic to discuss at classroom level, as one peer educator said:

"I approach homosexuality only superficially because it is a very difficult and sensitive issue"- a male peer educator

Female peer educators were more reluctant to discuss male-to-male sex as risk behaviour relative to male peer educators.

Condom use - Male peer educators were more open to discuss the use of condoms, than female peer educators. Female peer educators repeatedly reported that they were intimidated by the questions raised on condoms:

"Girls made me embarrassed by their questions about condoms"- a female peer educator

\section{Addressing high-risk behaviour and condoms out of the classroom setting}

Peer educators reported that it was much easier for them to discuss high risk behaviour and condom use with their peers out of the school setting. They thought that they succeeded in some cases to educate their peers to adapt less risky behaviour, and had little effect in other cases: 
"Some of my friends said they are now using condom to protect themselves; and some are asking me where they can get tested for HIV"- a male peer educator.

"We approached several girls with high-risk behaviours and explained the ways of HIV transmission and prevention. Some quitted such relations, some are now relying on condoms, while others continue practicing unprotected sex" - a female peer educator.

Peer educators indicated also that there were some rare non-sexual high risk behaviours, such as sharing glass for body carving, where girls carve the name of their boyfriends on their hands with sharp glass. Female peer educators reported that although some of their peers stopped such practices, others continued. Overall, peer educators were discussing use of condoms at much more ease than discussing male-to-male sex, which is even a harder topic to tackle among female peer educators.

\section{Difficulties faced during implementation}

Several constraints faced peer education in classroom setting. Time was mentioned as a major constraint by both peer educators and targeted students. They all stated that more time should be given to the sessions as many questions got unanswered after the session ended. Other constraints mentioned were the shortage of screens to display slides and the in-availability of printed material on HIV and life skills.

\section{Discussion}

This process evaluation aimed to highlight the factors that facilitated or inhibited the peer education intervention in the 27 schools of Aden, and to provide a deeper understanding of the quasi-experimental study outcomes, which revealed that the school-based peer education intervention succeeded in improving knowledge on HIV transmission and prevention and in improving attitudes towards people living with HIV. Given the conservative cultural context in Yemen, the setting where the intervention was conducted, it was necessary to understand the factors that enabled as well as impeded implementation, and to assess acceptability among targeted students, school management, and parents; and in addition, to shed more light on the effects of the school-based intervention on the life skills of peer educators and targeted students. 
The result of the process evaluation revealed that the intervention was highly accepted by parents, school management, and by students themselves. The main elements of success had been the involvement of school management and parents, and the high-quality training received by peer educators. This process evaluation has also indicated that the school-based interventions positively impacted on the life-skills of peer educators, mainly by improving communication, assertive behaviour, self esteem, decision making, and negotiation. This enabled peer educators to be "opinion leaders" and "change agents" among their peers. Peer educators were assumed to have this role by influencing not only their peers in schools for whom the activities were organized (active diffusion), but also others of relevance in the peer's environment (out-of-school peers) through an informal (passive) diffusion (Oldenburg \& Glanz, Diffusion of Innovations, 2008).

The high acceptance of the intervention by parents was mainly due to the key role of the school coordinators and the project coordinator in advocating with families. Interestingly, the main concern was not educating on HIV prevention, but rather the potential adverse effect on scholastic achievement as perceived by parents. This is an important finding, as the school-based peer education has been labelled by the Education Office in Aden as life skills and peer education programme rather than a sex education programme. Labelling as a 'sex education' programme might have doomed the failure of peer education intervention in the context of Yemeni schools. This "life skills" label of the intervention was also the sentiment which came forward from interviews with school principals and social workers. The capacity building opportunities with training and advocacy workshops of school principals and school social workers had created an enabling environment for the intervention. Their high acceptance for the peer intervention has facilitated implementation at classroom level as well as acceptance from families. School coordinators, who have acted as resource persons for hard-to-answer questions at classroom level, had contributed to the success of implementation. This is in line with existing research, which documents the important role of adult support in school-based peer education (Strange, Forrest, Oakley, \& the RIPPLE Study Team, 2002; Visser M. , 2007).

There is existing research, which has studied the implementation of HIV education in schools, mainly through process evaluation (Flisher, Ahmed, Jansen, Mathews, Klepp, \& Schaalma, 2009; Oakley, Strange, Bonell, Allen, Stephenson, \& the RIPPLE Study Team, 2006; James, Reddy, Ruiter, Mccauley, \& van den Borne, 2006; Visser M. 2005; Markham, Basen-Engquist, Coyle, Addy, \& Parcel, 2002; Strange, Forrest, Oak- 
ley, \& the RIPPLE Study Team, 2002). All of these studies revealed that the fidelity of implementation at class room level had a major impact on outcome of the intervention.

The fact that the majority of students considered peer education sessions beneficial and had appreciated the participatory nature of the sessions reflects the important role of peer educators in the successful implementation of peer education sessions at classroom level. It also emphasizes the fidelity of the programme. Previous research has also shown that peer led school-based intervention were more effective when they were participative and skills based (Oakley, Strange, Bonell, Allen, Stephenson, \& the RIPPLE Study Team, 2006).

The focus group discussions had provided a more in-depth understanding of the quasi-experimental study, which revealed a lower level of knowledge on condom use and male-to-male sex among female students compared to male students, as female peer educators were more reluctant to discuss these issues compared to male students. This gender difference is a reflection of the traditional Yemeni setting, which gives more freedom to boys to discuss sensitive sexual issues compared to girls, and is similar to existing research among young people in Yemen (Al-Serouri, Anaam, AlIryani, Ramaroson, \& Al-Deram, 2010).

The difficulties faced during implementation at class-room level which are mainly related to time and provision of necessary visual display material are two issues that will have to be tackled if peer education and life skills are to be taken to scale in Yemen. Visual display materials would not be available in the majority of Yemeni schools, due to poor funding. For this reason, peer educators have to be trained on using existing posters. The time allocated for the sessions and the frequency of the sessions are real hindering factors in any school-based peer education intervention (Ebreo, Feist-Price, Siewe, \& Zimmerman, 2002), and thus should be addressed in future interventions.

The present process evaluation has some limitations. The first limitation is due to the fact it was conducted after the impact evaluation, so there is an inherent bias on the results of the focus group discussions and in-depth interview (Oakley, Strange, Bonell, Allen, Stephenson, \& the RIPPLE Study Team, 2006). The second limitation is that peer educator and targeted students were not asked direct questions on the effect of the peer education and life skills on their sexual behaviour and practices. There might be a missing link between the consequence of having such a large improve- 
ment in life skills among peer educators and how it was translated in adoption of less risky behaviour or in continuing non-risky behaviour (Flisher, Ahmed, Jansen, Mathews, Klepp, \& Schaalma, 2009; Yankah \& Aggleton, 2008).

\section{Recommendations}

It is recommended that life skills education is integrated within the Yemeni school curriculum in the long term and as an extra-curricular activity in the short term. The life skills and peer education training package could be used as a national training manual among in and out-of-schools young people. Several researchers might argue with this recommendation as many studies have shown that there is no significant relation between acquiring life skills education and decreasing high risk behaviour or a decrease in sero-prevalence of HIV (Yankah \& Aggleton, 2008). However, we can argue that previous studies looking at this relation had several confounding factors, such as fidelity of the life skills education programmes, coverage, and dosage delivered (frequency of life skills sessions). There is existing research revealing that the development of effective school-based life skills programs focusing on HIV and AIDS is a sound investment toward the sexual health of young people (James, Reddy, Ruiter, Mccauley, \& van den Borne, 2006). Behavioural change is a long-term process, and it may not have a linear relationship with life skills education, but needs to reach a certain saturation point with life skills to induce a change in behaviour.

\section{Conclusion}

This process evaluation, which was theoretically based on the Diffusion of Innovation Theory (Rogers, 2003), has revealed that the "life skills" labelling of the HIV prevention peer education intervention was key in the acceptance of the intervention in such a very conservative setting like Yemen. Participation and training of school management, communication with parents, and support from project coordinators had created an enabling environment for implementation. Life-skills training was pivotal in building the capacities of peer educators, which enabled them to conduct successful peer education sessions at classroom level, and thus become 'opinion' leaders among their peers. 



\section{Chapter 5}

\section{Process evaluation of a three-year community-based peer education intervention for HIV prevention among Yemeni young people}

Submitted as:

Buthaina Al-Iryani, Khaled Al-Sakkaf, Huda Basaleem, Gerjo Kok and Bart van den Borne. Process evaluation of a three-year community-based peer education intervention for HIV prevention among Yemeni young people. 


\begin{abstract}
This community process evaluation aims to highlight the key enabling factors that facilitated the implementation of a community peer education program for youth HIV prevention in four poor and vulnerable areas of Aden, Yemen. It also explains the implementation process; and provides a deeper understanding of the impact evaluation outcomes, which revealed improved HIV knowledge and risk perception, and decreased stigma and risky behaviour. This process evaluation was based on qualitative methodologies, where 5 focus group discussions and 15 in-depth interviews were conducted among 52 participants: community peer educators, community focal points, targeted young people, and local councils. The results revealed that contributing factors to implementing the peer education program had been community participation, mobilization of targeted communities, and capacity building of all those included in the intervention. Existing community-based organizations like the Social Service Centre had played a key role in building trust with the targeted communities and linking HIV peer education intervention to other existing community services. This process evaluation provided lessons learned for replicating similar youth peer education programmes in conservative communities.
\end{abstract}




\section{Introduction}

Yemen, a highly conservative and tribal Arab country, is one of the poorest countries in the world, where more than $45 \%$ of the population lives in poverty (UNDP, 2010). Yemen's population is estimated around 22,492,035, of which, $67.3 \%$ is under the age of 25 years (Central Statistics Organization, Yemen Statistical Year Book., 2009). At $3.02 \%$, the country has one of the highest population growth rates globally, with the population expected to double in the next 23 years. This increases the demand for educational and health services, drinking water and employment opportunities. Yemen faces a severe water shortage, with available ground water being depleted at an alarming rate (UNDP, 2010). The Yemeni economy is caught in a jobless slow growth cycle, with an unemployment rate of 35\%, leading to stagnant per capita incomes and rising levels of unemployment, particularly amongst the youth (Library of Congress, 2008). Limited employment opportunities had forced many Yemenis to migrate for work to neighbouring countries leaving their families behind. Illiteracy rates are still high (47\%) with a huge gender gap, where $69.1 \%$ of the female population are illiterate compared to $27.3 \%$ of Yemeni males (Central Statistics Organization, 2009). Yemen continues to occupy the last place in the gender gap index rankings of 134 countries and remains the only country in the world to have closed less than $50 \%$ of its gender gap (Hausmann, Tyson, \& Zahidi, 2009).

High rates of illiteracy, poverty, unemployment, mobility, and gender disparities place the predominantly young Yemeni nation vulnerable to HIV infection. Epidemiologically Yemen is categorized as a low HIV prevalence country (National AIDS Programme, 2009); however, if urgent actions are not taken, especially among mostat-risk and vulnerable populations, young people who are usually vulnerable, concentrated focal epidemics might occur (UNAIDS, 2007). Aden, located on the coastal line of the Arabian Sea, is considered as most at-risk to HIV infection, especially the poor and high risk areas of Aden governorate (Al-Serouri, Anaam, Al-Iryani, Ramaroson, \& Al-Deram, 2010).

Abdul Qaui, Al Memdarah, Al Basateen, and Al Sesaban are four poor and most-atrisk areas in Aden city, with a total population of 71740, distributed in 11000 households. These four areas are inhabited by poor Yemeni citizens, marginalized groups (Al-akhdam), returnees, and refugees. Marginalized groups in Yemen, Al-akhdam, which literally means servants, are a social group distinct from the majority by their more African features. As a low caste group, they are discriminated against and 
mostly confined to menial jobs. Their origins are unclear. In Yemen, they are popularly believed to be the descendants of Ethiopian soldiers of the Aksumite Empire that occupied Yemen more than 1500 years ago and who remained there as servants of the local population after the occupation ended. Al-akhdam are stereotyped as dishonourable, immoral, dependent and dirty (Al-Ahmadi \& Beatty, 1997). Returnees are low-paid Yemeni workers who were expelled from Saudi Arabia during the Gulf War in 1990. When they came back to Yemen, they became an internally displaced population usually living in slum areas. Refugees in this study were mainly Somalis; some were of Yemeni descend and the rest were Somalis who fled the war in their country. The common characteristics among the four poor neighbourhoods were the large number of commercial sex workers, because they represent transit hubs for migrant populations coming from the Horn of Africa, where the prevalence of HIV is higher than in Yemen, as well as a transit area for truck drivers and local travellers (Al-Serouri, Anaam, Al-Iryani, Ramaroson, \& Al-Deram, 2010).

To explore risks and vulnerabilities in these four poor and high risk areas of Aden governorate, a community-based survey was conducted in 2005 among 601 young people living in these areas. The study revealed low levels of HIV knowledge, low levels of HIV risk perception, and high levels of stigma and discrimination against People Living with HIV (PLWH) (Al-Serouri, Anaam, Al-Iryani, Ramaroson, \& AlDeram, 2010). These results served as a baseline, for designing and implementing a HIV prevention and education intervention among youth at community level. The design of the intervention was based on the Theory of Diffusion of Innovations (Rogers, 2003), and was implemented during the period of 2005 till 2008. The community-based HIV prevention youth intervention was evaluated at the end of 2008, where data were collected using an interviewer-administered questionnaire among a sample of 700 young people randomly selected from the households of the four targeted communities (Al-Iryani, Basaleem, Al-Sakkaf, Kok, \& van den Borne, A QuasiExperimental Evaluation of A Three-Year Community-Based Peer Education Intervention For HIV Prevention Among Yemeni Young People, Submitted). Of this sample, those targeted by the intervention were compared to those not targeted. To increase internal validity, students were also compared with the cohort control sample surveyed in 2005. Results revealed that young people targeted by peer education attained a higher percentage of good knowledge (47.5\%) compared to those who did not receive peer education (25.4\%). Levels of stigma and discrimination at individual level decreased among those targeted by peer education. Among those targeted by peer education, $90.4 \%$ reported behavioural change, mainly related to avoiding shar- 
ing needles (53.3\%), avoiding sex with female sex workers (37.6\%), avoiding male-tomale-sex (18.6\%), and avoiding sex with multiple partners $(16.8 \%)$, and use of condoms (3.3\%). In comparison with the 2005 baseline, knowledge on the protective role of condoms increased from $29 \%$ to $49.5 \%$. In $2008,82.0 \%$ perceived themselves at risk for HIV infection compared to $62.0 \%$ in 2005; and $65.6 \%$ were willing to accept having a person living with HIV teaching their relatives in schools compared to $23 \%$ in 2005. This process evaluation was conducted after the completion of the quantitative evaluation.

Given the very conservative community and cultural setting of Yemen, it was important to know why the community-peer education intervention succeeded in such a difficult setting. There is limited research on community-based life skills and peer education programmes for HIV prevention in culturally conservative Islamic and Arabic settings. Frequently, the focus has been on studying the impact of interventions on outcomes such as self-reported knowledge, attitudes and behaviour. Much less research was conducted to document, assess, and explain how programs were implemented. A process evaluation identifies the procedures undertaken and the decisions made in developing the programme, describes how the program operates, the services it delivers, and the functions it carries out. By documenting the program's development and operation, it allows an assessment of the reasons for successful and unsuccessful performance, and provides information on potential replication (Steckler \& Linnan, 2002).

The process evaluation conducted on the present intervention program aimed to highlight the factors that enabled community peer education; and provides a deeper understanding of the quasi-experimental study outcomes. The evaluation was mainly based on qualitative data; however, some quantitative data were used, which were previously collected during the quasi-experimental outcome study.

\section{The Community Based Intervention and its implementation}

A community based intervention in Aden governorate was initiated in 2005, which aimed to equip young people residing in the four poor targeted communities with HIV information and skills. This intervention included culturally sensitive community based peer education and outreach. The intervention was designed after con- 
ducting a baseline study in these communities (Al-Serouri, Anaam, Al-Iryani, Ramaroson, \& Al-Deram, 2010).

Because of the conservative setting in these communities, the first step was to create an enabling environment through conducting advocacy sessions with religious leaders, local councils, district directors, and traditional leaders, which focused on the importance of establishing community based intervention where adolescents and young people lead peer education and outreach activities. The second step was building partnerships with Community Based Organizations (CBOs) and NonGovernmental Organizations (NGOs) existing in these communities through training programmes focusing on HIV prevention as well as on the right of adolescent and youth to participation and to access gender sensitive information and services. This was followed by creating community committees consisting of representatives of local councils, NGOs, CBOs, and the National AIDS Programme (NAP), which had the role of selecting community focal points and community peer educators from targeted communities, while ensuring at least $50 \%$ were girls to ensure a gender sensitive intervention.

The community outreach focal points and youth peer educators were trained in a 10days training workshops on life-skills and peer education, followed by 2-days prefield training before initiating peer education sessions and outreach activities. The training included a 9-days workshop, which was based on the Jordanian Peer Education and Life-Skills Package, in addition to 10 messages on HIV transmission, prevention, common misconceptions, and 5 life-skills messages. HIV messages involved the following: the first message on the definition of HIV and causative agent, the second on whether we can recognize an infected HIV person by the way he/she looks or do we have to do a blood test, and what does the window period means; the third message is on why HIV is a dangerous infection; the fourth message is on epidemiology of HIV in Yemen, the middle east and in the world, the fifth is on the mode of transmission, the sixth is on modes of prevention adopting the "ABCD" (Abstinence, Be faithful, use Condoms, don't use Drugs) approach, the seventh is on major misconceptions, the eighth is on risk perception and whether young people can be at risk, the ninth is on how we should deal with PLWH, which stresses the importance of the right of PLWH to live free of stigma and discrimination, and the tenth message is on what is the role of young people in educating the community. The life-skills messages are on communication and negotiation skills, self awareness and selfesteem, decision making, respecting difference in opinions, and assertive behaviour. 
Targeting young people at community level was done through in-door peer education session as well as outreach activities. In-door peer education was conducted as structured sessions with pre-and post-test, where peer educators conducted 5-hours sessions in the course of two days. The ten HIV messages and 2 life-skills messages (self-esteem and assertive behaviour) were the major topics covered by peer educators. Peer educators conducted two 90-minutes sessions twice a week. The peer educators used posters, one for each message. After the end of the second session, participants received leaflets on the 10 messages, as well as hats and T-shirts with a message: "Protect yourself with Abstinence and Knowledge". The slogan was chosen by the peer educators; the knowledge part referred to the knowledge on condoms and knowledge on avoiding drugs

In-door peer education sessions were conducted in NGOs and health centres. In neighbourhoods where no NGOs or health centres existed, schools were the site for peer education sessions during after school hours. Workers in community outreach focal points, who were familiar with the neighbourhoods, mobilized young people and families through home visits to encourage families to allow young people, especially adolescent girls, to participate.

The outreach peer education activities were conducted in homes, especially during Qat (or Khat) chewing sessions, in motels, hotels, beauty parlours, bus stops, and Qat markets (Qat is a plant that is a mild stimulant with amphetamine-like properties ). Outreach aimed to equip the hard to reach youth with necessary prevention information.

In 2008, and after three years of establishing the community based intervention, Voluntary Counselling and Testing (VCT) services were established in the targeted vulnerable communities. Social mobilization for VCT services was integrated as part of peer education and outreach activities, which aimed to increase the utilization of the services among most-at-risk populations.

\section{Methods}

Theoretical Model The theoretical model used in designing, implementing, and analysing the process evaluation included the theory of Diffusion of Innovations (Rogers, 2003). Diffusion of Innovations considers that an innovation can be new informa- 
tion, an attitude, a belief or a practice or any other object that is perceived as new by the individual or the community and can be diffused to a specific group. An innovation is communicated through certain channels over time amongst members of a social system (here, the four targeted communities). A central point in this theory is the use of opinion leaders as 'change agents' (Oldenburg \& Glanz, 2008).

Reaching a Consensus on Process Evaluation Questions:- The choices for the process evaluation instruments and the questions to be asked in each instrument were made in a participatory manner and in several stages. The first stage was during brainstorming sessions between the principal researcher and the coordinators from community based organizations in the targeted communities in Aden. The second stage was during a four-days training of data collectors. During this training, the data collectors had the chance to conduct focus group discussions and in-depth interviews with young people, who were targeted by peer education at community level, and who were not part of this study. This was done in coordination with a local NGO, which mobilized the group of young people to participate. The training workshop for qualitative data collectors had prepared for the research skill itself, and also resulted in refining the questions to be asked.

Sample and Instruments - The sample involved 52 participants, who took part in 5 Focus Group Discussions (FGD) and 15 In-Depth Interviews (IDI), while ensuring that all the four targeted areas were represented:

- Community focal points - 2 FGD: Male FGD (10 participants); Female FGD (6 Participants)

- Peer Educators - 3 FGD: 1male FGD (9 participants); $1^{\text {st }}$ female FGD (6 participants); $2^{\text {nd }}$ female FGD (6 participants)

- Key Informants: Local council members - 2 IDIs: 1male; 1female

- Targeted young people in communities - 10 IDIs: 5males; 5 females

- Targeted high-risk young people: Female Sex Workers- 3 IDI

Objectives of each instrument and probing questions are illustrated in Table 1. Questions were used as to lead the discussions and not to limit it as a question and answer style. 
Table 1: Process Evaluation Instruments of Community Based Intervention

\begin{tabular}{|c|c|c|}
\hline Target Group & Objectives/Leading \& Probing Questions & Tools \\
\hline & Objectives & \\
\hline \multirow[t]{9}{*}{$\begin{array}{l}\text { Community } \\
\text { focal points }\end{array}$} & $\begin{array}{l}\text { 1. To evaluate the programme (community peer education intervention) } \\
\text { from their side. }\end{array}$ & 2 FGD \\
\hline & $\begin{array}{l}\text { 2. To know their role in outreaching to vulnerable and most-at-risk } \\
\text { groups (high risk groups) }\end{array}$ & $\begin{array}{l}{ }^{*} \text { Male FGD } \\
(10 \text { partici- }\end{array}$ \\
\hline & Questions & pants) \\
\hline & $\begin{array}{l}\text { 1. What do you think about the programme? What have been the } \\
\text { strengths and weaknesses of the programme? }\end{array}$ & ${ }^{*}$ Female FGD \\
\hline & 2. What is your role in the programme? & (6 Partici- \\
\hline & 3. How did you manage to identify vulnerable and high risk groups? & pants) \\
\hline & $\begin{array}{l}\text { 4. How did you manage to convince vulnerable and high risk groups to } \\
\text { participate? }\end{array}$ & \\
\hline & $\begin{array}{l}\text { 5. What are the problems encountered in the outreach and identification } \\
\text { of vulnerable and high risk groups? }\end{array}$ & \\
\hline & $\begin{array}{l}\text { 6. What are your suggestions to improve outreach to vulnerable and high } \\
\text { risk groups? }\end{array}$ & \\
\hline
\end{tabular}

\section{Objectives}

Peer Educators 1. To evaluate the programme from their side

3 FGD

2. To study the effect of life skills on their life and the life of their peers

\section{Questions}

1. How was your experience with the programme?

2. To what extent do you think the program has impact on you?

3. How the programme affected your life skills and practices with the family as well as friends with examples? How has it affected your lives beyond peer education? Did it create new opportunities beyond peer education?

4. To what extent did the programme affected your targeted colleagues with regards to life skills and practices with examples?

5. To what extent did you have the chance to educate youth in the community?

*1male FGD

(9 partici-

pants)

${ }^{*} 1^{\text {st }}$ female

FGD ( 6

participants)

${ }^{*} 2^{\text {nd }}$ female

FGD (6

participants)

6. Do you have friends who are engaged in high risk behaviour? If yes, where you able to approach them with what you know on life skills and HIV prevention?

7. To what extent did the subject of male-to-male sex was raised during your session? Was it explained as one of the risk factors? What was the feedback from youth on this subject? What kind of questions was asked on male-to-male sex?

8. To what extent did the subject of condom as a protective method raised during your session? What was the feedback from young people on this subject?

9. Do you have VCT centre in your area? If yes, How do you see your role related to $\mathrm{VCT}$ ? 


\section{Objectives}

Key Infor-

1. To know their role, overall opinion on the programme, and their

2 IDIs mants: Local suggestions for future improvement.

$\begin{array}{ll}\text { council mem- } & \text { Questions } \\ \text { bers } & \text { 1. What do you know about the programme? }\end{array}$

1 male

2. What is your overall opinion on the programme in general?

3. What have been the strengths and weaknesses of the programme?

4. Were you involved as a local council? And how?

5 . What are your suggestions to improve the programme?

6. How do you think we can ensure sustainability of the programme?

\section{Objectives}

\section{Targeted}

1. To know their overall opinion on the programme

2. To know the impact of the programme on their sexual behaviour in communi-

3. To come up with suggestions for future improvement. ties

\section{Questions}

5 females

1. What do you know about the programme?

2. What is your overall opinion on the programme in general?

3. Do you know if high risk groups exist in your area? Have they participated?

4. What is the impact of the programme on behaviour of high-risk groups in your community?

5. What are your suggestions to improve the programme?

\section{Targeted high- Objectives}

1. To know the impact of the programme on their sexual behaviour

people: Female 2. To know their overall opinion on the programme

Sex Workers

3. To come up with suggestions for future improvement.

\section{Questions}

1. Have you participated in the peer education sessions? What is your overall opinion on the programme in general? What have you learned from the programme?

2. Have you been tested for HIV? Do you use condoms with your customers? How many customers do you have on average?

3. What are your suggestions to improve the programme?

FGD $=$ Focus Group Discussion

IDI= In-depth Interview 


\section{Data Collection and Analysis}

Qualitative Data- In-depth interviews and focus group discussion, were facilitated by nine data collectors (6 females and 3 males), who were trained in a four-day workshop. All focus group discussions and in-depth interviews were conducted during February 2009. Focus group discussions and in-depth interviews were conducted over two consecutive sessions, with 10 minutes break in-between, where refreshments were served, and casual discussions were stimulated by data collectors to further build trust with participants. All interviews and focus group discussions were tape-recorded and then were fully transcribed. The transcripts were translated into English, and analysed line-by-line and coded thematically.

Quantitative data - Some quantitative results were used from the quasi-experimental evaluation, which included a random sample of 700 young people from the four communities. These are mainly related to the following measure:

Receiving Peer Education and whether young people think it's beneficial- whether young people in communities were targeted by the intervention or not was assessed by a closed question on whether a young people have ever attended/heard AIDS education by peers in their communities; yes/no options were available. For those answering yes they move to the next closed question on whether they considered peer education in communities beneficial with the following options: very beneficial; beneficial, beneficial to some extent; and not beneficial.

\section{Ethical Considerations}

Written consent was obtained from the district directors and local councils of the Sheik Othman and Dar Saad Districts in Aden, where the four targeted neighbourhoods are located. In addition, verbal consent was obtained from all study participants, prior to interviews and focus group discussions.

\section{Results}

The themes emerging from the analysis of the focus group discussions and in-depth interviews were grouped into the following categories: Community acceptance and participation; community mobilization- the key role of the community based organization $(\mathrm{CBO})$ and community focal points; capacity building through life skills edu- 
cation, outreach peer education activities- a solution to overcome difficulties related to in-door peer education sessions; the intervention as viewed by targeted young people in communities; and peer education and outreach to Female Sex Workers (FSWs) in targeted communities.

\section{Community acceptance and participation}

Local council members highly appreciated the community peer education intervention. They indicated that the intervention helped to raise the HIV risk perception among community members:

"The peer education had a big effect on people here, even in streets and markets" a local council member

Local council members had also acknowledged the important role of the community based organization (CBO) in Sheik Othman district (The Social Service Centre) and the Civil Society Organization (CSO) in Basateen:

"Raising awareness among community members is the result of the cooperation between local council members, civil society organizations, and community based organizations- especially the Social Service Centre and its leadership"- a local council member

The CBO in Abdul Qaui coordinated the intervention in the neighbouring communities of Sesaban and Memdarah. This CBO has a social service centre that provides a wide range of community and health services, including distribution of free food items for needy family, vaccination and birth registration services, job training for women, health services for women, as well as voluntary counselling and testing for HIV. The CSO in Basateen only coordinated intervention in the Basateen community, and is present in the community through two health services: a general community health clinic and a maternal and child clinic. Also, they provide voluntary counselling and testing services, which is based in their community health clinic. Local council members stated that all those involved in the community based intervention, mainly peer educators and community focal points, and were selected from the same neighbourhoods, which gave a sense of ownership for the intervention. 


\section{Community mobilization- the key role of the $\mathrm{CBO}$ and community focal points}

Overview of the role of community focal points- Community Focal Points, although the majority were young people, also older residents from targeted communities participated who are known and respected by people in the neighbourhoods. For example, one of the community focal points in Sesaban was the head of a local NGO for marginalized groups. The main role of the community focal points was to facilitate the role of the peer educators by mobilizing young people to attend the peer education sessions. In fact, peer educators highly appreciated the facilitating role of the community focal points, as one peer educator stated:

"The success is attributed to the role of community focal points"- a male peer educator

They used various ways in approaching young people and their families. Female focal points indicated that they were focusing mainly on parents of young girls from the general population. They also approached the "gate-keepers" of female sex workers, which were usually older women. Male community focal points also mobilized male young people, although they had a much easier task than female community focal points.

"We approach parents, head of the neighbourhoods, the close friends of the targeted youth to influence them"-a male community focal point

Linking peer education with other Community Services- Female community focal points faced several difficulties when they started visiting homes in neighbourhoods to mobilize young people to attend peer education sessions. To overcome this problem, the coordinating community based organization involved community focal points in delivering services, such as birth registration and food distribution for poor families.

"People in Memdarah became more cooperative after helping them in issuing birth certificates for their new-borns and providing food rations"- a female community focal point

"At the beginning, people in Sesaban did not welcome me, but after birth certificates and food ration services, their attitudes had been totally changed"- a female community focal point 
Negotiations with families - in case of very conservative families, additional efforts were pursued to mobilize families to allow their daughter to participate in peer education sessions. Female community focal points always assure families that it is an all women session, and no men are allowed to be present. Even when they refuse in the beginning, older female community focal points, pay another visit, to explain the objective of the sessions. Also, community focal points always show their ID badge and an official letter from the $\mathrm{CBO}$ with details on the peer education timing and venue:

"We always present an official letter from the CBO to certify the date, place, and subject of the session"- a female community focal point

\section{Capacity building through life skills education}

One of the main themes across all participants is the impact of these capacity building opportunities on their life-skills, which, as they say, has enabled them to deliver the right information to targeted young people in their communities.

Local councils were also part of the community capacity building process, as they participated in two-day advocacy training, before the initiation of intervention. One female member of the local council was motivated to be also a community focal point for one of the neighbourhood

Effect of life-skills education on peer educators- there was a strong consensus among male and female peer educators that positive changes in their life-skills had impacted their lives tremendously. They stated that acquiring life-skills, especially, self-esteem, assertive behaviour, respecting differences in opinion, and communication skills had made them able to deliver good quality peer education sessions. Their work as peer educators had been a rewarding experience, and helped to practice theory in a real life situation, and have opened opportunities beyond peer education:

"We feel proud. We now have a role in our community"- a female peer educator

"I became a decision maker and able to say no to negative peer pressure"- a male peer educator

Local council members also stated that having well trained peer educators who can communicate the information to people with various educational levels had played a big role in the success of the intervention: 
"Communication skills of the peer educators were the most acknowledged strength point."- a local council member

Effect of life skills education on community focal points- Training opportunities, as well as the experience itself, had also benefited the community focal points. The said that the life-skills they acquired had a great impact on their lives, even beyond the programme, and had enabled them to efficiently purse their roles as community focal points and mobilize young people to participate in peer education activities:

"Previously, I felt always lonely and unconfident in myself. Now, I became more self confident. ... I had never imagined that I will be university graduate"- a female community focal point

"I feel more able to communicate with people"-a female community focal point

\section{Outreach peer education activities- a solution to overcome difficulties related to in-door peer education sessions}

Outreach activities were one of the ways to overcome the difficulties associated with conducting structured peer education sessions in the Civil Society organizations or Community Based Organizations:

"Addressing people in their usual settings helps us to avoid many problems when trying to recruit participants" - a male peer educator

Outreach activities are conducted in two ways: in-door outreach and out-doors outreach peer education. In-door outreach is when peer education sessions are conducted in one of the homes, workplaces, motels, or internet cafes. Out-door outreach is when peer education is conducted in markets, bus stations, or any out-door gatherings- out-doors usually don't need any previous coordination. However, in-door outreach is previously arranged by community focal points. In many of the cases, indoor outreach is done during Qat chewing sessions, which are usually practiced by both men and women, but separately. Peer educators conduct the sessions using big posters as many of the participants are illiterate.

During outreach activities peer educators are not restricted by the short timing of session in structured sessions conducted in CBO of CSO, because the halls where peer education is conducted are also reserved for other community activities. Peer 
educators also said that participants are more relaxed and ready to ask more questions related to behaviour.

"People feel more free, interact more, and ask more sensitive questions in outdoor activities"- a female community focal point

Another benefit of out-door peer education as stated by peer educators and community focal points, is that the time of sessions, which are usually conducted between 3:00 pm and 6:00pm, is Qat chewing time, and many young people are not interested to give up chewing, since chewing is not allowed in CBOs and CSOs.

As a local council member stated, the benefits of having outreach peer education has been proven to be a better than in-door structured approaches in reaching to young people.

"Outreach peer education is a preferable education modality"- local council member.

\section{The intervention as viewed by targeted youth in communities}

From the point of view of targeted youth, the most commonly acknowledged impact of peer education intervention is their improved knowledge on the modes of HIV transmission and prevention, and how to deal with PLWH in a "kind" way. They all mentioned the ten messages received during peer education sessions. Several targeted people had mentioned that the sessions influenced their behaviour, while others considered the sessions boring, and others considered the "dose" of education not enough to convince them to change their risky behaviour:

"At the beginning I liked it, but later I found it somewhat boring because they continued advising and advising all the time!"- a young woman from Basateen

Targeted young people who reported some degree of behavioural change didn't necessarily remember the life-skills discussed during the peer education sessions, although they vividly remembered the modes of transmission and prevention.

"I had been greatly impressed with the peer educators' talk. I reviewed my behaviours in light of their explanation about risky behaviours and decided to change"a young man from Sesaban

Some of the targeted young people had also tried to educate other young people in their neighbourhood. A young woman from Memdarah, although she didn't remem- 
ber the life-skills she learnt in the peer education sessions, said that she tried educating her friends in the neighbourhood on what she learned from peer education sessions.

"The programme had totally changed my life"; "I have started educating my neighbour" - a targeted young woman from Memdarah

Use of condoms - Controversy about male condoms (young males in the communities are more familiar and open to talk about condoms than females) still exist. Different responses were found among targeted young women in the communities:

"Some have the myth that two condoms are needed to provide protection against HIV transmission"- a young women from Memdarah

"Some girls feel shy and many families found it unsuitable to speak about condoms" - a young women from Sesaban

"I asked my husband to use the condom because he once got a bloody inflammation. I'm not sure about his faithfulness"- a young woman from Abdul Qaui

VCT services' utilization at community level- Responses of targeted young people, when asked about VCT services, had varied from not knowing about eh services at all, to being informed and willing to be tested, but constrained by social factors:

"I'm now engaged. Despite that my fiancé is good, I'm insisting that he should test for AIDS but he is still refusing". She justified her insistence: "I want to be sure he is free of AIDS. Even, I want myself to test for AIDS but my mother refused; my mother and my fiancé think that the test is not safe, because they needles might be re-used; also, they are afraid a person might be reported by mistake to have AIDS" - young woman from Memdarah

\section{Peer education and outreach to Female Sex Workers (FSWs) in targeted communities}

The intervention as viewed by FSWs- Three in- depth interviews were conducted with three FSWs. They all agreed that the peer education sessions were beneficial and informative, but there was little impact their high-risk behaviour, except for the FSW who went to the VCT services: 
"I participated in peer education sessions in the social service centre, and then I went for testing in the VCT centre, and turned to be fine. I started now go out with men to public places without having sex"- a 24-years old FSW

"I now know that any customer might be infected with HIV, I really don't want to be infected" - a 24-years old FSW

The second FSW did not believe in the protective role of condoms, as explained in the peer education session:

I wasn't convinced with what they told me in the AIDS awareness; they said that those "rubber cases" can protect from disease; I didn't believe them; anyway, some men carry them and wear them when they want to"- a 24 years old FSW

However, she said, she started using condoms consistently only after her friend died of AIDS:

"I decided to use condoms after my friend died of AIDS" - a 24 years old FSW

The third sex worker although stated that peer education sessions had made her aware that HIV existed in Yemen, still she didn't adopt safe-sex:

"Honestly, in the beginning I didn't believe there is AIDS in Yemen, and in Aden;

I now started to believe that"- a 23-years old FSW

Nevertheless, she continues to have unprotected sex with her customers:

"I don't use condoms because they always get torn and men feel more pleasure without them ... I also feel more pleasure without them" - a 23-years old FSW

Role of peer educators and community focal points in outreaching to FSWs - Building a trust relationship with FSW was the starting point to have them participate in peer education sessions, as they were always concerned to be caught by the police:

"Inviting those with high-risk behaviours to attend HIV sessions raises among them the fear of disclosing their identities to the public and the police"- a female community focal point

In other circumstances, FSW requested financial incentives to participate in peer education sessions: 
"FSW sometimes refuse to participate unless paying to them at least YR 1000 as a compensation for interrupting their work." - a female community focal point

It was difficult to convince older gatekeepers to allow FSW to participate, and female community focal points had to go through young gatekeepers, who were usually less rigid:

"Once I was unable to target the famous gatekeeper who brings girls to the hotels, but I managed that by contacting a younger gatekeeper who facilitated our meeting to educate FSW who worked with that famous pimp" - a female community focal point

Poverty, unemployment, economic hardship, and lack of programmes addressing youth in communities was mentioned by peer educators as underlying causes for not having an environment inductive for behavioural change among FSWs:

"Despite we are trying our best to influence them using peer education-life skills approach, very few were influenced. The majority unchanged because education is not enough; they are also in need for other programmes addressing poverty, unemployment and to occupy their spare time" - a female peer educator

\section{Discussion}

This community process evaluation aimed to highlight the factors that facilitated or inhibited community peer education in four poor and vulnerable areas of Aden, Yemen. It also aimed to provide a deeper understanding of the quasi-experimental evaluation outcomes, which revealed that community-based intervention succeeded in improving HIV knowledge and risk perception; and in decreasing stigma, and risky behaviour in a culturally conservative setting. Given the conservative cultural context in Yemen and the setting where the intervention was conducted, it was necessary to understand the factors that enabled as well as impeded implementation and to assess acceptability at community level.

The result of the process evaluation revealed that several factors had created an enabling environment to implement community peer education. These factors were community participation of all existing stakeholders, community mobilization through the community focal points networks, and capacity building of all those included in the intervention. There was a clear positive effect of the community- 
based peer education intervention on the life skills of peer educators and community focal points. Having better life skills, mainly, assertive behaviour, respecting differences in opinion, communication skills, and self-esteem, had enabled community peer educators and community focal points to be "opinion leaders" and "change agents" among their peers. They had assumed this role by influencing, not only those who they contacted directly through peer education sessions and outreach (active diffusion), but also indirectly, through "passive" diffusion. This happened where those directly targeted by the intervention might have 'diffused' information on HIV prevention to their peers in communities (Oldenburg \& Glanz, 2008).

Community Participation and the involvement of local council members, who are elected by communities, had given the programme a "legal" code. Having one of the community focal points from the local council also supported the intervention politically. The role of the coordinating community based organization and the civil society organization had been crucial in pulling all parts of the intervention together. The fact that all those involved in the intervention from the targeted communities, had also given participants a sense of ownership. Previous research has highlighted the importance of community participation in the success of peer education activities (Kinsman, et al., 2002; Campbell, Nair, \& Maimane, 2007; Cornish \& Campbell, 2009).

Capacity building through life skills education was a key element in the success of the intervention. High quality training had been one of the elements of success. This is in line with findings by (Rispel, Peltzer, Nkomo, \& Molomo, 2010), who illustrated that the successes of a HIV and AIDS Community Training Partnership Program (CTPP) implemented in five diamond mining areas in three provinces of South Africa were related to capacity building of trainers .

Community focal points' role in mobilizing communities was crucial in this community-based peer education. Community focal points acted as the link between targeted young people and the peer education intervention, which was crucial in mobilizing young people from the neighbourhoods to participate in the peer education sessions. The coordinating community based organization's credibility in the neighbourhoods was one of the essential elements that enabled community focal points to pursue their work. The fact that the coordinating $\mathrm{CBO}$ recruited community focal points from local NGOs representing marginalized groups, had led to targeting the hard-to-reach marginalized groups. 
Outreach peer education activities- Although in-door structured peer education had been logistically cumbersome; it had paved the road for outreach peer education. Outreach had been a solution to overcome difficulties related to in-door peer education sessions structured peer education in CBOs and CSO had built the experience of community focal points and peer educators. It also introduced the intervention to the community and linked it to respectable places in neighbourhoods. Shifting to outreach peer education had been crucial to target hard-to reach high-risk groups, especially for reaching female sex workers as well as young men, who are not willing to give-up their Qat chewing for peer education sessions.

The intervention as viewed by targeted youth- The fact that targeted youth are discussing use of condoms and high risk behaviour in addition to their change in knowledge emphasizes the fidelity of the programme. Targeted youth in communities in this process evaluation had also given some explanation of why knowledge on condoms is still low. Young people still needs more detailed information on the use of condoms and its protective role. VCT services can play a key role in providing confidential sessions on condoms. Young people in communities still don't fully trust VCT services. This might be due to the fact that VCT services were established in March of 2008, while the process evaluation was conducted in February 2009. One year might not have been enough to ensure social mobilization for seeking a new service, which is also related to a sensitive issue like HIV.

Role of the head of Social Service Centre- The head of the community based organization (Social Services Community Centre), who was also the overall project supervisor, had a key role in ensuring community participation and mobilization, and in the overall success of the project. Previous research had documented the important role of having a committed project supervisor in the community based HIV intervention (Evans \& Lambert, 2008).

Impact of intervention on FSW- The intervention did not seem to be tailored to this group, but rather to general youth residing in the targeted neighbourhoods. Female sex workers were targeted, since they are living in the targeted neighbourhoods. It was clear that their knowledge on modes of transmission and prevention had improved, but not their behaviour. Voluntary counselling and testing services should be the main entry point for future interventions for this group. Interestingly, risk perception was key to behavioural modification, while knowledge did not seem to play a 
key role. Several research studies on community-peer education for sex workers exist. Successful interventions for FSW entail recruitment of peer educators from sex workers themselves (Luchters, et al., 2008; Evans \& Lambert, 2008; Cornish \& Campbell, 2009).

\section{Limitations}

There are several limitations to this study. The first limitation is due to the fact that this process evaluation was done after the outcome evaluation, and thus there may be a bias in our interpretation of the results (Oakley, Strange, Bonell, Allen, Stephenson, \& the RIPPLE Study Team, 2006). The second limitation is that the results of this study could be useful to replicate community interventions only in settings where community based organizations (CBOs) exist. This is a limitation in the Yemeni context where CBOs that provide community and social services are only present in few cities. In addition, the context where this community-based intervention programme was implemented could be only generalized to few coastal governorates with similar societal and cultural norms. It should be noted that Aden, although it is a conservative setting, is still less conservative than other Yemeni governorates, where women participation is very limited. The third limitation was related to recruitment of participants in this study, especially female sex workers. Although the social services centre in the targeted communities played a key role in outreaching to FSW, yet, only 3 FSW were willing to participate, as sex work is illegal in Yemen.

\section{Recommendation}

Community based intervention have proven to be successful for youth from general population and those who are vulnerable to HIV infection in conservative settings and could be replicated in other areas, while taking in consideration lessons learned from this process evaluation. However, the intervention should be tailored if it was to be replicated to reach to high-risk youth groups. Linking high-risk groups, such as FSW, to sexually transmitted infection clinics, VCT services, and creation of livelihoods are key to address HIV prevention among these groups. 


\section{Conclusion}

This process evaluation, which was theoretically based on the Diffusion of Innovation Theory (Rogers, 2003), indicated that peer educators and community focal points were able to be 'opinion leaders' in their communities due to several enabling factors. These elements were mainly community acceptance \& participation of all existing stakeholders, community mobilization through the community focal points networks, and capacity building of all those included in the intervention. The results from this evaluation could be useful in replicating or implementing future community-based peer education interventions in conservative settings. 

General Discussion 


\section{Overview}

The aim of this dissertation was to study the impact of peer education and life skills based HIV prevention among adolescents and young people in Aden governorate, Yemen. It also aimed to explore why the interventions were possible in a very conservative and traditional Muslim setting; and documented how the interventions were implemented. It is expected that the interventions might be replicated in other parts of Yemen and in similar conservative Arab and Islamic settings.

The school and community peer education and life skills based interventions that were implemented in 27 schools and in four vulnerable communities of Abdul Qaui, Al Memdarah, Al Basateen, and Al Sesaban have succeeded in improving HIV knowledge and risk perception; decreasing levels of misconceptions, stigma and discrimination towards people living with HIV (PLWH), and in promoting less risky practices and behaviours related to HIV infection among vulnerable young people in communities. Both the school and community intervention were theoretically based on the Diffusion of Innovation Theory (Rogers, 2003).

The school and community interventions were implemented with high levels of fidelity and were well accepted by young people as well as by the main stakeholders. The main enabling elements for the school and community intervention had been the culturally sensitive messages on HIV prevention, advocacy with decision makers and parents, and participation and capacity building of all existing stakeholders at school and community level. The life skills based training of community and school peer educators were pivotal in building their capacities, and had enabled them to become 'opinion' leaders among their peers. The cultural sensitive messages and the "life skills" labelling were key in the acceptance of the interventions in a rigid and conservative setting like Yemen.

In the Middle East and North Africa (MENA) region, where Yemen is located, there is no single study documenting a peer education and life skills programme in schools or communities. The only study found in MENA describes a rapid school peer education that was implemented among high school, but the peer sessions were implemented by college medical students (Barss, Grivna, Ganczak, Bernsen, \& Al-Maskari, 2009); also, the intervention did not have a life skills component nor did it constitute any capacity building or advocacy opportunities for key stakeholders. Furthermore 
the training package and messages were developed by experts and not through a participatory process involving young people and key stakeholders.

The relatively new aspects in the present dissertation are three folds. It involves the design, implementation, and evaluation of community and school based interventions among young people using both peer education and life skills methodologies; it demonstrates that HIV education among female and male young people at school and community level is possible in a very conservative Muslim and traditional setting; it includes a respectable sample size and duration - a total of 6221 young people were included in the school and community baselines and evaluations and the duration of the interventions were three years (2005-2008).

This chapter will elaborate and further analyse the findings in this dissertation; will shed light on how the interventions were possible in the conservative Yemeni setting and how the findings can be applied for policy development vis-à-vis youth HIV education in and out of schools.

\section{Main Findings}

\subsection{Knowledge}

The peer education and life skills based interventions among young people in Aden, which were implemented in the 27 high school and the four vulnerable communities of Abdul Qaui, Al Memdarah, Al Basateen, and Al Sesaban had significantly improved the knowledge on HIV modes of transmission and prevention, and decreased levels of misconceptions among those targeted by peer education in comparison with those not targeted; and in comparison with the 2005 cohort group. The improved knowledge on the protective role of condoms, and how this outcome has a gender and socio-economic dimension are noteworthy.

The school-based peer education has succeeded in closing the knowledge gender gap on condoms (Al-Iryani, Raja'a, Kok, \& van den Borne, 2010). In fact, female students attained better knowledge on condoms after being targeted by peer education, compared to male students, although they had lower levels of baseline knowledge. They also reported more life skill changes than male students. This indicates that girls in Yemen make maximum benefit of all existing educational opportunities, and that 
girl's education is the most important determinant factor that can lead to gender equality, in a nation with huge gender disparities (Hausmann, Tyson, \& Zahidi, 2009).

The gender gap favouring males, regarding the knowledge on condoms, was also huge among young people in communities, and this gap was also evident in the community baseline study conducted in 2005 (Al-Serouri, Anaam, Al-Iryani, Ramaroson, \& Al-Deram, 2010). Although the process evaluation has indicated the gender sensitiveness and inclusion of young women at community level in all the phases of the intervention, still the community-based peer education was not successful in closing this gap. The main reason is the presence of a major confounding factor in the poor communities, which have high rates of illiteracy among females at community level compared to males. The community quasi-experimental evaluation has shown that improvement in HIV knowledge was directly related to level of education, and being illiterate was significantly associated with being female and attaining lower levels of knowledge. Another explanation revealed by the community process evaluation is that females were more reluctant to discuss condoms compared to males. This gender difference is a reflection of the traditional Yemeni setting at community level, which gives men more freedom than women to discuss sexual related matters, which is common among many conservative societies (Al-Serouri, Anaam, Al-Iryani, Ramaroson, \& Al-Deram, 2010). Regardless of this existing gender gap, the fact that both male and female young people at community level (as indicated by the community process evaluation) are now discussing use of condoms and high risk behaviour, is a crucial outcome given the conservative setting, and is a starting point for further gender sensitive community interventions.

Although many researchers might argue that improving the level of knowledge does not necessarily lead to behavioural change, it should be noted that reporting life skills changes was associated with a good knowledge score, which indicates that the peer education interventions have not only increased HIV knowledge and decreased stigma, but also improved life skills, which are an integral part of adopting safe sexual behaviour (Medley, Kennedy, O’Reilly, \& Sweat, 2009; Hagquist \& Starrin, 1997). In addition, in a setting like Yemen, where access to information by adolescents and young people is still limited, increase in knowledge and awareness is a crucial step towards behaviour change, as one of the factors that influence HIV risk behaviour among young people is their HIV knowledge (Fernandez, Figueroa, Gomez, Maysonet, Olivaers, \& Hunter, 2004). 
Several research studies have also indicated that school-based peer education had positive effect on HIV knowledge (Agha \& van Rossem, 2004; Ozcebe, Akin, \& Aslan, 2004; Chhabra, Springer, Rapkin, \& Merchant, 2008; Barss, Grivna, Ganczak, Bernsen, \& Al-Maskari, 2009; Li, et al., 2010). There is also exiting research on life skills based HIV education in schools that documents the positive effect on knowledge of (Harvey, Stuart, \& Swan, 2000; James, Reddy, Ruiter, Mccauley, \& van den Borne, 2006; Klepp, Ndeki, Leshabari, Hannan, \& Lyimo, 1997; Kinsler, Sneed, Morisky, \& Ang, 2004).

Moreover, previous evaluations of community based peer education have shown a positive effect on HIV knowledge, although they were not focused specifically on adolescents and young people, but adult community members with high risk behaviour (Williams, et al., 2003; Norr, Norr, McElmurry, \& Moeti, 2004). .

\subsection{Decreased Stigma, Discrimination and misconceptions}

One of the remarkable outcomes of the peer education interventions has been the improved attitude of targeted young people towards people living with HIV (PLWH) both at school and community level. This improved attitude was paralleled with decreased levels of misconceptions in schools and communities. Previous research documents that misconceptions on HIV modes of transmission and prevention were found to be predictors of HIV related stigma and discrimination (Bekele \& Ali, 2008; Chiao, Mishra, \& Sambisa, 2009).

In schools, care, support and no discrimination actions for PLWH were significantly associated with being targeted by peer education. Similarly, young people in communities who were targeted by peer education were more willing to buy greenery from a person living with HIV, to accept having a person living with HIV teaching in schools, and to suggest that the community should deal with PLWH with care and compassion. What is interesting is that these findings were realized in a conservative setting, where HIV is still related to pre-marital and extra-marital sex, which is considered immoral, illegal, and against religious and social code of conduct. The fact that the majority of suggested actions by young people are related to care, treatment, support, and no discrimination, is an indication of the success of the intervention in such a traditional setting, especially in communities, where poverty and illiteracy are prevalent. 
Despite the decreased levels of stigma among targeted young people in schools and communities, the impact was more apparent in schools. Students targeted by peer education did not mention even one suggestion for punishing PLWH, in comparison with targeted young people in communities, where a minority still believed that PLWH should receive punishment from the government. This difference is mainly due to the better attainment of HIV knowledge in schools, as well as the educational background. Chiao et al (2009) investigated the influence of individual- and community-level factors on accepting attitudes toward PLWH, among a sample of 7377 women and 3109 men randomly sampled from the 2003 Kenya Demographic and Health Survey, and found that individuals who expressed greater acceptance of PLWH were more likely to be more educated and with high AIDS knowledge. Chiao et al have also indicated that at the community level, differences in accepting attitudes were also associated with community AIDS knowledge and community education (Chiao, Mishra, \& Sambisa, 2009).

Previous research has documented the positive effect of life skills and peer education in decreasing stigma and discrimination. Barss et al, 2009, have reported that rapid and single peer education sessions among high school students in the United Arab Emirates, a high income Arab and Muslim country, has improved attitudes towards PLWH (Barss, Grivna, Ganczak, Bernsen, \& Al-Maskari, 2009). Klepp et al. 1997 reported that life skills education in schools had improved tolerance towards PLWH (Klepp, Ndeki, Leshabari, Hannan, \& Lyimo, 1997), and other studies had reported that life skills education at community level has led to accepting attitudes toward people living with HIV (Yankah \& Aggleton, 2008). However, there is no existing research documenting the reduction of stigma among in and out of school adolescents and young people in a low income Muslim and Arab setting by interventions that embrace both life skills and peer education methodologies.

\subsection{Increased Risk Perception and Decreased Risky Behaviour}

The vast majority of targeted male young people at community level, reported positive behavioural changes, mainly related to avoiding sharing shaving blades and needles, as well as reductions in sexual risk-behaviour, which included avoiding sex with female sex workers, avoiding male-to-male sex, and avoiding multiple partners. Use of condoms was also reported, but the increase in percentages of condom use by young people, were much less than the reductions in other risk behaviours. Although we can say that it is an achievement to have even a small percentage of young people 
reporting use of condoms as a result of the community peer activities, it does indicate that the intervention focused on abstinence and mutual faithfulness as HIV preventive strategies far more than on promotion of condom use. This was documented by the community process evaluation, which revealed that peer educators faced difficulties to deeply discuss the use of condoms as an HIV preventive method.

In all the reported behavioural changes by targeted young people, huge gender differences were found. Males were four times more likely to report reduction in riskbehaviours compared to females. This does not necessarily mean that females were more reluctant to change. It might be due to the fact that males were more engaged in high risk behaviour, or that females were less reluctant to disclose being engaged in high risk behaviour. The Yemeni culture, like other traditional culture, condemns females far more than males if they were engaged in sexual activity outside wedlock. Girls and women who transgress rules of sexual behaviour may be subjected to physical assault and social exclusion (Bennett, 2007; Chakraborty, 2010).

Previous research has a wide spectrum of findings on the effect of life skills and peer education among young people in and out of schools. Several studies had reported that peer led school interventions, although had positive knowledge outcomes, had weak to moderate effects on sexual risk behaviour of adolescents (Agha \& van Rossem, 2004; Speizer, Tambashe, \& Tegang, 2001; Aaro, et al., 2006; Gallant \& Maticka-Tyndale, 2004; Mukoma, 2001; Harrison, Smith, \& Myer, 2000). .

Other studies have shown that peer-led programmes improved students' attitudes and behaviour compared with students who did not receive such prevention education (Li, et al., 2010; Rickert, Jay, \& Gottlieb, 1991).

There are also existing studies that reported positive behavioural outcomes of school-based life skills education, in addition to positive knowledge and skills (Paine, Hart, Jawo, Jallow, Morison, \& Walraven, 2002; Ross, Changalucha, Obasi, Todd, Plummer, \& Cleophas-Mazige, 2007; Harvey, Stuart, \& Swan, 2000), while others had documented no effect on sexual behaviour (James, Reddy, Ruiter, Mccauley, \& van den Borne, 2006; Klepp, Ndeki, Leshabari, Hannan, \& Lyimo, 1997; MartinezDonate, Hovell, Zellner, Sipan, Blumberg, \& Carrizosa, 2004).

Community based life skills interventions have also shown to have a positive impact on reducing risky behaviours among youth (Harper, Bangi, Sanchez, Doll, \& Pedraza, 2009)while others have shown no behavioural impact (Kinsman, Nakiyingi, Kamali, Carpenter, Quigley, \& Pool, 2001). 
All the previous mentioned studies on life skills and peer education illustrate several facts. The majority of them document either life skills interventions, which are not always encompassing peer education methodologies, or any other participatory approaches, or are documenting peer education interventions that are not necessarily life-skills based. The majority of studies, whether they are peer education or life-skills based, are usually conducted in schools, and rarely in communities. The reason behind the success of the school and community based interventions in Aden might also be due to the fact that they are both life-skills based as well as participatory in nature through the peer education that was applied.

\section{Elements of the culturally sensitive approach of the interventions}

One of the main aspects of this dissertation is not only the findings per se, but why the school and community interventions among young people were possible in such a very conservative setting. The cultural sensitiveness was one of the main aspects of the interventions both at community and school level.

Researchers have argued that health promotion prevention programmes are most likely to be effective when their objectives and strategies match the cultural contexts and social reality of priority populations (Resnicow, Baranowski, Ahluwalia, \& Braithwaite, 1999; Parker, Easton, \& Klein, 2000; Kreuter, Lukwago, Clark, \& Sandersthompson, 2003; Kreuter \& Mcclure, The Role Of Culture In Health Communication, 2004). In order to accomplish cultural sensitivity of programmes, it has been suggested that interventionists have to consider both the explicit or surface cultural manifestations, such as language, clothing, contexts and traditions, and the implicit or deep manifestations of culture, such as beliefs, values, norms and roles (Resnicow, Baranowski, Ahluwalia, \& Braithwaite, 1999; Resnicow, Soler, Braithwaite, Ahluwalia, \& Butler, 2000; Wilson \& Miller, 2003). Several strategies have been distinguished to accomplish cultural sensitivity (Kreuter \& Mcclure, The Role Of Culture In Health Communication, 2004; Wilson \& Miller, 2003): i) presentation strategies, referring to peripheral, evidential and linguistic strategies enhancing message receptivity and accessibility, e.g. by using peer educators, native language, and cultural sensitive scripts and contexts, ii) socio-cultural strategies, referring to approaches to enhance message salience by grounding the intervention content in the 
context, experiences, values, beliefs and norms of the priority population. In addition, constituent-involving strategies have been suggested to create cultural sensitivity, referring to active participation of members of the cultural group of interest in the programme design process (Bertens, Eiling, van den Borne, \& Schaalma, 2008).

The following paragraphs will focus on 5 main constituents of establishing culturally sensitive school and community interventions: 1. Development of culturally sensitive messages; 2. Development of a culturally sensitive training framework; 3. Life skills and peer education as cultural sensitive approaches; 4. Participation, acceptance and ownership, including acceptance of the intervention from an Islamic prospective; and 5. Diffusion of Innovations as a cultural sensitive theoretical framework.

\subsection{Development of Culturally Sensitive Peer Education Messages}

The Information, Education, Communication (IEC) material, mainly the posters, booklets, flyers, and leaflets, which contained the HIV messages, played a key role in the success of the intervention. The preparation of the IEC material was one of the initial steps of preparing for the school and community interventions.

In 2005, and just directly after conducting the school baseline survey (Al-Iryani, Raja'a, Kok, \& van den Borne, 2010) and the community baseline survey (Al-Serouri, Anaam, Al-Iryani, Ramaroson, \& Al-Deram, 2010), the process of developing the messages to be used during the peer education interventions was initiated. The goal was to develop messages that would address the gap in knowledge, high stigma, and low risk perception revealed by the 2005 baseline surveys. The development of the messages was done in several steps, where the participation of key stakeholders and young people was a priority in the entire process.

The first step was through consultation with key stakeholders in the National AIDS Programme, which represent the technical authority in the country. This step resulted in a first draft of 10 messages addressing the gaps as per the baseline findings.

The second step was through the consultation with religious leaders in the Ministry of Endowment, which is the official religious authority in the country. The main issue raised by religious leaders is the message explaining the modes of HIV prevention, which states the role of condom in prevention. The initial message, which is based on the ABCD approach: Abstinence, Be Faithful, use Condoms, and Don't use drugs. 
The message on condoms was initially stated as follows: condom use is an effective prevention and should be used among partners in every sexual intercourse. During the first consultation, the religious leaders were outraged as the message related to condoms could promote pre-marital and extra-marital sex among young people, as the word partner was used, and not married couples. The initial reaction was total rejection of the messages by religious leaders. Another round of consultations with religious leaders in the Ministry of Endowment was done, where it was stated that the objective was to give the right information to young people, and not to promote any practices against Islamic teachings. The consultation resulted in changing the message related to condoms to be worded as follows: "In case that one of the married couple is HIV positive, then condoms should be used, as use of condoms is an effective prevention from HIV if they are used correctly and consistently during every sexual intercourse". Religious leaders were relieved to see the word married couple replacing the word partners, and thus endorsed the messages.

The third step was through consultation with the Ministry of Education, which was completely against mentioning condoms, but then accepted the message after they were informed on the acceptance of religious leaders. However, the Ministry of Education approved the IEC material to include the revised message on condoms for high school students only, but insisted to delete the message if younger students were to be targeted.

The fourth step was consultation with key stakeholders in Aden, mainly with the education office, and with community based organizations in the targeted communities, and the National AID Programme in Aden. This step was the easiest step, as key stakeholders were previously part of the peer education and life skills training conducted in 2004, and they have been well advocated.

The fifth step was field testing the messages among young people in and out of schools through focus group discussions. The field testing was done in Aden and included students from high schools as well as young people from targeted communities. In this step, a professional designer, as well as a technical person from the National AIDS Programme, was involved to ensure that the content was technically correct, and that messages were also reflected into drawings that facilitate the understanding of illiterate young people. The fifth step was the real work, as young people had valuable suggestions to the way the information in the messages were conveyed and how it was conveyed in art form. They also suggested including verses from the 
Quran, which called for tolerance, to further potentiate the message on combating stigma. This step resulted in a second draft of the 10 messages, which was then again field tested among young people in Aden, and further modifications were added resulting in the final form of the 10 messages, which were then the basis of the peer education sessions in and out of schools. Many at that time have argued that why the same messages were used among in and out school young people? Why they were not changed to tailor to the different audience? The main justification was that standard 10 generic messages should be developed, with easy to understand text for young people, which is illustrated by easy to understand drawings by illiterate young people. Young people during the field testing had also requested to have images that represent the Yemeni cultural clothing for both males and females. Females were illustrated to be wearing face veil, which is prevalent in Yemen, as well as head cover.

In these five steps of developing the IEC material the application of strategies for the development of cultural sensitive educational material is clearly demonstrated (Kreuter \& Mcclure, The Role Of Culture In Health Communication, 2004; Wilson \& Miller, 2003).

The ten messages in the IEC material contained the full spectrum for behavioural strategies, which focused not only on the ABCD approach, but also involved messages on stigma reduction, risk perception, prevention of mother to child transmission, access to Voluntary and Counselling services; previous research documents that such messages are the main goals for behavioural strategies (Coates, Richter, \& Caceres, 2008).

Although there is existing research disputing the use of the ABC strategy compared with full-fledge condom promotion and safe-sex strategies, stand-alone condom promotion would have failed in the Yemeni context. Previous research from Uganda, where the estimated prevalence of HIV in adults has fallen from 15\% to 5\% during the past decade, indicated that each component of the ABC approach probably had an important role (Shelton, Halperin, Nantulya, Potts, Gayle, \& Holmes, 2004).

\subsection{Development of a culturally sensitive training framework}

One of the main results of the school and community based peer education interventions for HIV prevention among young people is the finalization and endorsement of the National life skills and peer education youth manual. This manual has been the 
training framework and the main guiding principle for training peer educators, master trainers, and key stakeholders (UNICEF, 2009).

In 2005, when the school-based interventions were initiated, the "ten HIV messages" were used in the peer education sessions; in addition, the peer education sessions were an opportunity to field test the Jordanian peer education and life skills manual, which was supported by UNICEF Middle East and North Africa Regional Office (UNICEF, 2006). The field tested sessions were focusing on life skills, changes during puberty, sexually transmitted infections, and HIV. The field testing was done among 500 male and female students in Aden, and provided valuable information for the "Yemenization" process of the manual. This manual was then modified according to the results of the field testing by a high level technical committee from the Ministry of Education, Ministry of Health, National AIDS Programme, Ministry of Youth, Aden Education Office, and with direct support from UNICEF Yemen country office.

The adapted "Yemenized" Manual was then endorsed as the "National Life skills Manual", which includes themes focusing on life skills education, peer education, training of trainers methodology, HIV prevention, prevention of sexually transmitted infections, changes during puberty, and healthy life-styles for young people. This adapted national manual was the basis of the theoretical as well as practical basis for trainings of peer educators. The fact that several key decision makers, as well as governorate level stakeholders from Aden were involved in the adaptation of the life skills and peer education manual had impacted the acceptance of the whole intervention. It created a sense of ownership as they were involved at all stages: since the early design of the interventions, and even at the design of training and capacity building packages. It should be noted that the life skills and peer education labelling of the manual has impacted the labelling of the interventions at community and school level.

\subsection{Life skills and peer education as cultural sensitive approaches}

Capacity building of peer educators through high-quality life skills-based peer education training was a key enabling element in school and community interventions. There was a clear impact of the school and community-based peer education intervention on the life skills of peer educators in schools and communities. Having better life skills, mainly, assertive behaviour, respecting differences in opinion, communication skills, and self-esteem, had enabled peer educators to be "opinion leaders" and 
"change agents" among their peers. They had assumed this role by influencing, not only those who they contacted directly through peer education sessions and outreach in communities (active diffusion), but also indirectly, through "passive" diffusion. This happened where those directly targeted by the intervention might have 'diffused' information on HIV prevention to their peers in schools and communities (Oldenburg \& Glanz, Diffusion of Innovations, 2008). Previous research has also documented that life skills based and peer education for HIV prevention also impact those who were not directly targeted, through the diffusion of knowledge to nonparticipants (Yankah \& Aggleton, 2008).

The fact that the peer education and life skills training package was based on a "Yemenized" national life skills and peer education manual seems to have been a very important dimension. It gave peer educators as well as key stakeholders in schools and communities the comfort zone that peer educators are not being trained on an "imported" package that does not match the values of Yemeni culture.

Selection of peers at school and community level was also an important part of the intervention, as the proper selection of peer educators is always crucial to success of interventions (Medley, Kennedy, O’Reilly, \& Sweat, 2009). In schools, although the recruitment was on voluntarily basis, only students who met standard criteria of having good communication skills, being accepted by classmates, and good academic achievement were selected as peer educators; and the selection was done by a committee consisting of the school coordinators and school social workers to ensure that only possible "opinion leaders" were recruited, who also represent the social values of the Yemeni culture, yet are open enough to discuss a sensitive topic like HIV. This careful selection of peer educators ensured an important step for the success of the programme, even before starting the peer education and life skills training. In communities, peer educators were also selected according to standard criteria, which entailed to be in the age group of 15-24, to be residing in the community and from the same socio-economic background; and to have good communication skills and were accepted by youth in the community. So basically, potential youth opinion leaders were recruited as peer educators, but who also represented the community mainstream cultural values.

The current educational system in Yemen does not give much space for students to fully participate and express their views. One might wonder why peer education was possible in the 27 schools of Aden. The fact that students led the educational session 
at class room level could have been understood as a real challenge for the role of teachers that might be threatened by peer educators. However, the advocacy workshops and trainings targeting school head masters, educational supervisor, and school social workers played a vital role, not just in accepting HIV education per se, but in accepting the new concept of having in school adolescents in a leadership role.

In the four targeted communities, we can highlight another dimension of the methodology of peer education in such a poor and disadvantaged context. The high rates of illiteracy make the choice of getting HIV information through reading impossible. Even among those young people in communities who are literate, they would have difficulty in reading written information. This was revealed during the data collection, where all young people needed to be assisted in reading the questionnaires, even among those who can read and write.

Yemen is traditionally an oral culture (Al-Syaghi, 2008); where in addition to a formal written history, information over generations had also been transferred orally. Peer education is an iteration of this oral culture. Also, Yemeni young people, in and out of schools, have limited opportunities for meaningful participation (Al-Nabulsi, 2004) and thus peer education and outreach activities had been a great opportunity for youth civic engagement.

Previous research has documented the importance of capacity building through high quality training, in the success of community interventions (Rispel, Peltzer, Nkomo, \& Molomo, 2010). Rispel et al (2010) have illustrated that the successes of a HIV and AIDS Community Training Partnership Programme (CTPP) implemented in five diamond mining areas in three provinces of South Africa were related to capacity building of trainers.

\subsection{Participation, Acceptance and Ownership}

Acceptance of the intervention from an Islamic prospective: The real challenge facing HIV interventions and any related sex education among young people is how to address sexuality and use of condoms without being confrontational with Islamic teachings. This challenge is a common issue whether they are located in the Middle East (DeJong \& El-Khoury, 2006), Asia (Bennett, 2007), Africa (Maulana, Krumeich, $\&$ van den Borne, 2009) or even among Moslem young people in Europe (Smerecnik, Schaalma, Kok, Meijer, \& Poelman, 2010). 
The acceptance of the HIV interventions among young people in schools and communities was inherently related to the fact that the interventions did not challenge religious teachings. The main slogan of the interventions, which was formulated by peer educators, was stated as "Protect yourself from HIV with Abstinence and Knowledge". Abstinence in Arabic, Iffa, refers to abstinence from sex before marriage, as well as abstinence from sex outside wedlock. Knowledge, as interpreted by peer educators, is the knowledge on protection, which included the use of condoms. However, details on condoms are discussed during peer education session, but in public, the "Abstinence" is what is highlighted. This has been really critical to market the peer education activities at community level, where many fundamentalist groups exist.

As discussed earlier, the IEC material and messages were culturally sensitive. In addition, the fact that the IEC material quoted text from the Quran that calls for protection and tolerance, as well as from Prophet Mohamed teachings, which call for being proactive to pass useful messages (here this was used to promote the idea of peer education), had made community members feel comfortable that the interventions were not western teachings aiming towards confronting religious values.

Acceptance and participation by school stakeholders: The capacity building opportunities with training and advocacy workshops of school principals and school social workers had created an enabling environment for the intervention. Their high acceptance for the peer intervention has facilitated implementation at classroom level as well as acceptance from families. School coordinators, who have acted as resource persons for hard-to-answer questions at classroom level, had contributed to the success of implementation. This is in line with existing research, which documents the important role of adult support in school-based peer education (Strange, Forrest, Oakley, \& the RIPPLE Study Team, 2002; Visser M. , 2007).

Acceptance by parents of school peer education: The high acceptance of the intervention by parents was mainly due to the key role of the school coordinators and the project coordinator in advocating with families. Interestingly, the main concern was not education on HIV prevention, but rather the potential adverse effect on scholastic achievement as perceived by parents. This is an important finding, as the schoolbased peer education has been labelled by the Education Office in Aden as life skills and peer education programme rather than a sex education programme. Labelling as a 'sex education' programme might have doomed the failure of peer education inter- 
vention in the context of Yemeni schools. This "life skills" label of the intervention was also the sentiment which came forward from interviews with school principals and social workers. Moreover, peer education, and as revealed by the process evaluation, was perceived by parents as a capacity building opportunity for their children.

Acceptance and participation by targeted young people: The fact that the majority of young people in schools and communities considered peer education sessions beneficial and had appreciated the participatory nature of the sessions reflects the important role of peer educators in the successful implementation of peer education sessions. It also emphasizes the fidelity of the programme. Previous research has also shown that peer led intervention were more effective when they were participative and skills based (Oakley, Strange, Bonell, Allen, Stephenson, \& the RIPPLE Study Team, 2006).

Participation, Acceptance and Ownership of Key stakeholder in communities: Community participation and the involvement of local council members, had given the programme a "legal" code. Having one of the community focal points from the local council also supported the intervention politically. The role of the coordinating community based organization and the civil society organization had been crucial in pulling all parts of the intervention together. The fact that all the peer educators and community focal points were selected from the same communities was an important aspect of the intervention as it assured that no stranger is coming to their areas. It should also be noted that key community stakeholders were part of the selection panel for recruiting peer educators and community focal points, which created a further sense of ownership, as they were involved in each and every step of the intervention.

Previous research has highlighted the importance of community participation in the success of peer education activities (Cornish \& Campbell, 2009; Campbell, Nair, \& Maimane, 2007; Kinsman, et al., 2002). The head of the community based organization (CBO) (Social Services Community Centre), who was also the overall project supervisor, had a key role in ensuring community participation and mobilization, and in the overall success of the project. Previous research had documented the important role of having a committed project supervisor in the community based HIV intervention (Evans \& Lambert, 2008). The coordinating CBO's credibility in the neighbourhoods was one of the essential elements that enabled community focal points to pursue their work. Outreach had been a solution to overcome difficulties 
related to conducting in-door peer education sessions, and had built the experience of community focal points and peer educators. It also introduced the intervention to the community and linked it to respectable places in neighbourhoods. Shifting to outreach peer education had been crucial to target hard-to-reach high-risk groups, especially for reaching female sex workers as well as young men, who were not willing to give-up their Qat (Khat) chewing for peer education sessions.

Participation of Young People from Marginalized Group (Al-akhdam): A common feature in the four targeted communities is the presence of marginalized groups, or as called in Yemen, Al-akhdam. Marginalized groups in Yemen, Al-akhdam, which literally means servants, are a social group distinct from the majority by their more African features. As a low caste group, they are sometimes discriminated against and mostly confined to menial jobs. In Yemen, they are popularly believed to be the descendants of Ethiopian soldiers of the Aksumite Empire that occupied Yemen more than 1500 years ago and who remained there as servants of the local population after the occupation ended. Al-akhdam are stereotyped as dishonourable, immoral, dependent and dirty (Al-Ahmadi \& Beatty, 1997). Al-akhdam are also known to have high risk sexual behaviour, which makes them a most-at-risk group to HIV infection. It is rarely that Al-akhdam adolescents and youth are included in any programmes or interventions with other segments of the society. The community peer education was a unique opportunity for Al-akhdam young people to meaningfully participate by being trained as peer educators and community focal points, along with their nonmarginalized peers. The fact that the coordinating $\mathrm{CBO}$ recruited community focal points from local NGOs representing marginalized groups, had led to targeting the hard-to-reach marginalized groups through outreach peer education activities. The community-based nature of the intervention made it possible to target a most-at-risk population like Al-akhdam without stigmatizing them, because they were included as part of the community and were not targeted as a standalone population.

\subsection{Diffusion of Innovations as a cultural sensitive theoretical framework}

The use of Diffusion of Innovations (DOI) in the development, implementation and evaluation of the school and community based HIV prevention programmes has been compatible with the cultural sensitive aspects of the interventions. DOI is largely a sociological theory that uses social roles, norms, and networks to explain behaviour (Kegler \& Glanz, 2008). Roger's basic definition of the elements of DOI includes: 1 . an innovation; 2 . communicated via certain channels; 3 . over a period of 
time, 4. to members of social system (Rogers, 2003). The following paragraphs will focus on the application of the four key elements of DOI in this dissertation:

The characteristics of the innovation itself - Rogers' theory posits that an innovation is more likely to be adopted if it is perceived as having relative advantage, high compatibility with the values and norms of the potential adopters, high trialability, high observability, and less complexity. The development of culturally sensitive peer education messages and training framework, which was compatible with Islamic teachings have been key in the acceptance, and thus the adoption of the interventions. The vigorous field testing of the messages and IEC (Information, Education, and Communication) material had ensured that they are comprehendible to young people in and out schools. The main slogan of the interventions, which was printed on all IEC material "Protect yourself from HIV with Abstinence and Knowledge" stated the relative advantage of the intervention, which is protection from HIV. This slogan also re-iterated the compatibility with Islamic teachings that calls for abstinence.

The communication channels to be selected for sharing information about the new idea-one of the most important determinants of success according to DOI theory is the degree of homophily (or similarity) between the change agents (peer educators) and the clients (young people in and out of schools) (Rogers, 2003). DOI therefore maintains that the most effective communicators are properly trained popular opinion leaders. The vigorous selection and training of peer educators in schools and communities had ensured that potential youth opinion leaders were recruited as peer educators, who also represented the community mainstream cultural values.

The time and differential adoption of decision makers - The innovation-decision process is the process through which a targeted audience or a decision making unit passes from gaining initial knowledge of an innovation, to forming an attitude toward the innovation, to a decision to adopt or reject it, to implementation of the new idea, and to confirmation of this decision (Rogers, 2003). The early adoption by the school coordinators and the community based organization coordinator have facilitated the adoption by other key stakeholders at community and school level (Oldenburg \& Glanz, Diffusion of Innovations, 2008). The high-quality life skills based training of school and community coordinators had facilitated the innovation-decision process, and accelerated the rate of adoption. 
The social system to which the individuals belong - DOI aims to describe the processes involved in encouraging a social system to adopt a new idea or intervention. Diffusion concepts emphasize the importance to address the context in which behaviour change must take place. In this dissertation, the community-based interventions focused on creating an enabling environment by advocacy with local councils and religious leaders; and partnership with community-based organizations and nongovernmental agencies. The school-based interventions focused on creating an enabling environment for HIV prevention activities in schools by advocacy with parents; training of school supervisor, social workers, and school management teams. The existence of an enabling environment has been key to the adoption of interventions.

\section{Limitations}

\subsection{The Quasi-experimental design}

Randomized Controlled Trials (RCTs) are usually considered the golden standard in evaluation research. A Randomized Controlled Trial was not possible, but instead a quasi-experimental design was used in evaluating school and community based interventions. In schools, randomization was not feasible as it was considered interfering with internal school affairs and was considered un-ethical by the implementing as well as the funding organizations. Assignment of students to the intervention condition was based on the time table for extra-curricular activities, where every two weeks around 25 "new" students per school participated in the sessions. The planning of students for extra-curricular activities was indiscriminate, and no systematic selecting of students took place.

In communities randomization was also not possible given the inter-linkages between the four neighbouring targeted communities, which were geographically and socially inter-linked. Also, the randomization was not accepted by the local authorities, implementing CBOs and NGOs, as well as the funding organization. Assignment of young people at community level to the intervention condition was based on the outreach work done by the community focal points and the CBOs and NGOs in the four targeted neighbourhoods. The criteria applied by CBOs and NGOs were age and place of residence; only those living in the targeted neighbourhoods, and of the age group 15-24 years were targeted with peer education, while ensuring to target equal numbers of male and female youth. 
It is well known that there are methodological limitations related to quasiexperimental designs, where internal validity is a concern because of the lack of randomization among intervention and control groups (Shadish, Cook, \& Campbell, 2002). However, several measures were undertaken to improve the similarities between cases and controls. The fact that students from the same schools were cases and controls decreased the non-equivalency between them. Also, the 2005 school baseline was used as a cohort control group, which helped to increase the internal validity of the study. Similarly, in the community based interventions, young people from the same communities were cases and controls decreased the non-equivalency between them. Also, the 2005 community baseline was used as a cohort control group, which helped to increase the internal validity of the study (Shadish, Cook, \& Campbell, 2002). Another factor, which contributed to increasing internal validity, was the randomization and large size of study samples used for evaluations. In 2005, the school baseline included 2274 students who were randomly selected from the 27 high schools. The school evaluation in 2008 included 2510 from the same 27 schools. The 2005 community baseline included 601 young people randomly selected from the four targeted areas. The 2008 community evaluation included 700 young people from the same four targeted areas.

\subsection{Sexual behavioural outcomes}

The school evaluation did not measure the impact on sexual behaviour, as peer educator and targeted students were not asked direct questions on the effect of the peer education and life skills on their sexual behaviour. This is because discussing sexual behaviour in schools is very difficult due to the conservative educational system which aims to protect social and cultural norms. There might be a missing link between the consequence of having such a large improvement in life skills among school peer educators and how it was translated in adoption of less risky behaviour or in continuing non-risky behaviour (Flisher, Ahmed, Jansen, Mathews, Klepp, \& Schaalma, 2009; Yankah \& Aggleton, 2008). In the community evaluation, and although questions on changes in sexual behaviour were asked, the nature of the evaluation design, which was a household survey, was not the ideal environment for young people to report on such changes. This is especially true for female youth, where mothers and older sisters in several instances were insisting to be present during the data collection, in spite that all data collectors interviewing female youth were 
females. This might be the reason why males reported more behavioural modifications than females.

\subsection{Generalizability of Results}

The fact that the school and community based interventions were conducted in Aden governorate, does not necessarily mean that the findings can be generalized to all of Yemen. Aden governorate is an urban setting, while $75 \%$ of the Yemeni population is living in rural areas (Central Statistics Organization, Yemen Statistical Year Book., 2009). Moreover, although Aden is still a conservative Yemeni setting, it is far less conservative than other Yemeni governorates, given the influence of the long years of colonization by the British Empire, as well as the history of being a communist state for tens of years. However, one can argue that the mean age of students in schools was 17 years and 19 years in communities, which means that they were born after the unification between south and north Yemen (May, 1990). Therefore, young people were raised within the same political context with other northern governorates.

Despite all of the mentioned limitations, the studies in this dissertation yields relevant findings for HIV prevention among youth in Yemen, as well as highlights the significance of life skills and peer education methodologies for HIV prevention.

\section{Recommendations}

\subsection{Recommendations for programme design and implementation}

Based on the results of the studies reported in this thesis it is recommended to continue school and community based peer education among young people in Aden, and also to be introduced to other governorates, while keeping in mind lessons learned and documented in our studies. In fact these interventions provide lessons learned to be replicated in similar conservative settings of the Arab and Islamic world. For future sustainable effects, HIV education should be integrated in extra-curricular activities, as studies have indicated that an integrated school approach, especially with long-term implementation of prevention programmes, is likely to be more effective (Leurs, Schaalma, Jansen, Mur-Veeman, Leger, \& De Vries, 2005). Counselling services at school level should also be provided by school social workers to tackle overall 
sexual issues that are related to sexual abuse, exploitation and high risk sexual activity.

Community-based interventions, as revealed in this dissertation, could be a successful entry point to reach young people in very conservative settings, and the results could be used for scaling up similar interventions among other poor and high risk communities in Yemen, as well as in countries of similar context, given the presence of community based organizations that can facilitate the whole process. However, these interventions should also be synergized with other culturally sensitive services, and should always aim to close the gender gap in knowledge, skills, and risk perception between female and male youth.

While this research has indicated that community based peer education has proven to be successful for youth from different populations and for those who are vulnerable to HIV infection in high risk areas, the intervention should be tailored if it is to be replicated to reach high-risk youth groups. Linking high-risk groups, such as FSWs, to sexually transmitted infection clinics and VCT services and the creation of livelihoods for these groups, are key to address HIV prevention. Moreover, FSWs should be trained as peer educators to outreach to their peers (Cornish \& Campbell, 2009; Evans \& Lambert, 2008; Luchters, et al., 2008)

However, we should always keep in mind that peer education and life skills should not be regarded as a magic potion or cure-it-all, but it can function effectively amidst other interventions (Visser M. , 2007; Yankah \& Aggleton, 2008). Tackling root causes of poverty, gender and education disparities, and addressing unemployment and creating safe leisure options are key to sustainable HIV prevention among young people in Yemen.

\subsection{Recommendation for policy development}

Implementation of the Yemeni National Strategy for Children and Youth, which calls for the protection and development of all children and youth in Yemen, and which clearly calls for HIV prevention among adolescents and young people in and out of schools, is key to decrease risks and vulnerabilities among adolescents and young people. 
It is also recommended that life skills education, which also links to HIV prevention as well as culturally appropriate and Islamic compatible sex education, is integrated within the Yemeni school curriculum as a long term strategy. This integration requires policy development by the Ministry of Education and the gap in the short term should be filled through integration in extra-curricular activities (as mentioned in $5.1)$

Education is still the most determining factor to achieve a sustained and long-term strategy to combat HIV among young people (Bastien, 2008). Community-based HIV prevention programmes in Yemen, where only $62.2 \%$ of children of 6-15 years are enrolled in schools (Central Statistics Organization, Yemen Statistical Year Book., 2009), with a huge gender gap, should also focus on re-integration of drop outs in schools and enrolling older adolescents in adult literacy classes (Dyer, 2007), with a special focus on girls education, given the huge gender gap in enrolment between girls and boys. It is well documented that not going to school, or leaving school early, at a life stage characterized by change and experimentation with potential risk behaviours, may be associated with a host of ill social, health and economic consequences. These might include alcohol and substance abuse, early marriage and sexual debut, unwanted or unintended pregnancy, unsafe abortion, sexually transmitted infections (STIs) including HIV, exploitation, violence and limited employment prospects (Bastien, 2008).

\subsection{Recommendations for future research}

Three main areas of research are recommended to be conducted, which were beyond the scope of this dissertation. These areas are: (1) A national Youth Risk Assessment Survey; (2) Behavioural \& biological (HIV sero-prevalence) surveillance and studies among most-at-risk groups; (3) and a national HIV sero-prevalence survey among the general population.

A youth risk assessment survey, which could be conducted every two or four years, would be a valuable tool in the context of Yemen, where there is much more to learn on the risks and vulnerabilities associated with adolescents and young people in Yemen. Such a survey, although research tools are available from other countries, should be tailored to the Yemeni context. The survey should not only focus on youth vulnerabilities and risks to HIV, but also sexually transmitted infections, alcohol abuse, and Qat (Khat) consumption. Khat, a green shrub, which is a mild narcotic 
with amphetamine-like effects, is widely chewed by Yemeni youth. Previous research had conflicting conclusions on whether Khat could be a risk factor for HIV infection (Beckerleg, 2010; Kebede, et al., 2005), and thus this issue has to be further explored within the context of a youth risk assessment survey.

Behavioural and biological surveillance of HIV sero-prevalence studies among mostat-risk groups should be established periodically. A prerequisite to such studies is a national wide mapping of most-at-risk groups, i.e., female sex workers (FSW), male sex workers (MSW), men who have sex with men (MSM), and intravenous drug users (IDU). Such studies should not be focusing only on sexual behaviour, but also on Intravenous Drug Use (IDU). Although Yemen is known to have no reported cases due to IDU, this study indicated that IDU exists in the neighbourhoods investigated in this study, and therefore future research on this issue is needed. An HIV sero-prevalence survey among the general population will reveal the real epidemiological profile of HIV in Yemen, as until now, we only know the estimated HIV seroprevalence (UNAIDS, UNGASS Yemen Progress Report on HIV and AIDS., 2010). To ensure cost effectiveness, such a sero-prevalence survey could be conducted in combination with other population based sero-prevalence studies, e.g. a hepatitis B survey, which is known to be a major cause of mortality and morbidity in Yemen (Sallam, Cuevas, \& Tong, 2003).

\section{Conclusion}

The studies in this dissertation, which included 6221 Yemeni adolescents and young people from schools and communities, revealed that peer education and life-skills based education is an effective methodology for HIV prevention in a very traditional Moslem setting. The findings demonstrated that the interventions were addressed in a culturally sensitive manner, and involved all key stakeholders from early stages of the interventions. The "life skills" labelling was key in the acceptance of the intervention in such a very conservative setting like Yemen. The results from this evaluation could be useful in replicating or implementing future community-based peer education interventions in similar conservative Muslim and Arab settings. 


\section{Current Status of the peer and life skills interventions in Yemen}

Although the evaluations of the peer and life skills interventions were conducted between October 2008 and March 2009, there were initial success indicators that created a demand to scale up the interventions beyond Aden Governorate. On-going field monitoring, which indicated the high acceptance and benefit of the interventions among all stakeholders, had led to scaling up the interventions into new geographic areas and more target groups (UNICEF, 2007; UNICEF, 2008-a; UNICEF, 2009)

In 2007, and after two years of implementation of the community and school based peer education, the interventions were scaled-up to include two additional areas in Aden (Maalla and Seera) and three more governorates (Sana'a, Hodeida, and Taiz). There was a shift in 2007 from the conventional peer education and life skills sessions to focus more on outreach activities to most at- risk groups, including street children and children in juvenile care centres, who were also trained on conveying HIV messages through puppet theatre (UNICEF, 2007). In 2008, the interventions were further scaled up to reach 40,892 children and young people with life skills and HIV peer education; 10,745 of them were targeted in Schools, 28,663 in poor neighbourhoods, 870 in street children centres, 480 in juvenile care centres and 40 in orphanages (UNICEF, 2008-a). In 2009, peer education and life skills interventions were scaledup to include an additional governorate (Hadhramout) in addition to the four governorates of Aden, Sana'a, Taiz and Hodeida, and 84,000 young people were reached by peer educators (UNICEF, 2009; UNICEF, 2010).

At national level, the school and community based peer education interventions in Aden, have led to the endorsement of the National Youth Life Skills and Peer Education Manual by the Ministry of Youth, and will be mainstreamed in all scouts and guides trainings as well as in the sports and youth clubs at national level (UNICEF, 2008-b). In addition, the Ministry of Education has integrated life skills in the national teachers' training manual, and has initiated the training of 110 educational leaders on the life skills component as an initial capacity building step for educational leaders at national and governorate level. Peer education and life skills education has been also included in the National Strategy for Children and Youth Action Plan, which was endorsed by the government cabinet in 2007. In addition, peer education has created a demand for establishing VCT services (UNICEF, 2009). 
The school and community peer education interventions showed that successful small-scale pilot projects may lead to broader implementation endorsed at policy and strategic levels. They also indicate that interventions related to youth HIV prevention in conservative settings are better to be started at a small scale and then to be expanded, especially given the sensitivities related to HIV education and prevention. 


\section{References}

Aaro, L., Flisher, A., Kaaya, S., Onya, H., Fuglesang, M., Klepp, K., et al. (2006). Promoting sexual and reproductive health in early adolescence in South Africa and Tanzania: Development of a theory- and evidence-based intervention programme. Scandinavian Journal of Public Health, 34, 150-158.

Abu-Raddad, L. J., Akala, F. A., Semini, I., Riedner, G., Wilson, D., \& Tawil, O. (2010). Characterizing the HIV/AIDS epidemic in the Middle East and North Africa: Time for Strategic Action. Middle East and North Africa HIV/AIDS Epidemiology Synthesis Project. Washington DC: World Bank/UNAIDS/WHO.

Abu-Raddad, L. J., Hilmi, N., Mumtaz, G., Benkirane, M., Akala, F. A., Riedner, G., et al. (2010). Epidemiology of HIV infection in the Middle East and North Africa. AIDS, 24 (Suppl 2), S5-23.

AFHS Ministry of Health and Population. (2003). the PanArab Project for Family Health.

Agha, S., \& van Rossem, R. (2004). Impact of a schoolbased peer sexual health intervention on normative beliefs, risk perceptions, and sexual behavior of Zambian adolescents. J Adolesc Health, 34 (5), 441-52.

Al-Ahmadi, A., \& Beatty, S. (1997). Participatory Socioeconomic Needs Survey of the Sana'a Urban Settlements Dwellers with Special Reference to Women. Sana'a: Oxfam, Yemen.

Al-Iryani, B., Al-Sakkaf, K., Basaleem, H., Kok, G., \& Borne, B. v. (In Press). Process evaluation of a threeyear community-based peer education intervention for HIV prevention among Yemeni young people. International Quarterly of Community Health Education.

Al-Iryani, B., Basaleem, H., Al-Sakkaf, K., Crutzen, R., Kok, G., \& Borne, B. v. (In Press). Evaluation of a School-Based HIV Prevention Intervention for Yemeni Adolescents. BMC Public Health.

Al-Iryani, B., Basaleem, H., Al-Sakkaf, K., Kok, G., \& Borne, B. v. (Submitted-a). Process Evaluation of School-Based Peer Education for HIV Prevention among Yemeni Adolescents.

Al-Iryani, B., Basaleem, H., Al-Sakkaf, K., Kok, G., \& van den Borne, B. (In Press). A Quasi-Experimental Evaluation of A Three-Year Community-Based Peer Education Intervention For HIV Prevention Among Yemeni Young People.

Al-Iryani, B., Raja'a, Y. A., Kok, G., \& van den Borne, B. (2010). HIV Knowledge and Stigmatization among Yemeni Adolescents in Schools. International Quarterly of Community Health Education, 30 (4), 311-320.

Al-Nabulsi, K. (2004). Its about Time: Percpectives and Aspirations of Yemeni Young People. UNICEF, The Social Fund for Development, The World Bank.

Al-Serouri, A., \& Takioldin, M. (2002). Knowledge, attitudes and beliefs about HIV/AIDS in Sana'a, Yemen. Eastern Mediterranean Health Journal, 8 (6), 706-715. 
Al-Serouri, A., Anaam, M., Al-Iryani, B., Ramaroson, S., \& Al-Deram, A. (2010). AIDS Awareness and Attitudes among Yemeni Young People Residing in High Risk Areas. Eastern Mediterranean Health Journal, 16 (3), 242-250.

Al-Syaghi, K. (2008, May 31). culture and society. Retrieved November 2010, from www.yobserver.com: http://www.yobserver.com/culture-and-society/10014361.html

Assaad, R., Barsoum, G., Cupito, E., \& Egel, D. (2009). Youth Exclusion in Yemen:Tackling The Twin Deficits Of Human Development And Natural Resources. Wolfensohn Center For Development/Dubai School Of Government.

Barss, P., Grivna, M., Ganczak, M., Bernsen, R., \& Al-Maskari, F. (2009). Effects of a Rapid Peer-Based HIV/AIDS Educational Intervention on Knowledge and Attitudes of High School Students in a HighIncome Arab Country. J Acquir Immune Defic Syndr, 52 (1), 86-98.

Bastien, S. (2008). Out-of-school and 'at risk'? Socio-demographic characteristics, AIDS knowledge and risk perception among young people in Northern Tanzania. International Journal of Educational Development, 28, 393-404.

Beckerleg, S. (2010). East African discourses on khat and sex. Journal of Ethnopharmacology, doi:10.1016/j.jep.2010.08.057.

Bekele, A., \& Ali, A. (2008). Effectiveness of IEC interventions in reducing HIV/AIDS related stigma among high school adolescents in Hawassa, Southern Ethiopia, Ethiop. Ethiop.J.Health Dev, 22 (3), 232-242.

Bennett, L. R. (2007). Zina and the enigma of sex education. Sex Education, 7 (4), 371-386.

Bertens, M. G., Eiling, E. M., van den Borne, B., \& Schaalma, H. P. (2008). Uma Tori! Evaluation of an STI/HIV Prevention Intervention for Afro-Caribbean Women in the Netherlands. Patient Education and Counseling.

Bertrand, J. (2004). Diffusion of Innovations and HIV/AIDS. Journal of Health Communication, 9 (6), 113 $-121$.

Busulwa, R. (2003). HIV/AIDS situation analysis study, conducted in Hodeidah, Taiz, Aden and Hadhramut, Republic of Yemen. Sana'a: United Nations Development Programme/World Health Organization/National AIDS Program, Ministry of Health and Population.

Busulwa, R., Takiyaddin, M., Azzubeidi, A., El Zein El Mousaad, H., Tawillah, J., \& Ziady, H. (2006). Perceptions of the condom as a method of HIV prevention in Yemen. Mediterranean Health Journal, 12 (Supplement 2), S64-S77.

Campbell, C., Nair, Y., \& Maimane, S. (2007). Building contexts that support effective community responses to HIV/AIDS: a South African case study. Campbell, C., Nair, Y., Maimane, S. (2007) Building contexts that support effective community responses to HIV/AIDS: a South African case study. Am J Community Psychol, 39, 347-363, 39, 347-363.

Central Statistical Organization-HBS. (2005/2006). Household Budget Survey. Central Statistical Organization, Sana'a: Republic of Yemen.

Central Statistics Organization, Y. (2009). Yemen Statistical Year Book.

Central Statistics Organization, Y. (2009). Yemen Statistical Year Book.

Chakraborty, K. (2010). The sexual lives of Muslim girls in the bustees of Kolkata, India. Sex Education, 10 (1), DOI: 10.1080/14681810903491339.

Chhabra, R., Springer, C., Rapkin, B., \& Merchant, Y. (2008). Differences among male/female adolescents participating in a school-based teenage education programme (STEP) focusing on HIV prevention in India. Ethn Dis., 18 ( (Suppl 2)), 123-7. 
Chiao, C., Mishra, V., \& Sambisa, W. (2009). Individual-andcommunity-leveldeterminantsof social acceptance of people living with HIV in Kenya:Results from a national population-based survey. Health \&Place, 15, 742-750.

Coates, T. J., Richter, L., \& Caceres, C. (2008). Behavioural strategies to reduce HIV transmission: how to make them work better. The Lancet, DOI:10.1016/S0140-6736 (08)60886-7.

Cornish, F., \& Campbell, C. (2009). The social conditions for successful peer education: A comparison of two HIV prevention programs run by sex workers in India and South Africa. Am J Community Psychol, 4, 123-135.

DeJong, J., \& El-Khoury, G. (2006). Reproductive health of Arab young people. BMJ, 333, 849-51.

Dyer, C. (2007). Working children and educational inclusion in Yemen. 27, 512-524.

Ebreo, A., Feist-Price, S., Siewe, Y., \& Zimmerman, R. (2002). Effects of peer education on the peer educators in a school-based HIV prevention program: Where should peer education research go from here? Health Education \& Behavior, 29, 411-423.

Elford, J., Sherr, L., Bolding, G., Serle, F., \& Maguire, M. (2002). Peer-led HIV prevention among gay men in London: Process evaluation. AIDS Care, 14 (3), 351- 360.

Evans, C., \& Lambert, H. (2008). Implementing community interventions for HIV prevention: Insights from project ethnography. Social Science \& Medicine, 66, 467-478.

Fernandez, D., Figueroa, W., Gomez, M. L., Maysonet, J., Olivaers, E., \& Hunter, R. (2004). Changes in HIV/AIDS knowledge among adolescents in Puerto Rico. Ethn Dis, 18 (Suppl 2), 146-150.

Flisher, A., Ahmed, N., Jansen, S., Mathews, C., Klepp, K., \& Schaalma, H. (2009). Process evaluation of a school-based HIV/AIDS intervention in South Africa Wanjiru Mukoma. Scand J Public Health, 37, S37-47.

Gallant, M., \& Maticka-Tyndale, E. (2004). School-based HIV prevention programmes for African youth. Social Science and Medicine, 58, 1337-1351.

Ghys, P. D.-T. (2002). Increase in condom use and decline in HIV and sexually transmitted diseases among female sex workers in Abidjan, Cote d' Ivoire. AIDS, 16, 251-258.

Hagquist, C., \& Starrin, B. (1997). Perspectives: Health Education in school- from information to empowerment models. Health Promot Int, 12 , 225-32.

Harper, G., Bangi, A., Sanchez, B., Doll, M., \& Pedraza, A. (2009). A Quasi-Experimental Evaluation of a Community-Based HIV Prevention Intervention for Mexican American Female Adolescents: The SHERO's Program AIDS Education and Prevention. AIDS Education and Prevention, 21 (Supplement B), 109-123.

Harrison, A., Smith, J., \& Myer, L. (2000). Prevention of HIV/AIDS in South Africa: A review of behaviour change interventions, evidence and options for the future. South African Journal of Science, 96 (6), $285-291$.

Harvey, B., Stuart, J., \& Swan, T. (2000). Evaluation of a drama-in-education program to increase AIDS awareness in South African high schools: A randomized community intervention trial. International Journal of STD and AIDS, 11 (2), 105-111.

Hausmann, R., Tyson, L. D., \& Zahidi, S. (2009). The Global Gender Gap Report. Retrieved July 2010, from World Economic Forum, Geneva, Switzerland.: [http://www.weforum.org/pdf/gendergap/report2009.pdf]

IRIN, t. h. (2010). IRIN-Humanatarian News and Analysis. Retrieved November 2010, from www.irinnews.org: http://www.irinnews.org/Report.aspx?ReportId=72906

James, S., Reddy, P., Ruiter, R., Mccauley, A., \& van den Borne, B. (2006). The impact of an HIV and AIDS life skills program on secondary school students in Kwazulu-Natal, South Africa. AIDS Education and Prevention, 18, 281-294. 
Kebede, D., Alem, A., Mitike, G., Enquselassie, F., Berhane, F., Abebe, Y., et al. (2005). Khat and alcohol use and risky sex behaviour among in-school and out-of-school youth in Ethiopia. BMC Public Health, 5 (109), doi:10.1186/1471-2458-5-109.

Kegler, M., \& Glanz, K. (2008). Perspectives on group, organizational, and community interventions. In K. Glanz, B. Rimer, \& K. Viswanath, Health Behavior and Health Education- Theory Research, and Practice (4th ed., pp. 389-403). San Francisco: Jossey-Bass.

Kelly, J. A., Lawrence, J. S., Diaz, Y. E., Stevenson, L. Y., Hauth, A. C., Brasfiel, T., et al. (1991). HIV Risk Behavior Reduction following Intervention with Key Opinion Leaders of Population: An Experimental Analysis. American Journal for Public Health, 81 (2), 168-171.

Kinsler, J., Sneed, C., Morisky, D., \& Ang, A. (2004). Evaluation of a school-based intervention for HIV and AIDS prevention among Belizean adolescents. Health Education Research, 19 (6), 730-738.

Kinsman, J., Kamali, A., Kanyesigye, E., Kamulegaya, I., Basajja, V., Nakiyingi, J., et al. (2002). Qualitative process evaluation of community-based HIV/AIDS Behavioural intervention in rural Uganda. Health Education Research, 17, 253-265.

Kinsman, J., Nakiyingi, J., Kamali, A., Carpenter, L., Quigley, M., \& Pool, R. (2001). Evaluation of a comprehensive school-based AIDS education program in rural Masaka,Uganda. Health Education Research, 16, 85-100.

Klepp, K., Ndeki, S., Leshabari, M., Hannan, P., \& Lyimo, B. (1997). AIDS education in Tanzania: Promoting risk reduction among primary school children. American Journal of Public Health, 87 (12), 19311936.

Kreuter, M. W., \& Mcclure, S. M. (2004). The Role Of Culture In Health Communication. Annual Review Of Public Health, 25, 439-455.

Kreuter, M. W., Lukwago, S., Clark, E. M., \& Sandersthompson, V. (2003). Achieving Cultural Appropriateness In Health Promotion Programs: Targeted And Tailored Approaches. Health Education\& Behavior, 30 (2), 133-146.

Leurs, M. T., Schaalma, H. P., Jansen, M. W., Mur-Veeman, I. M., Leger, L. H., \& De Vries, N. (2005). Development of a collaborative model to improve school health promotion in the Netherlands. Health Promotion International, 20 (3), 296-305.

Li, S., Huang, H., Cai, Y., Ye, X., Shen, X., Shi, R., et al. (2010). Evaluation of a school-based HIV/AIDS peer-led prevention programme: the first intervention trial for children of migrant workers in China. Int J STD AIDS, 21 (2), 82-6.

Library of Congress. (2008). Yemen country profile. Retrieved July 2010, from Library of Congress - Federal Research Division: http://memory.loc.gov/frd/cs/profiles/Yemen.pdf

Luchters, S., Chersich, M., Rinyiru, A., Barasa, M., King'ola, N., Mandaliya, K., et al. (2008). Impact of five years of peer-mediated interventions on sexual behavior and sexually transmitted infections. BMC Public Health, 8 (143), doi:10.1186/1471-2458-8-143.

Maas, F. v., \& Otte, W. (2009). Evaluation of HIV/AIDS secondary school peer education in rural Nigeria. Health Educ Res, 24 (4), 547-57.

Markham, C., Basen-Engquist, K., Coyle, K., Addy, R., \& Parcel, G. (2002). Safer Choices, a school-based HIV, STD and pregnancy prevention program for adolescents. In A. a. Steckler, \& 1st (Ed.), Process evaluation for public health intervention and research (pp. 209-238). San Fransisco: Jossey-Bass.

Martinez-Donate, A., Hovell, M., Zellner, J., Sipan, C., Blumberg, E., \& Carrizosa, C. (2004). Evaluation of two school-based HIV prevention interventions in the border city of Tijuana, Mexico. Journal of Sex Research, 41 (3), 267-278.

Maticka-Tyndale, E., \& Barnett, J. (2010). Peer-led interventions to reduce HIV risk of youth: A review. Evaluation and Program Planning, 33, 98-112. 
Maulana, A. O., Krumeich, A., \& van den Borne, B. (2009). Emerging discourse: Islamic teaching in HIV prevention in Kenya. Culture, Health \& Sexuality, 11 (5), $559-569$.

Medley, A., Kennedy, C., O’Reilly, K., \& Sweat, M. (2009). Effectiveness of Peer Education Interventions for HIV Prevention in Developing Countries: A Systematic Review and Meta-Analysis. AIDS Education and Prevention, 21 (3), 181-206.

Merakou, K. (2006). Peer education in HIV prevention: an evaluation in schools. The European Journal of Public Health, 16 (2), 128-132.

Milburn, K. (1995). A critical review of peer education with young people with special reference to sexual health. Health Education Research, 10 (4), 407-420.

Mukoma, W. (2001). Rethinking school-based HIV/AIDS interventions in South Africa. Southern African Journal of Child and Adolescent Mental Health, 13 (1), 55-66.

National AIDS Programme. (2004). HIV/AIDS Surveillance Report, Yemen-fourth quarter.

National AIDS Programme. (2009). HIV/AIDS surveillance report Yemen- fourth quarter.

National AIDS Programme. (2010). HIV/AID surveillance report, Yemen- third quarter. Sana'a.

Norr, K., Norr, J., McElmurry, B., \& Moeti, M. (2004). Impact of Peer Group Education on HIV Prevention Among Women in Botswana. Health Care for Women International, Norr, K.F., Norr, J.L., McElmurry, B.J., Moeti, M.R. (2004). Impact of Peer Group Education on HIV Prevention 25, 210-226.

Oakley, A., Strange, V., Bonell, C., Allen, E., Stephenson, J., \& the RIPPLE Study Team, a. (2006). Process evaluation in randomised controlled trials of complex intervention. Oakley, A., Strange, V., Bonell, C., Allen, E., Stephenson, J. \& the RIPPLE StudyBMJ, 332, 413-416.

Oldenburg, B., \& Glanz, K. (2008). Diffusion of Innovations. In K. R. Glanz, \& K. B. Viswanath, Health Behavior and Health Education- Theory Research, and Practice (4th ed., pp. 313-330). San Francisco: Jossey-Bass.

Oldenburg, B., \& Glanz, K. (2008). Diffusion of Innovations. In K. R. Glanz, \& K. B. Viswanath, Health Behavior and Health Education- Theory Research, and Practice (4th ed., pp. 313-330). San Francisco: Jossey-Bass.

Orroth, K., Gavyole, A., Todd, J., Mosha, F., Ross, D., \& Mwijarubi, E. (2000). Syndromic treatment of sexually transmitted diseases reduces the proportion of incident HIV infections attributable to these diseases in rural Tanzania. AIDS, 14, 1429-1437.

Oshi, D., \& Nakalema, S. O. (2005). Cultural and social aspects of HIV/AIDS sex education in secondary schools in Nigeria. J Bio.Soc Sci., 37 (2), 175-83.

Ozcebe, H., Akin, L., \& Aslan, D. (2004). Peer education example on HIV/AIDS at a high school in Ankara. Turk J Pediatr, 46 (1), 54-9.

Paine, K., Hart, G., Jawo, M., Jallow, M., Morison, L., \& Walraven, G. (2002). Before we were sleeping, now we are awake: Preliminary evaluation of the Stepping Stones sexual health program in the Gambia . African Journal of AIDS Research, 1 (1), 39-50.

Parker, R. G., Easton, D., \& Klein, C. H. (2000). Structural Barriers and Facilitators in HIV Prevention: A Review of International Research. AIDS, 14 (1), S22-S32.

Resnicow, K., Baranowski, T., Ahluwalia, J. S., \& Braithwaite, R. L. (1999). Cultural Sensitivity In Public Health: Defined And Demystified. Ethnicity \& Disease, 9 (1), 10-21.

Resnicow, K., Soler, R., Braithwaite, R. L., Ahluwalia, J. S., \& Butler, J. (2000). Cultural Sensitivity In Substance Use Prevention. Journal Of Community Psychology, 28, 271-290.

Rickert, V., Jay, M., \& Gottlieb, A. (1991). Effects of peer-counseled AIDS education program on knowledge, attitudes and satisfaction of adolescents. J Adolesc Health, 12, 38-43. 
Rispel, L., Peltzer, K., Nkomo, N., \& Molomo, B. (2010). Evaluating an HIV and AIDS community training partnership program in five diamond mining communities in South Africa. Evaluation and Program Planning, 33, 394-402.

Rogers, E. ( 2003). Diffusion of innovations.

Ross, D., Changalucha, J., Obasi, A., Todd, J., Plummer, M., \& Cleophas-Mazige, B. (2007). Biological and behavioral impact of an adolescent sexual health intervention in Tanzania: A community-randomised trial. AIDS, 21, 1943-1955.

Sallam, T. A., Cuevas, L. E., \& Tong, C. Y. (2003). Increase in susceptibility of young adults to hepatitis B infection in the Republic of Yemen. Transactions of the Royal Society of Tropical Medicine and Hygiene, 97 (3), 302-304.

Shadish, W. R., Cook, T., \& Campbell, D. T. (2002). Experimental and Quasi-Experimental Designs-For Generalized and Causal Inference. Boston: Houghton Mifflin Press.

Shelton, J. D., Halperin, D. T., Nantulya, V., Potts, M., Gayle, H. D., \& Holmes, K. K. (2004). Partner reduction is crucial for balanced "ABC" approach to HIV prevention. BMJ, 328, 891-4.

Smerecnik, C., Schaalma, H., Kok, G., Meijer, S., \& Poelman, J. (2010). An exploratory study of Muslim adolescents' views on sexuality: Implications for sex education and prevention. BMC Public Health, 10 (533), doi: 1471-2458/10/533.

Smith, M., \& DiClemente, R. (2000). STAND: A Peer Educator Training Curriculum for Sexual Risk Reduction in the Rural South. Preventive Medicine, 30, 441-449.

Speizer, I., Tambashe, B., \& Tegang, S. (2001). An evaluation of the "Entre Nous Jeunes" peer-educator program for adolescents in Cameroon. Stud Fam Plann, 32 (4), 339-351.

Steckler, A., \& Linnan, L. (2002). Process evaluation for public health interventions and research (1st ed.). San Francisco: Jossey-Bass.

Strange, V., Forrest, S., Oakley, A., \& the RIPPLE Study Team, a. (2002). What influences peer-led sex education in classroom? A view from the peer educators. Health Education Research, 17, 339-349.

Sweat, M., Gregorich, S., Sangiwa, G., Furlonge, C., Balmer, D., Kamenga, C., et al. (2000). Costeffectiveness of voluntary HIV-1 counseling and testing in reducing sexual transmission of HIV-1 in Kenya and Tanzania. Lancet, 356:113.

Turner, G., \& Shepherd, J. (1999). A method in search of a theory: peer education and health promotion. Health Education Research, 14 (2), 235-247.

UNAIDS. (2007). UNAIDS. Retrieved from Implementing the UN learning strategy on HIV/AIDS: Sixteen case studies. : [http://data.unaids.org/pub/Report/2007/jc1311-un-learning-strat07_en.pdf]

UNAIDS. (2010). UNGASS Yemen Progress Report on HIV and AIDS.

UNCTAD. (2009). The Least Developing Countries- United Nations Conference on Trade and Development Report.

UNDP. (2010). Yemen country profile. Retrieved July 2010, from www.undp.org: [http://www.undp.org.ye]

UNICEF. (2005-a). Multiple indicator cluster surveys-round 3.

UNICEF. (2005-b). State of the World Report-Children under Threat. UNICEF.

UNICEF. (2006). Mapping of Children, Young People and HIV/AIDS Activities in the Middle East and North Africa Region. Amman: UNICEF. Mapping of Children, Young People and HIV/AIDS Activities in the Middle East and NortUNICEF Middle East and North Africa Regional Office; July 2006.

UNICEF. (2007). Annual Report-Yemen Country Office.

UNICEF. (2008-a). Annual Report-Yemen Country Office.

UNICEF. (2008-b, April 13). UNICEF and partners organize national peer education workshop on HIV and AIDS in Yemen. Retrieved November 2010, from www.unicef.org: http://www.unicef.org/media/media_43545.html 
UNICEF. (2009). Annual Report-Yemen Country Office.

UNICEF. (2010). UNICEF at a Glance/Helping young people help themselves through peer education in Yemen. Retrieved July 2010, from www.unicef.org.

Visser, M. (2005). Life skills training as HIV/AIDS preventive strategy in secondary schools: evaluation of a large-scale implementation process. SAHARA J, 2 (1), 203-16.

Visser, M. (2007). HIV/AIDS prevention through peer education and support in secondary schools in South Africa. Journal of Social Aspects of HIV/AIDS, 4, 678-694.

Williams, B., Taljaard, D., Campbell, C., Gouws, E., Ndhlovu, L., Dam, J., et al. (2003). Changing patterns of knowledge, reported behaviour and sexually transmitted infections in a South African gold mining community. AIDS, 17, 2099-2107.

Wilson, B. D., \& Miller, R. L. (2003). Examining Strategies For Culturally Grounded Hiv Prevention: A Review. AIDS Education and Prevention, 15 (2), 184-202.

Yankah, E., \& Aggleton, P. (2008). Effects and effectiveness of life skills education for HIV prevention in young people. AIDS Education and Prevention, 20 (6), 465-485. 



\section{Summary}

The republic of Yemen is located in the southern part of the Arabian Peninsula and is surrounded by Oman to the east, Saudi Arabia to the north, the Red Sea to the west and the Arabian Sea and the Gulf of Aden to the south. Yemen is the poorest country in the Middle East and one of the poorest countries in the world, where more than 45 $\%$ of the population lives in poverty. Yemen's population is around 22.5 million people, of which, $67.3 \%$ is younger than 25 years. At $3.02 \%$, the country has one of the highest population growth rates globally, with the population expected to double in the next 23 years. Yemen faces significant challenges in helping youth to reach their full potentials due to decreasing natural resources, low levels of human development, high levels of poverty, and policies and institutions that are not focusing on youth development. The Yemeni economy is caught in a slow growth cycle, with an unemployment rate of $35 \%$ in general and as high as $50 \%$ among youth, leading to stagnant per capita incomes and rising levels of unemployment, particularly amongst the youth. Limited employment opportunities have forced many Yemenis to migrate for work to neighbouring countries leaving their families behind. Illiteracy rates are still high (47\%) with a huge gender gap, where $69.1 \%$ of the female population are illiterate compared to $27.3 \%$ of Yemeni males. Yemen continues to occupy the last place in the gender gap index rankings of 134 countries and remains the only country in the world to have closed less than $50 \%$ of its gender gap. Although HIV prevalence is still around $0.2 \%$, high rates of illiteracy, poverty, unemployment, mobility, and gender disparities place the predominantly young Yemeni nation vulnerable to HIV infection. In addition, Yemeni youth, are experiencing increased premarital sex, peer pressure to engage in risky behaviour, and changing lifestyle norms. 
Aden, a governorate in the southern part of Yemen, lies on the coastal line of the Arabian Sea and is located in close proximity to the horn of Africa. As indicated by previous research, Aden governorate, especially its young people, are vulnerable to HIV infection. There was an urgent need to further explore risks and vulnerabilities to HIV among in and out of school young people, and to respond accordingly with cultural sensitive interventions. For this reason, two baseline surveys among students and out of school young people were conducted in 2005. The results of the two surveys revealed that young people in and out of schools had low levels of HIV knowledge, and high levels of stigma towards people living with HIV. All the existing high schools in Aden (27 high schools) were included in the baseline (Chapter 1); in addition to the four poor and most-at-risk neighbourhoods of Abdul Qaui, Al Memdarah, Al Basateen, and Al Sesaban. The reason for targeting these four areas, which are inhabited by a total population of 71,740 people distributed in 11,000 households, was based on previous research documenting that most-at-risk groups existed in these four areas. The results from these surveys have been the basis for designing a school and community-based intervention.

The results from the school baseline survey and from the community baseline survey convinced key stakeholders from governmental and non-governmental organizations to implement school and community based peer education programmes for HIV prevention in Aden governorate. The community based intervention programme mainly focused on creating an enabling environment by advocacy with local councils and religious leaders; training youth peer education and community outreach networks in vulnerable neighbourhoods; partnership with community based organizations and non-governmental agencies; and reaching out to vulnerable and most-atrisk youth with HIV messages. The School based interventions focused on creating an enabling environment for HIV prevention activities in schools by advocacy with decision makers; training of school supervisor, social workers, principals, and vice principals; and training school peer educators, who have reach out to their peers during school academic year and in youth summer camps.

To ensure measuring the impact of the HIV prevention interventions in schools and communities, two quantitative impact assessments for community and school-based interventions were conducted between October 2008 and March 2009. The impact assessment of school-based interventions included 2,510 students selected from all 27 secondary schools in Aden (Chapter 2).The impact assessment of the community- 
based interventions included 700 young people from 600 households of the four poor and vulnerable areas in Aden (Chapter 3).

To have a deeper understanding on the implementation of the intervention, the quantitative impact evaluations were followed by qualitative process evaluations for school and community interventions. The school process evaluation included 12 focus groups discussions and 12 in-depth interviews with school peer educators, students, school social workers, school principals, and parents (Chapter 4). The community process evaluation included five focus group discussions and 15 in-depth interviews with community peer educators, community outreach focal points, targeted young people, local councils, NGO leaders, and most-at-risk young people. (Chapter 5).

The aim of this dissertation was to study the impact of peer education and life skills based HIV prevention among young people in the schools and targeted communities of Aden governorate. It also aimed to explore why the interventions were possible in a very conservative and traditional Muslim setting; and documented how the interventions were implemented.

The new aspects in the present dissertation are three folds. It involves the design, implementation, and evaluation of the first ever community and school based HIV interventions among young people in Yemen, which are based on both peer education and life skills methodologies; it demonstrates that HIV education among female and male young people at school and community level is possible in a very conservative Muslim and traditional setting; it includes a respectable sample size and duration - a total of 6221 young people were included in the school and community baselines and evaluations and the duration of the interventions were three years (2005-2008).

The school and community peer education and life skills based interventions that were implemented in 27 schools and in four targeted vulnerable communities of Aden have succeeded in improving HIV knowledge and risk perception; decreasing levels of misconceptions, stigma and discrimination towards people living with HIV (PLWH), and in promoting less risky practices and behaviours related to HIV infection among vulnerable young people in communities. Both the school and community intervention were theoretically based on the Diffusion of Innovation Theory. 
The school and community interventions were implemented with high levels of fidelity and were well accepted by young people as well as by the main stakeholders. The main enabling elements for the school and community intervention had been the culturally sensitive messages on HIV prevention, advocacy with decision makers and parents, and participation and capacity building of all existing stakeholders at school and community level. The life skills based training of community and school peer educators were pivotal in building their capacities, and had enabled them to become 'opinion' leaders among their peers. The cultural sensitive messages and the "life skills" labelling were key in the acceptance of the interventions in a rigid and conservative setting like Yemen. It is expected that the interventions might be replicated in other parts of Yemen and in similar conservative Arab and Islamic settings. 


\section{Samenvatting}

De republiek Jemen ligt in het zuidelijke deel van het Arabische schiereiland. Het grenst in het oosten aan Oman, in het noorden aan Saoedi Arabië, in het westen aan de Rode Zee en in het zuiden aan de Golf van Aden. Jemen is het armste land in het Midden-Oosten en is een van de armste landen ter wereld. Meer dan 45 procent van de bevolking leeft in armoede. De bevolking van Jemen telt ongeveer 22,5 miljoen mensen waarvan 67,3 procent jonger is dan 25 jaar. De bevolkingsgroei, 3,02 procent, is een van de hoogste ter wereld en de verwachting is dat de bevolking binnen 23 jaar zal verdubbelen. In Jemen is het moeilijk voor jongeren om zich ten volle te ontplooien. Dit vanwege de afnemende natuurlijke hulpbronnen, het gebrek aan goed onderwijs, de hoge graad van armoede en een overheidsbeleid dat niet gericht is op ontwikkeling van de jeugd. Vooral door deze factoren zit de economie van Jemen gevangen in een trage groeispiraal die, gekoppeld aan de sterke bevolkingsgroei, leidt tot een hoge gemiddelde werkloosheid van 35\% van de bevolking en een werkloosheid van $50 \%$ onder jongeren. Hierdoor stagneert ook de inkomensgroei. Door de lage kansen op werk zijn veel Jemenieten gedwongen in een van de buurlanden te gaan werken, met achterlating van hun gezinnen. Analfabetisme komt nog veel voor, 47 procent, vooral bij vrouwen, 69,1 procent, tegenover 27,3 procent bij mannen. Jemen staat daarmee onderaan de lijst van de 134 landen waarvan het verschil in analfabetisme tussen mannen en vrouwen bekend is. Het is ook het enige land met nog steeds meer dan 50 procent verschil. Hoewel de HIV prevalentie nog rond de 0,2 procent is, vormen Jemenitische jongeren een risicogroep vanwege het analfabetisme, de armoede, de werkloosheid, de mobiliteit en de sekseverschillen. Bovendien hebben Jemenitische jongeren tegenwoordig vaker seks voor het huwelijk, ervaren ze meer druk van leeftijdsgenoten tot riskant gedrag en zijn de maatschappelijke normen veranderd. 
Aden is een provincie in het zuiden van Jemen grenzend aan de Arabische Zee dicht bij de Hoorn van Afrika. Uit eerder onderzoek is gebleken dat bewoners van Aden en vooral jongeren, een hoog risico lopen op HIV infectie. Daardoor ontstond een dringende behoefte om die risico's bij jongeren, zowel binnen als buiten schoolverband, beter in kaart te brengen en op basis daarvan interventies te ontwikkelen die passen binnen de bestaande culturele gevoeligheden.

Het doel van het project dat in deze dissertatie wordt beschreven, was om het effect na te gaan van HIV-preventie interventies, gebaseerd op peer-educatie en vaardigheidstraining, die gericht waren op jongeren op scholen en op niet-schoolgaande jongeren in hoogrisico buurten in Aden. Ook werd nagegaan hoe deze interventies mogelijk bleken te zijn in een zeer conservatieve en traditionele Moslimomgeving en hoe ze werden geïmplementeerd.

Om de risico's op HIV infectie in kaart te brengen, zijn eerst in 2005 twee grote vragenlijstonderzoeken uitgevoerd onder schoolgaande en niet schoolgaande jongeren. Die twee onderzoeken lieten zien dat jongeren een lage kennis hadden van HIV en dat zij mensen met HIV in hoge mate stigmatiseerden. Alle 27 scholen voor voortgezet onderwijs in Aden namen deel aan het onderzoek onder jongeren op school (zie hoofdstuk 1). Het onderzoek onder buitenschoolse jongeren werd uitgevoerd in de buurtgemeenschappen Abdul Qaui, Al Memdarah, Al Bsateen en Al Sesaban in Aden. Die laatste vier buurten, met 71740 bewoners in 11000 huishoudens, werden gekozen omdat eerder onderzoek liet zien dat daar de groepen met het hoogste risico werden gevonden. De resultaten van beide onderzoeken hebben de basis gevormd voor de ontwikkeling van een schoolgerichte en een buurtgerichte interventie.

De uitkomsten van de school- en buurtonderzoeken vormden voldoende reden voor belangrijke sleutelfiguren in overheids- en niet-overheidsorganisaties in Aden om over te willen gaan tot HIV-preventie interventies voor scholen en buurten, volgens het principe van peer-educatie: voorlichting door getrainde jongeren aan hun leeftijdsgenoten. De buurtinterventie richtte zich op het creëren van een faciliterende omgeving, via pleitbezorging bij lokale overheden en religieuze leiders, training van jongeren en veldwerkers tot voorlichters in de hoogrisico buurten, samenwerking met organisaties in de buurten en op het proberen in contact te komen met kwetsbare en hoogrisico jongeren met boodschappen over HIV. De schoolinterventie richtte zich op het creëren van een faciliterende omgeving voor HIV-preventie activiteiten in de school, via pleitbezorging bij het management van de scholen, training van schoolleiding, (school)maatschappelijk werkers en schooldirecteuren, en training van de 
jongeren die op school en in zomerkampen voorlichting gaven aan hun leeftijdsgenoten.

Om het effect te kunnen bepalen van de HIV-preventie interventies in de scholen en buurten zijn er twee effectevaluaties uitgevoerd tussen oktober 2008 en maart 2009. De effectevaluatie op de scholen betrof 2510 leerlingen op alle 27 scholen voor voortgezet onderwijs in Aden (zie hoofdstuk 2). De effectevaluatie in de wijken betrof 700 jongeren uit 600 huishoudens in de vier arme en hoogrisico buurten in Aden (zie hoofdstuk 3).

Voor een beter begrip van de implementatie van de interventies, werden de kwantitatieve evaluatieonderzoeken gevolgd door kwalitatieve procesevaluaties van de schoolen buurtinterventies. De procesevaluatie op de scholen betrof twaalf focusgroepdiscussies en twaalf diepte-interviews met de jongeren die als voorlichter op de school waren getraind, met leerlingen, (school)maatschappelijk werkers, schooldirecteuren en ouders (zie hoofdstuk 4). De procesevaluatie in de buurten betrof vijf focusgroepdiscussies en vijftien diepte-interviews met de jongeren die als voorlichter in de buurt waren getraind, met veldwerkers, jongeren uit de doelgroep, vertegenwoordigers van lokale overheids- en niet-overheidsinstellingen, en de groep jongeren met het hoogste risico (zie hoofdstuk 5 ).

Er zijn drie innovatieve aspecten aan deze dissertatie. Ten eerste is er de ontwikkeling, implementatie en evaluatie van de eerste school- en buurtgerichte HIV preventie interventie ooit voor jongeren in Jemen, gebaseerd op peer-educatie en vaardigheidstraining. Daarmee wordt gedemonstreerd dat HIV preventie interventies op scholen en in wijken en voor jongeren van beide sekse, mogelijk en uitvoerbaar is in een zeer conservatieve en traditionele Moslimomgeving. De interventies betroffen een substantiële onderzoekspopulatie en duur; in totaal 6221 jongeren namen deel aan de onderzoeken en de duur van de interventie was drie jaar, 2005-2008.

Ten tweede hebben de HIV preventie interventies gebaseerd op peer-educatie en vaardigheidstraining in 27 scholen en 4 hoogrisico buurten in Aden, geresulteerd in een relevante toename van kennis over HIV en risicoperceptie, een afname van misconcepties en van het stigmatiseren en discrimineren van mensen met HIV, en een afname van risicogedrag bij deze hoogrisico jongeren. De theorie over Diffusie van Innovaties vormde de basis voor zowel de school- als de buurtinterventie. 
Ten derde bleek dat zowel de school- als de buurtinterventie geïmplementeerd zijn met een hoge graad van kwaliteit, dat wil zeggen uitgevoerd zoals bedoeld, en dat zij bovendien goed werden geaccepteerd door zowel de relevante sleutelfiguren als de jongeren. Heel belangrijk daarbij waren de zorgvuldig cultuursensitieve formulering van de HIV-preventie boodschappen, de pleitbezorging bij sleutelfiguren en bij ouders, en de participatie en empowerment van alle betrokkenen bij de scholen en in de buurten. De training van de jongeren die als voorlichters voor hun leeftijdsgenoten fungeerden, was essentieel voor het ontwikkelen van hun vaardigheden en gaven hen de status van opinieleiders bij hun leeftijdsgenoten. De cultuursensitieve boodschappen en het benoemen van de doelstelling als 'vaardigheden', vormden de sleutel voor acceptatie van de interventies in een rigide en conservatieve omgeving zoals Jemen. Het is te verwachten dat deze interventies zeker ook uitgevoerd kunnen worden in andere delen van Jemen en in vergelijkbare conservatieve Arabische en Moslimlanden. 


\section{Acknowledgements}

I am deeply indebted to my supervisors Professor van den Borne and Professor Kok, whose continous guidance and support helped me in the writing of this dissertation. I would like to thank all colleagues in the Department of Health Promotion for making me feel at home during my stay in Maastricht. Special thanks to Ms. Marja Vissers for her continous kind support.

My sincere appreciation to my family: my parents, Fatima Yahiya Al-Iryani and Abbas Mohamed Al-Iryani; to my husband, Arif, and my children, Amr, Aya, and Ammar - your love, care, and great support have made this work a reality. 



\section{Biography}

Buthaina Al-Iryani grew up in Taiz, Yemen, where she attended Mohamed Ali Othman High School, in Taiz, Yemen, and received the International Baccalaureate diploma. She studied at Oregon State University, the United States of America (USA), and obtained B.Sc. in Pharmacy in 1993.

She started her professional career in 1994 as a teaching assistant in the Faculty of Medicine and Health Sciences, Sana'a University, Yemen. In 1996 she established the Yemeni Society for Rational Use of Drugs, a non-profit organization that aimed to promote health awareness and conduct research on the use of prescription and nonprescription medications in Yemen. In 1998, and after four years of working in Sana'a University, she was awarded a Fulbright scholarship to study Masters in Public Health in the University of South Florida, USA, where she graduated with honours in 1999.

She worked as a freelance consultant for several years and then joined UNICEFYemen Country Office in December, 2003, where she still works until today as the HIV and Youth programme specialist. During her work in UNICEF she worked closely with governmental and non-governmental organizations, local councils, religious leaders, schools, communities and young people from vulnerable groups to support access of youth to information and HIV preventive services. In 2008, she received an honorary award from the Yemeni Vice President for her role in the formulation of the National Strategy for Children and Youth. 